University of Rhode Island

DigitalCommons@URI

Open Access Master's Theses

2007

\title{
Improvement of Current Pharmaceutical Manufacturing Systems Utilizing Practices from Outside Industries
}

Cyrus D. Agarabi

University of Rhode Island

Follow this and additional works at: https://digitalcommons.uri.edu/theses

\section{Recommended Citation}

Agarabi, Cyrus D., "Improvement of Current Pharmaceutical Manufacturing Systems Utilizing Practices from Outside Industries" (2007). Open Access Master's Theses. Paper 915.

https://digitalcommons.uri.edu/theses/915

This Thesis is brought to you for free and open access by DigitalCommons@URI. It has been accepted for inclusion in Open Access Master's Theses by an authorized administrator of DigitalCommons@URI. For more information, please contact digitalcommons-group@uri.edu. 
IMPROVEMENT OF CURRENT PHARMACEUTICAL MANUFACTURING SYSTEMS UTILIZING PRACTICES FROM OUTSIDE INDUSTRIES

\author{
BY \\ CYRUS D. AGARABI PHARM.D, M.S.
}

A THESIS SUBMTTED IN PARTIAL FULFILLMENT OF THE

REQUIREMENT FOR THE DEGREE OF

MASTER OF SCIENCE

IN

MANUFACTURING SYSTEMS ENGINEERING

UNIVERSITY OF RHODE ISLAND

2007 


\title{
MASTER'S OF SCIENCE THESIS
}

\author{
OF
}

CYRUS AGARABI

APPROVED:

Dissertation Committee:

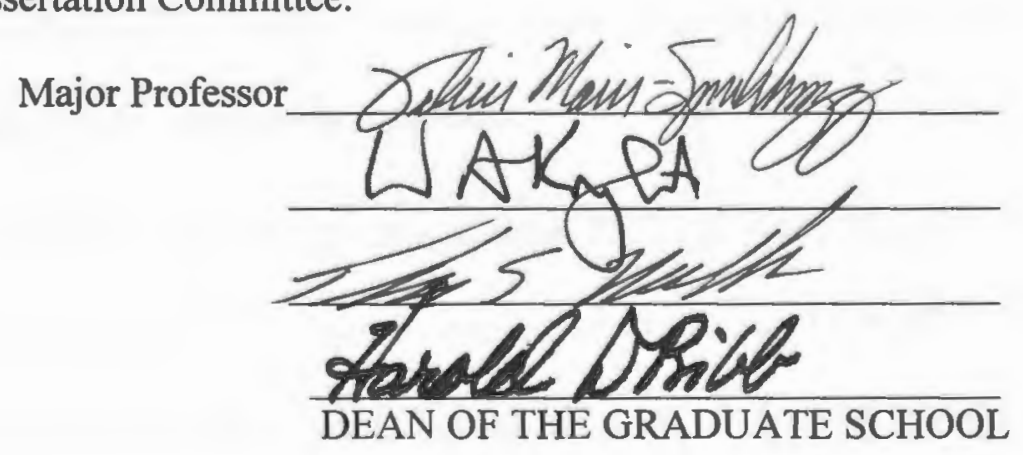

UNIVERSITY OF RHODE ISLAND

2007 


\section{Abstract}

Current Good Manufacturing Practices (cGMP's) were developed to keep the public safe and ensure quality products. Technological evolution of the industry resulted in cGMP requirements which could not keep pace, and ultimately had a restrictive effect on daily operations and process improvements for pharmaceutical manufacturers. In response, the FDA has recently released new Guidances for Industry, PAT-A Framework for Innovative Pharmaceutical Development, Manufacturing, and Quality Assurance and Pharmaceutical cGMP's for the $21^{\text {st }}$ Century-A Risk-Based Approach, to encourage innovation in the pharmaceutical industry. The current focus is to understand the product, the manufacturing process and operations rather than the previous focus on product testing and release. Other industries have developed innovative approaches to competitive improvement and it is important to learn from their successes and failures.

The aim of this study is to identify critical areas for improvement in current pharmaceutical manufacturing practices and to explore solutions to these problems using principles found outside of the pharmaceutical industry. A facility producing pharmaceutical products under cGMP's will be evaluated to gain a "baseline" understanding of current manufacturing practices. Critical and problematic areas will be identified as well as potential opportunities to incorporate external industry practices, with a focus on the Toyota Production System ${ }^{\circledR}$, to improve the manufacturing process.

A ProModel ${ }^{\circledR}$ simulation was developed in as a proof of concept to evaluate proposed improvements to the system. This simulation was run with a number of 
theoretical changes to the scenario to evaluate the effects and interactions of the proposed improvements. These areas of improvements include: Shrinking traditional batching rules to create a more semi continuous production system, cross training personnel on equipment and responsibilities, and the addition of parallel machines at the equipment bottleneck.

Results from the simulation experimentations indicated that significant improvements to product throughput time can be achieved. While all three individual factors studied were found to be significant, the greatest gains were achieved using a combination of batch rule changes and cross training of personnel. Changing the batching rules was found to have the greatest effect on reducing throughput times, due to the drastic reduction of time spent waiting to batch in the system. Cross training resulted in increased capacity in the bottleneck machine with availability during all hours of operation. While parallel machining did achieve improved throughput times when compared to the current state of the system, the additional machine was not justified when compared with the scenario yielding superior results.

Lean manufacturing and other alternative techniques should be explored in the pharmaceutical industry to improve current systems and utilized early in the development of new systems. This case study represents a number of possible opportunities for specific areas of improvement as well as suggesting an overall change in manufacturing mindset. The pharmaceutical industry can learn a great deal from outside industries where competitiveness is required to ensure solvency. 


\section{Acknowledgements}

I would like to thank my major professor Dr. Valerie Maier-Speredelozzi for all of her help in my studies and research in the Industrial and Manufacturing Engineering department. Without her guidance my research and development as an industrial engineer would not have been possible.

I would also like to thank my longtime advisor from the Biomedical and Pharmaceutical Sciences department, Dr. Thomas Needham, for his pharmaceutical expertise and advice.

A special thanks to the owners of XYZ Pharma for allowing me free reign over their company and their cooperation to gather information for this study.

I would like to thank my parents for supporting all of my academic endeavors, no matter how ridiculous they may seem. 


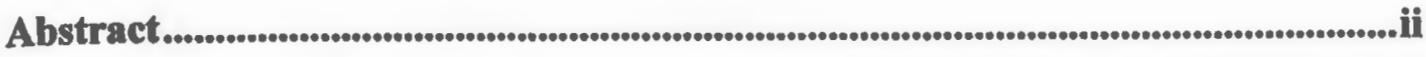

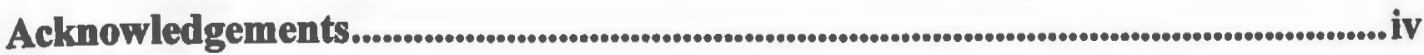

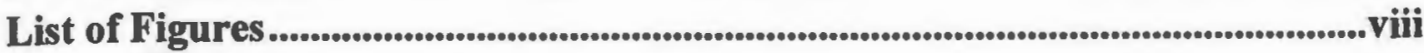

List of Tables .............................................................................................................................. $\mathrm{x}$

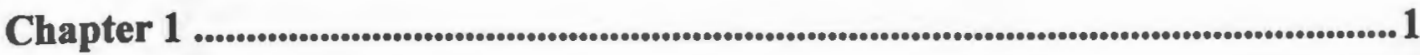

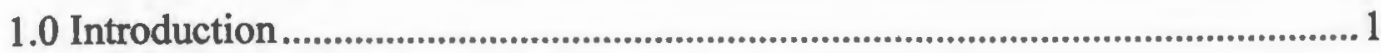

1.1 Brief History of Manufacturing ...................................................................... 1

1.2 Brief History of Pharmaceutical Manufacturing.................................................3

1.3 Study Objectives ............................................................................................ 4

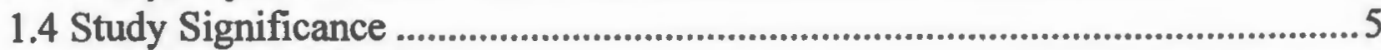

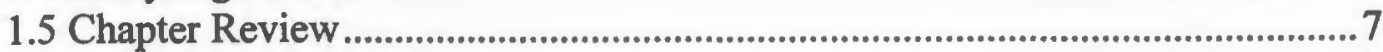

Chapter 2 ..................................................................................................................................8

2.0 Tools Utilized by Other Industries .................................................................. 8

2.1 Current State of Lean Manufacturing ......................................................................8 8

2.2 Tools for Leaner Manufacturing ..................................................................... 12

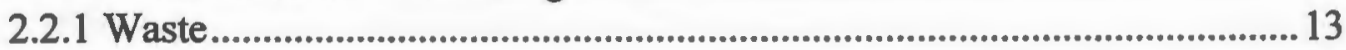

2.2.2 Autonomation........................................................................................ 14

2.2.3 Error-Proofing ........................................................................................ 15

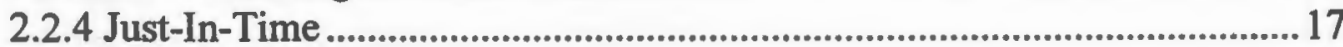

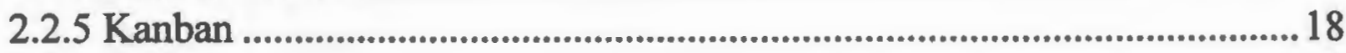

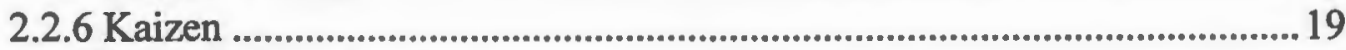

2.3 System Configurations..........................................................................................223

2.4 Chapter Review ................................................................................................224

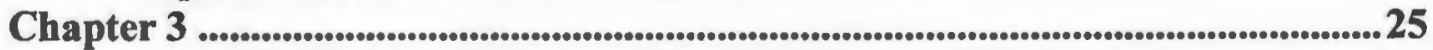

3.0 Pharmaceutical Manufacturing Background.....................................................22

3.1 Current State of Pharmaceutical Regulations for Manufacturing .....................25

3.2 Examples of Current PAT Use..........................................................................229

3.3 Over-The-Counter Product Regulations ..........................................................32

3.4 Opportunities for Pharmaceutical Manufacturing............................................. 33

3.4.1 Batch vs. Continuous Processing .............................................................. 34

3.4.2 Lean Techniques ..................................................................................... 36

3.4.3 Design for Manufacturing ....................................................................37

3.4.4 Simulation .......................................................................................... 38

3.4.5 Other Manufacturing Tools....................................................................... 39

3.5 Chapter Review.................................................................................................. 39

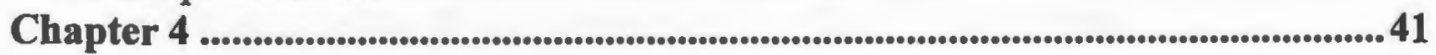

4.0 Methodology and Procedures..............................................................................4 41

4.1 Phase I - Current State of Pharmaceutical Manufacturing...............................41

4.1.1 Evaluation of the Current System ............................................................41

4.1.2 Simulation Modeling................................................................................... 42

4.1.3 Statistical Methods.................................................................................... 43

4.2 Phase II - Future State of Pharmaceutical Manufacturing ................................44 
4.2.1 Development of the Future State Model ....................................................4 44

4.3 Chapter Review.......................................................................................................45

Chapter 5 .................................................................................................................... 47

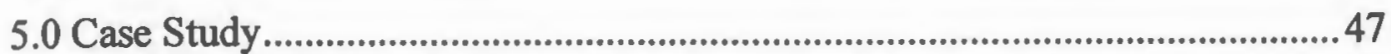

5.1 Background of the Pharmaceutical Company Selected for Study .................... 47

5.1.1 Facility ............................................................................................................. 47

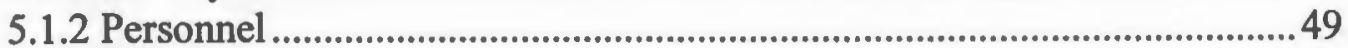

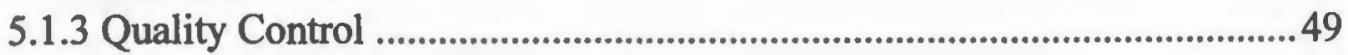

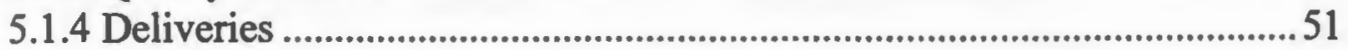

5.2 Current State for Manufacturing of Product X ...............................................55

5.2.1 Formulation of Product X .......................................................................56

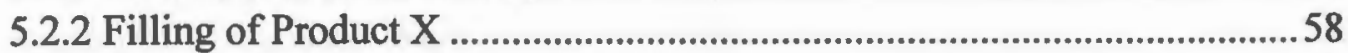

5.2.3 Cartoning of Product X .................................................................................61

5.2.4 Current State Value Stream Map ..............................................................63

5.3 Development of the ProModel ${ }^{\circledR}$ Simulation of Current State.............................67

5.3.1. Current State Model Assumptions ............................................................67

5.4 Chapter Review..................................................................................................71

Chapter 6 ........................................................................................................................ 72

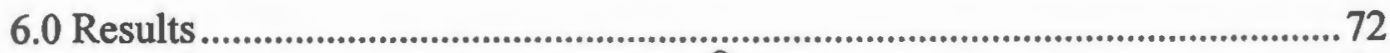

6.1 Results of the Current State ProModel ${ }^{\circledR}$ Simulation ............................................72

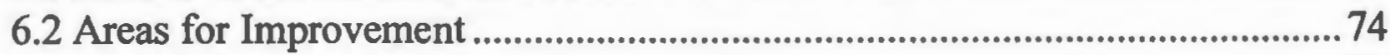

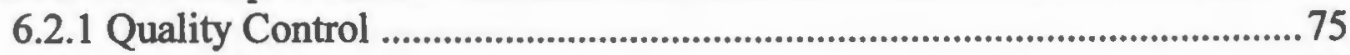

6.2.1.1 Testing.................................................................................................. 75

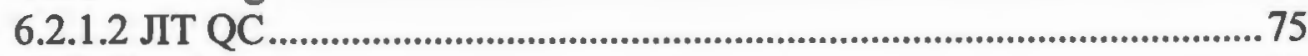

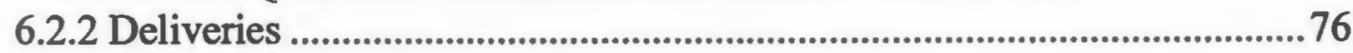

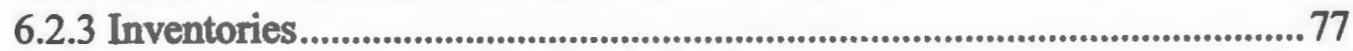

6.2.3.1 Decreasing Storage Vessel Batch Sizes ..............................................77

6.2.3.2 Decreasing WIP Buffers ..................................................................78

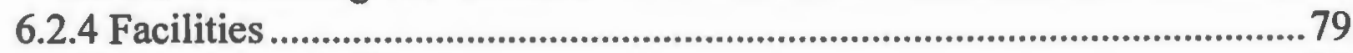

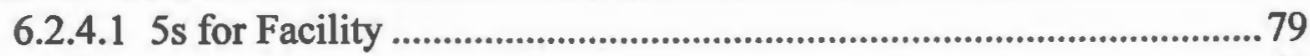

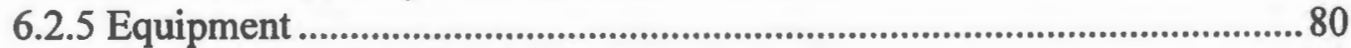

6.2.5.1. Visual controls to decrease setup times ..........................................8 80

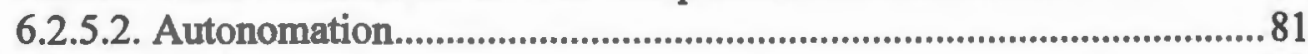

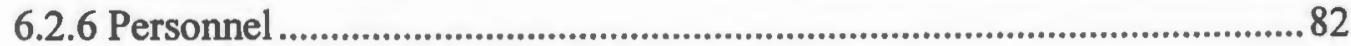

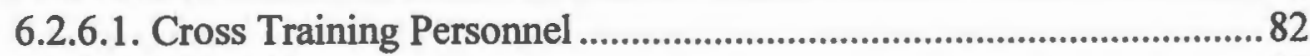

6.2.6.2. Off shift personnel...............................................................................83

6.3 Development of the Future State ProModel ${ }^{\circledR}$ Simulation ..................................8 84

6.3.1 Assumptions of the Future State ProModel ${ }^{\circledR}$ Simulation............................ 85

6.4 Results of the ProModel $\otimes$ Simulations...............................................................8 89

6.4.1 Statistical Analysis of Results.......................................................... 102

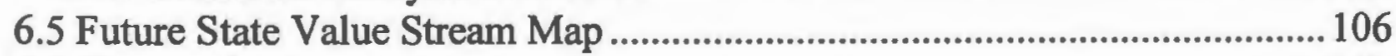

6.6 Chapter Review.................................................................................................... 109

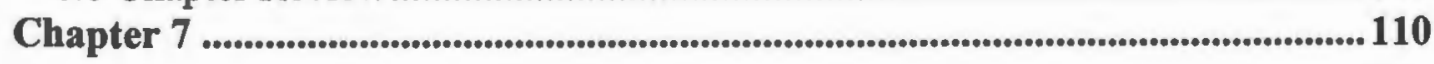

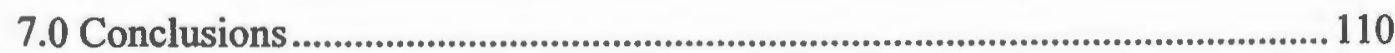


7.1 Linking Pharmaceutical Manufacturing to Outside Industries 110

7.1.1 Approach to Manufacturing

7.1.2 Quality

7.1.3 Equipment

7.1.4 Facility

7.2 Study Limitations

7.3 Future Work

Appendix I: Definitions of current value stream map example (US EPA, 2006b)

Appendix II: Facility Layout

Appendix III: ProMode ${ }^{\circledR}$ Simulation- Current State

Appendix IV: ProModel ${ }^{\circledR}$ Simulation- Future State

Bibliography: 


\section{List of Figures}

Figure 1. Example of a Current State Map with additional environmental data (US

EPA, 2006a) 9

Figure 2. EPA Future State Value Stream Map (EPA, 2006a) ................................ 12

Figure 3. Automation versus Autonomation (Hirano, 1987) ..................................15

Figure 4a. Electrical connection before error-proofing (QS Consult, 2006) ............. 16

Figure 4b. Electrical connection after error-proofing (QS Consult, 2006)............... 16

Figure 5. Conceptual Diagram of the Kanban System (Toyota Motor Co. (8)........ 19

Figure 6. Comparison of innovation and Kaizen improvement (Imai, 1986)..........20

Figure 7. Overview of areas of improvement and benefits of using $5 \mathrm{~S}$ (Hirano, 1995)

Figure 8. Hierarchy of manufacturing control strategy (Low, 2006).......................28

Figure 9. Simulation Overview (Sanchez, 2006) ....................................................42

Figure 10. Material Flow Chart..........................................................................................55

Figure 11. Current State Value Stream Map............................................................66

Figure 12. Current State ProModel@ Simulation Layout ..............................................70

Figure 13. Future State ProModel@ Simulation Layout ...............................................8

Figure 14. Average Throughput Time for all ProModel $@$ scenarios...........................90

Figure 15. Raw Ingredients Holding Time for Batch Processing .................................93

Figure 16. For scenarios implementing more Continuous Processing........................93

Figure 17. Holding Time for WIP in the System for Batch Processing....................95

Figure 18. Holding Time for WIP in the System for more Continuous Processing .. 95

Figure 19. Finished Goods Inventory across all scenarios 
Figure 20. Utilization (\%) of Inventory Transfers and Holding .............................. 100

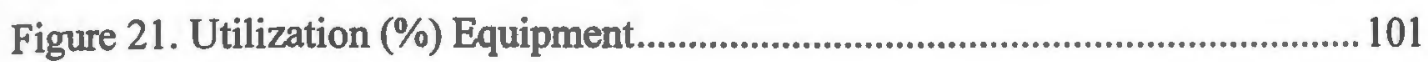

Figure 22. Prediction Profiler of the Factors............................................................ 105

Figure 23. Pareto Plot of Estimates........................................................................... 105

Figure 24. Future State Value Stream Map based on Scenario 4............................... 108 
Figure 20. Utilization (\%) of Inventory Transfers and Holding 100

Figure 21. Utilization (\%) Equipment.................................................................. 101

Figure 22. Prediction Profiler of the Factors.................................................................... 105

Figure 23. Pareto Plot of Estimates............................................................................ 105

Figure 24. Future State Value Stream Map based on Scenario 4............................... 108 


\section{List of Tables}

Table 1. Overview of Experimental Design....................................................................45

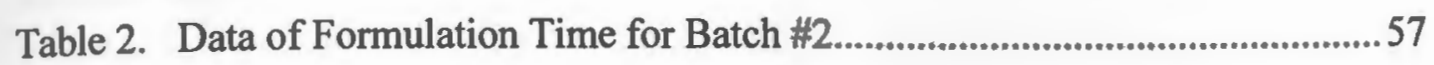

Table 3. Data for Tube Filling Batch \#3 ........................................................5

Table 4. Jones Cartoner Data Collection for Batch \#3...........................................63

Table 5. Overview of Batch Records of Product X ................................................64

Table 6. Results of the Current State ProModel ${ }^{\circledast}$ Simulation................................... 73

Table 7. $2^{3}$ Factorial Design of Three Factors Selected for Experimentation ..........84

Table 8. Rounded Average Throughput Times (Hr) of all ProModel ${ }^{\circledR}$ Scenarios... 89

Table 9. Average Time Per Entry (Min) of all ProModel@ Scenarios .....................91

Table 10. Utilization (\%) of locations .........................................................................98

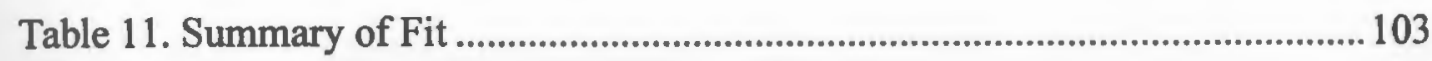

Table 12. Lack Of Fit...............................................................................................103

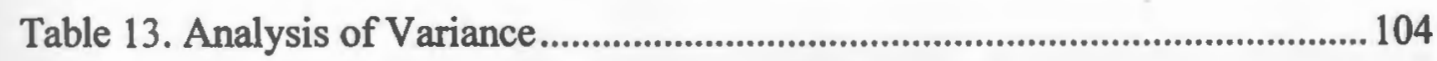

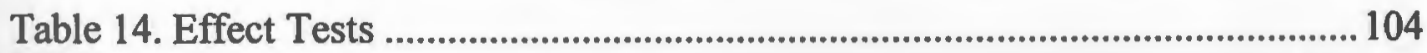




\section{Chapter 1}

\subsection{Introduction}

Chapter one aims to orient the reader with a brief history of both general manufacturing and pharmaceutical manufacturing. The history discussed is not intended as a comprehensive review of manufacturing, rather it will give the reader perspective with regard to the origins and ongoing evolution of the state of manufacturing. This chapter will also describe the general study objectives of this thesis.

\subsection{Brief History of Manufacturing}

In 1776 Adam Smith published "An Inquiry into the Nature and Causes of the Wealth of Nations" and introduced the concept of the division of labor. Smith felt that by dividing complex jobs which were previously performed by skilled artisans (carpenters, smiths, etc...) into simplified tasks, greater levels of efficiency could be achieved. His experiments first assessed the production of metal pins by unskilled laborers using traditional craft methods, which required all aspects of manufacturing. He then compared these laborers to a group which had the manufacturing process divided into one or a few simple tasks. Each laborer was responsible for their individual area of pin manufacturing and he found a large increase in productivity. He attributed the increased output to three reasons: 1. An increase in the operator's dexterity due to simple and repetitive tasks. 2. Minimization of travel time because the product moved and the people did not and 3. 
Tools used in the manufacturing can be optimized based on the operator's superior knowledge of the process (Smith, 1776).

The introduction of interchangeable parts for the manufacturing of muskets by Honoré Blanc in the late 1700's also signaled an important milestone in the evolution of manufacturing. By creating interchangeable parts through the standardization of templates and equipment, he replaced artisan craftsman and enabled unskilled laborers to be trained with manufacturing tools to generate greater production numbers at lower costs. This new method was adopted in many other industries throughout the world and facilitated the rapid growth of mass production (Gillespie, 1998; Hopp, 2001).

In 1913, Henry Ford introduced a continuously moving assembly line which allowed workers to remain in their workstations to add parts to cars as they passed by. Parts were supplied to workers through conveyors and timed to keep workers well stocked with necessary components. This new method drastically reduced automobile assembly times, lowered vehicle costs, and propelled the Model T to a dominant share of the market at the time (The Henry Ford Museum, 2003). The expensive, single function machinery limited flexibility and required many buffers of supplies, workers and storage space in order to maintain a smooth operation. Additionally, changing between products was an expensive and time consuming process due to system rigidity, and resulted in fewer options for consumers (Womack, 1990).

Ford's breakthrough changed the face of the automobile industry, and Toyoda Kiichirō of Toyota Motors, was eager to learn from the automotive giant. In 
1933 Kiichirō stated, "We shall learn production techniques from the American method of mass production. But we will not copy it as is. We shall use our own research and creativity to develop a production method that suits our own country's situation" (Ohno, 1988). The Toyota Production System was founded on the principle of waste elimination, utilizing autonomation and just-in-time principles. Under the guidance of Taiichi Ohno, this system evolved greatly from its inception to the present day concept of "World Class Manufacturing," with an overriding goal of continual and rapid improvement while maintaining flexibility (Schonberger, 1986). These concepts have been termed "lean production" (Womack, 1990) and have resulted in the commitment to improve industry flexibility and competitiveness.

\subsection{Brief History of Pharmaceutical Manufacturing}

In 1938, The Food and Drug Administration (FDA) enacted the Federal Food, Drug, and Cosmetic Act and subsequently developed the Code of Federal Regulations (CFR), which contained current Good Manufacturing Practices (cGMP's). These practices were intended to keep the public safe and ensure quality products (FDA, 2006a). The pharmaceutical industry developed rapidly in response to the great need for penicillin and medical supplies during World War II. Following the war, manufacturers began researching and developing new drugs to expand the industry. Drug discovery evolved over the next 50 years from traditionally random occurrences to a highly focused methodology. Screening of target receptors and functional chemical structures makes it possible to identify potential successful therapeutic opportunities from a large pool of candidates (Ratti, 2001). While drug 
discovery experienced rapid growth with relatively little regulatory oversight, the manufacturing areas of the industry were under the strict guidance of the FDA's cGMP's. These regulations resulted in a strong commitment to quality and industry adoption of Total Quality Management (TQM) (Ghobadian, 1995), Statistical Process Control (SPC), Six Sigma (Swarbick, 2006), and other quality programs. Rapid technological evolution of the industry resulted in cGMP's which could not keep pace, and ultimately had a restrictive effect on daily operations and process improvements for pharmaceutical manufacturers. The industry fell behind other less regulated manufacturing industries, where innovative practices and procedures were critical for global competition.

\subsection{Study Objectives}

The aim of this study is to identify critical areas for improvement in current pharmaceutical manufacturing practices and to explore solutions to these problems using principles found outside of the pharmaceutical industry. The study will be divided into two phases:

\section{Current State:}

1. The evaluation of a manufacturing facility currently producing pharmaceutical products under current Good Manufacturing Practices is to gain a "baseline" understanding of the state of the art of manufacturing.

Using this knowledge to develop an accurate model of the system will identify critical and problematic areas.

Future State: 
2. The utilization of external industry practices, such as the Toyota Production System ${ }^{\$}$, system designs to evaluate the introduction of continuous or semi continuous manufacturing. Other lean ideals and outside industry approaches will be used to improve the current manufacturing process and develop a new model. Quantitatively assess current processing standards and metrics with the newly designed model for pharmaceutical manufacturing based on manipulation of critical parameters. The theoretical improvements will follow the new FDA guidance documentation, as well as explore new boundaries.

\subsection{Study Significance}

Currently, there is little publicly available information about improving processes through innovational approaches. The National Institute for Pharmaceutical Technology and Education (NIPTE) has identified that while manufacturing is a significant expense to industry, there is very little industry and federal research funding in this area as compared to drug discovery. The lack of interest in funding manufacturing and processing research can be attributed to both the pharmaceutical industry and the FDA. The pharmaceutical industry is focused on bringing their product to the market place as rapidly as possible prior to the expiration of the patent in order to recoup the large investment made during the development process. The FDA is a regulatory agency concerned with product safety and has fostered a long tradition of discouraging risk taking involved in technological changes. As a result, industry has little incentive to invest dollars 
geared at the advancement of product/process development and manufacturing technologies/practices. Additionally, the National Institute of Health (NIH) is focused on funding predominately discovery related basic research, while the National Science Foundation has focused on manufacturing industries that are critical to the economy but struggling or threatened (Couts, 2006).

This research will serve as a model for pharmaceutical processing in order to encourage novel approaches to manufacturing, through specific and system wide solutions. Ideally this research will serve small to medium sized pharmaceutical manufacturers who are considering or implementing changes in their processes, where simply improving their current system will be inadequate to meet the future needs of manufacturing. Through experimental and statistical modeling, conclusions can be drawn about altering the traditional mentality of manufacturers to improve production. Additionally, because the pharmaceutical industry is so diverse, research must be conducted in all aspects of the field. While powder based processing (tablets, capsules, etc...) and biotechnology has received wide attention, smaller sectors have not been explored in depth. Contract manufacturing can be considered a specialty area of the pharmaceutical industry requiring flexible personnel, equipment and production capabilities. This research should also be considered by other regulated industries such as food, cosmetics, nutraceutical, etc. for viable methods for improvement. 


\subsection{Chapter Review}

Manufacturing has evolved over the past two hundred years and has created different levels for operational standards throughout industries. It is important to understand how the pharmaceutical industry was born and its evolution, to better grasp the current state of pharmaceutical manufacturers. Identifying developmental differences in outside industries will encourage greater fundamental understanding of why pharmaceutical manufacturing is unique. 


\section{Chapter 2}

\subsection{Tools Utilized by Other Industries}

Chapter two will give the reader an overview of the current state of lean manufacturing and commonly used lean tools in order to familiarize the reader with methods used in outside industries. Value Stream Mapping (VSM) is discussed as an important method to identify problematic areas. System configuration is addressed with regard to flexibility and responsiveness through parallel machining.

\subsection{Current State of Lean Manufacturing}

Toyota is the developer and leader in the use of lean manufacturing, which has been widely adopted with applicability to any industry. Prior to beginning improvement, there must be an understanding of the current system. In order to gain a baseline understanding of the current system, VSM has been used as a critical first step in the process. The process involves the investigation and recording of all activities involved with manufacturing of a product from raw materials to finished goods. By mapping the overall process, a systemic view can be created to evaluate total efficiency instead of individual efficiencies or areas. The map includes two classes of work: 1 . Work that adds value to the product as defined by the customer (value added) and 2. Non-value added work. By addressing both types of work, a strategy can be devised to implement lean tools to decrease non-value added work and create a long term vision. The long term vision can be shown through a future state map which would employ the improvements and their estimated effects on the system (Hall, 2001). 


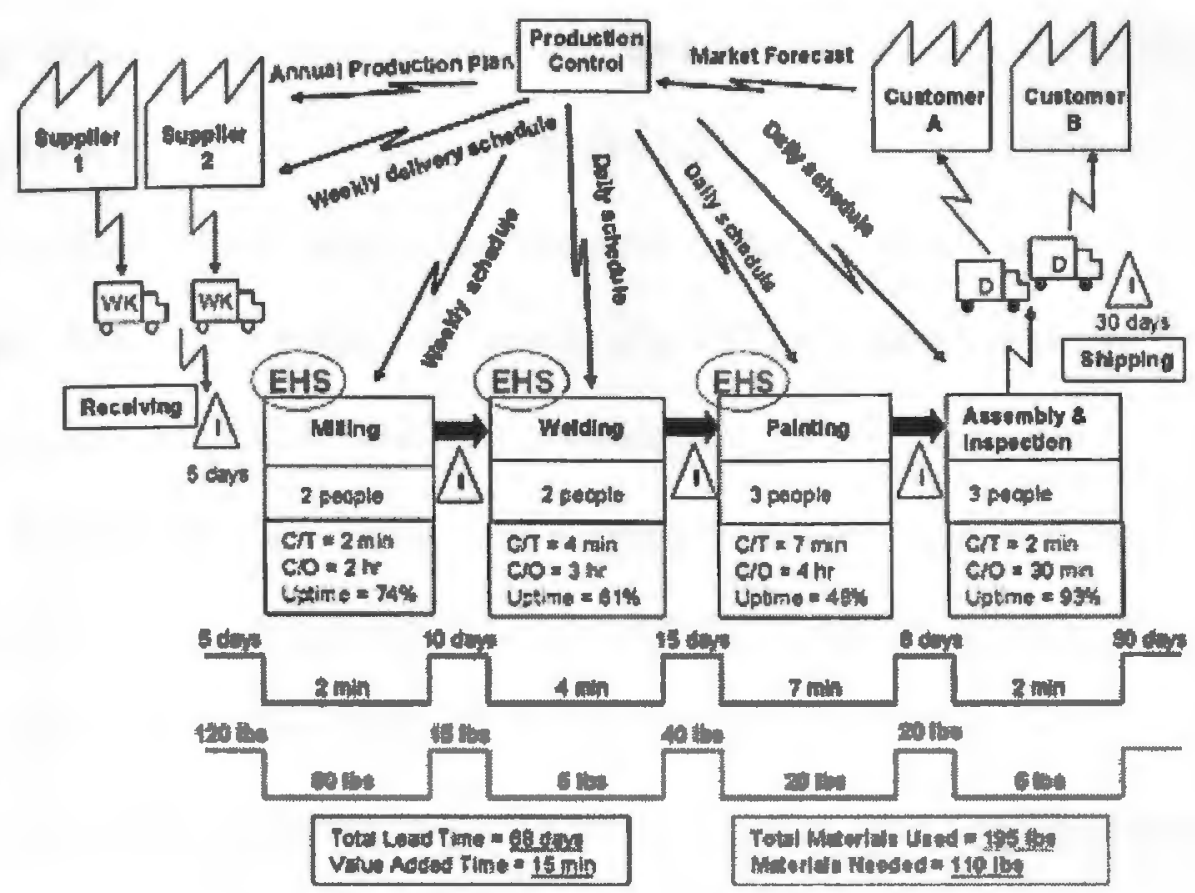

Figure 1. Example of a Current State Map with additional environmental data (US EPA, 2006a)

Figure 1 is an example of a current state map used by the Environmental Protection Agency (EPA). Definitions of the icons used in this value stream map can be found in appendix I. The current state map is comprised of three basic elements: "1. Product flow is the path(s) the product take through production, before being shipped to the customer. 2. Information flow is how information is shared and communicated during the production process. 3. Material flow deals with how incoming material is moved and replenished and in what quantities during production" (Hall, 2001).

To create an accurate depiction of the three flows in the map, there must be accurate data from the production floor. "Gemba" is defined by Liker (2004) as the "actual place" and is the first step used by Toyota when solving a problem. The 
concept reinforces the need for first hand knowledge and challenges conventional management methods of system reports and computer analysis. While many tools can be utilized by personnel, it is important to have a firm grasp on the actual situation. In order to illustrate the benefits of a VSM, an example is given. The EPA collected the following pieces of data to create their current state map:

- Cycle time: The average time a specific routing spends from the point of release at the beginning of the routing until it reaches an inventory point at the end of the routing (Hopp, 2001).

- Change Over Times: The total amount of time it takes to change machinery, tools, personnel, etc... from the last unit of good production at normal line efficiencies to the first good production unit of another product at normal line efficiency (Henry, 2001).

- Total Lead Time: The EPA used throughput time, (composed of processing time, setup time, move time, plus waiting time) (Askin, 1993) plus delivery time to calculate the total time from the release of the product to the shop floor to the time of delivery.

- Number of operators at each station: Additional information about manpower requirements versus actual staffing.

- Inventory levels: The amount and locations of the three inventory types is considered. Raw materials are used to make components and sub assemblies, work-in-process are materials and components waiting to be completed, and finished goods are completed products. 
- Uptime (Utilization): The fraction of time the system or machine is not idle for lack of parts, calculated by dividing the arrival rate of parts by the effective production rate of the machine. The effective production rate is the maximum average rate at which the workstation can process parts, while accounting for failures, setups and other pertinent factors over the planning period of interest (Hopp, 2001).

Additionally, value stream maps can contain many more pieces of data dependent on the scope and depth of the project. Work schedules and time available to manufacture is important when calculating run ratios, which divides total available time to manufacture by number of good parts. Scrap rates, batch sizes, and other production information are useful in gaining an accurate portrait of the system.

While much of the focus of Value Stream Mapping is based on understanding the value added time and reducing the percentage of non-value added time, the EPA measured the baseline usage of raw materials in an effort to calculate the value added materials. The materials line drawn below the operational time line differentiates between the two classes of materials. The total amount of raw materials used in each process and the amount of materials that are actually incorporated into the product add value to the consumer. Operations chosen for assessment of material usage are indicated by the EHS (Environmental Health \& Safety) oval icon based on data collection and expertise in the field. 
Lean techniques, which will be discussed in detail later, such as Kaizen events, Kanban systems, Just-In-Time production and other strategies to eliminate waste and improve production flow, were evaluated to determine where decreases in the quantity of raw material usage could be achieved. The EPA then created an action plan for these areas of opportunity in order to decrease wasted materials in each operation. New values were then calculated and changes in flow patterns (material, informational, production) are expressed in the future state map, found in figure 2 .

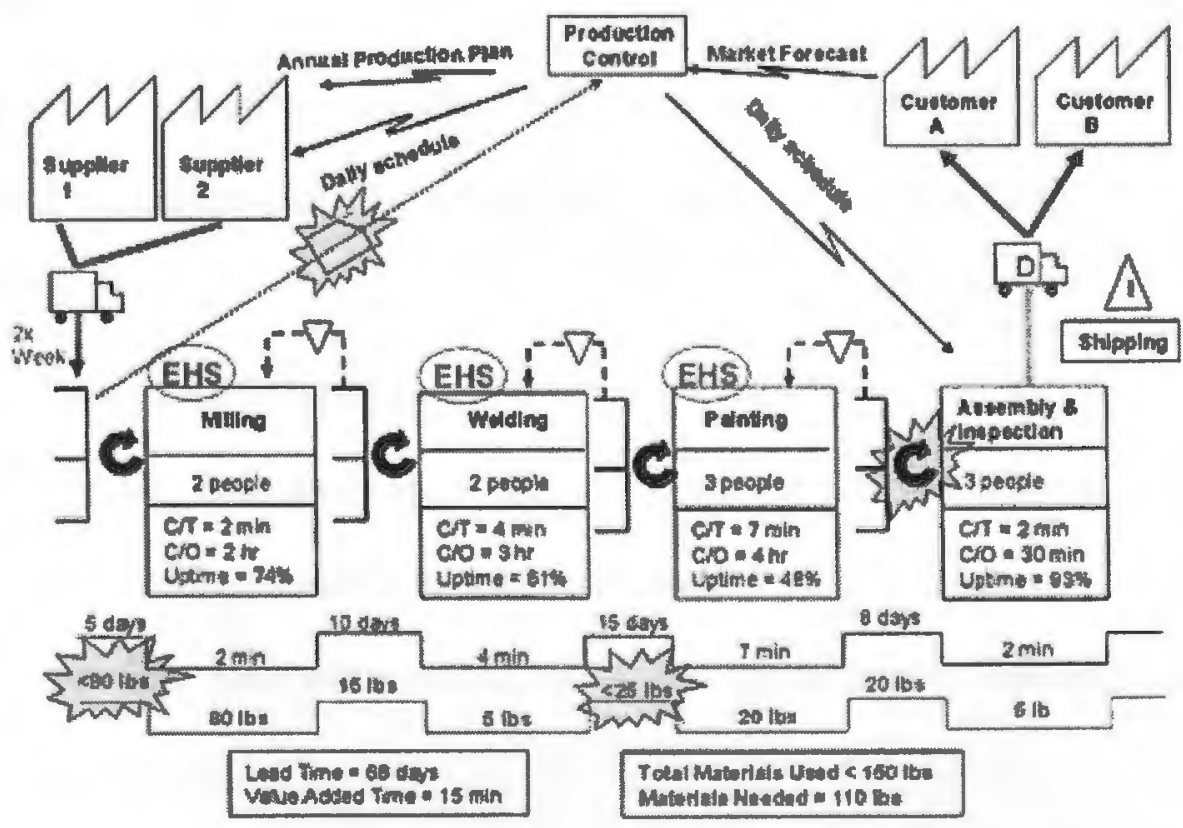

Figure 2. EPA Future State Value Stream Map (EPA, 2006a)

\subsection{Tools for Leaner Manufacturing}

Lean manufacturing has been considered to capitalize on the advantages of both mass production and artisan crafting. Cross trained workers are defined as "workers trained over time to perform a variety of tasks within their work area" 
(Askin, 2002) and then often rotated throughout the positions. Utilizing cross trained employees with flexible autonomated processing equipment enables the production of a wide variety of products in high volumes. "Production is lean if it is accomplished with minimal waste due to unneeded operations, inefficient operations, or excessive buffering in operations" (Narasimhan, 2006). It is considered "lean" because it utilizes far fewer resources, such as worker effort, production/storage space, on site inventory, less equipment investments while striving to achieve defect free processing (Womack, 1990).

\subsubsection{Waste}

In order to improve any company's leanness, it is important to identify and address the seven forms of waste which were identified by Taiichi Ohno of Toyota (Ohno, 1988):

1) Defects: Parts that are manufactured but do not meet specifications

2) Waiting: Operators/equipment that is starved for work due to a lack of materials, equipment, or pertinent information.

3) Motion: Non value added movement of personnel, inventory, and/or equipment.

4) Over-Processing: Any extra operations that are not required to manufacture a product.

5) Over-Production: Making more product than the customer has ordered.

6) Inventory: Having excess raw materials, work-in-process, and finished goods. 
7) Inefficiency: Using excess material to process; people wasting time, ideas, effort, and time, and under usage of capacity (Allen \& Robinson, 2001).

The following lean techniques were developed in the pursuit of achieving zero wastes.

\subsubsection{Autonomation}

Autonomation (Jidoka) in Japanese has two distinct meanings: 1) A change from a manual process to a machine process. 2) Automatic control of defects or automation with a human mind (Monden, 1998). Machines normally operate at very high rates in manufacturing organizations; when dies or tools break there is a rapid proliferation of defective products if the machine is incapable of differentiating between acceptable and defective products. The founder of Toyota Motor Company ${ }^{\circledR}$, Toyoda Sakichi, invented an auto-activated weaving machine capable of instantly stopping if any of the necessary threads broke. This was a significant

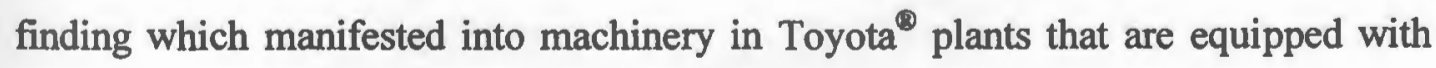
detection sensors linked to automatic stopping devices. Additionally, workers are empowered and encouraged to stop production if they feel an error is occurring. Machinery stoppage requires immediate attention to repair and improve the system. If the machine can not be fixed in a set period of time, five minutes for example, then all members of the production team become involved with a repair solution because the entire production line is stopped. The cartoon below, figure 3, is a simple example but shows two scenarios, the top portion represents a traditional automated 
machine which will produce whether the products are good or defective. In the lower portion, there is the addition of a stop button which the machine can activate itself in addition to a siren on top of the machine alerting the operator that there is a problem. Ohno said, "A problem early in the process always results in a defective product later in the process. This will stop the production line or change a plan whether you like it or not" (Ohno, 1988).

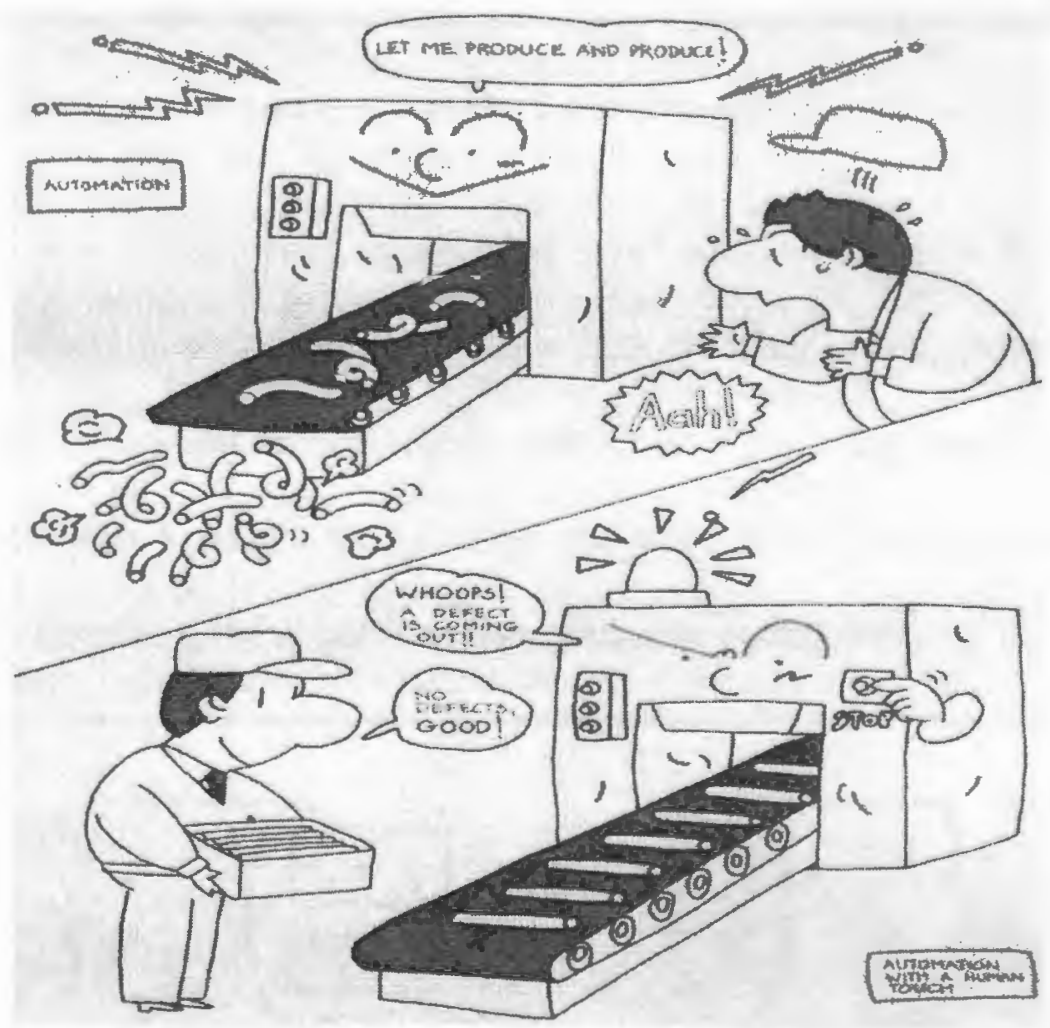

Figure 3. Automation versus Autonomation (Hirano, 1987)

\subsubsection{Error-Proofing}

The term "Baka-Yoka" (idiot proofing) was first used by Shigeo Shingo, and evolved into, "Poka-Yoka" (fool-proofing) (Shingo, 1985) and is now widely recognized as error-proofing. This technique places various checking devices on equipment and tools to remove the potential for error and ultimately the creation of 
defects. A simple example can be seen in figure $4 \mathrm{a}$, where an electrical socket could potentially be plugged into the incorrect charge.

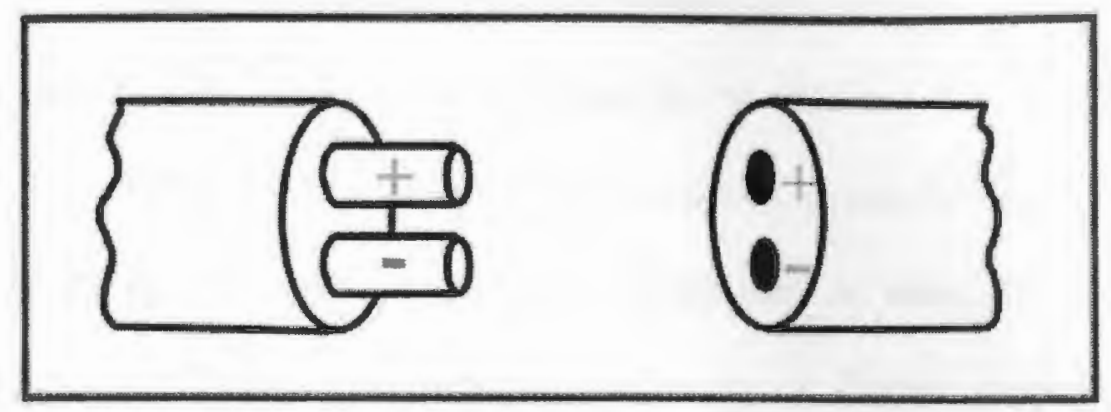

Figure 4a. Electrical connection before error-proofing (QS Consult, 2006)

This error could cause an electrical short and would result in a defective connection and an unusable product. When error-proofing is implemented, the part is redesigned to prevent the erroneous connection from being made. Figure $4 \mathrm{~b}$ below depicts how a simple modification can achieve this result and remove the potential for error from the operator or manufacturing equipment.

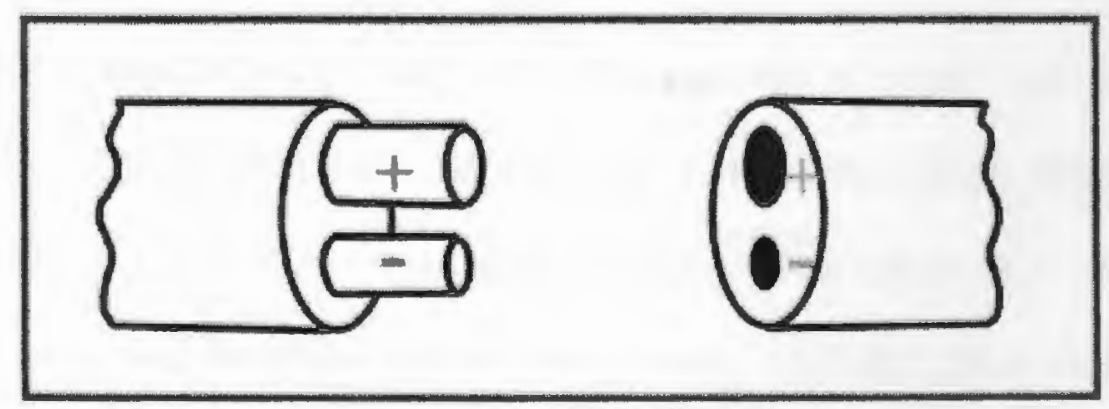

Figure 4b. Electrical connection after error-proofing (QS Consult, 2006)

Error-proofing is used extensively throughout the Toyota Production System in conjunction with autonomation to minimize the production and passage of defective parts to the next process and to the ultimate consumer (Ohno, 1988). 


\subsubsection{Just-In-Time}

Just in time (JIT) systems require a holistic approach to ensure accurate production, ordering, and stock quantities to ensure that the right parts needed in an assembly are available at the exact time they are needed and only in the amount needed (Ohno, 1988). While this may seem intuitive, it can be difficult to create such a system for a complex product where there may be many components and subassemblies. Additionally, JIT systems are reliant on flexible internal and third party component suppliers to cooperate with variability in ordering and delivery agreements. This approach requires synchronization throughout the company and transition from traditional "push" systems to a more flexible "pull" system. Push systems utilize a central planning system to determine and dictate production schedules, based upon sales forecasts, past sales records and customer orders. The demand forecast is used by production control as the basis of how many components to purchase, how much raw material to buy, at what rate to produce and when to place orders (Plossl, 1967). A pull system regulates materials and production through the withdrawal of only the necessary parts at the needed times from a previous (upstream) process which has only produced enough units to replace the parts that have been withdrawn. Company-wide JT implementation results in the elimination of unnecessary inventory thereby removing the need for warehouse and storage space, while simultaneously decreasing inventory holding costs and improving the ratio of capital turnover (Monden, 1998). Organization wide implementation of JIT can be difficult, but research has shown the positive impacts of the system on other operational areas such as organization, human resources, 
quality management, information systems, technology development, and manufacturing strategy (Matsui, 2006). This indicates a synergistic impact on a highly linked system and an overall contribution to competitive performance improvements.

\subsubsection{Kanban}

Kanban (sign board) is a communication tool to convey information about picking up or receiving the production order (Ohno, 1988). Kanbans vary in form (cards, bins, electronic signs, etc....) but they all circulate between the processes to control the amount of production to ensure that only what is needed is produced. Withdrawal Kanbans specify the type and amount of product required for the next process to withdraw from the previous process, and a production-ordering Kanban specifies the kind and quantity of product which the preceding process must produce (Monden, 1998). This system is vital for a pull system to maintain just-in-time manufacturing and prevent overproduction or underproduction of necessary components. Figure 6 is a simplified example of the use of Kanbans to communicate both withdrawal (retrieval) and production in the Toyota Production System 
Ooerational Flow of Production

Instruction Kanban A

\section{2}

and in easd nuntat of ports thented on the kutan are wetsed.

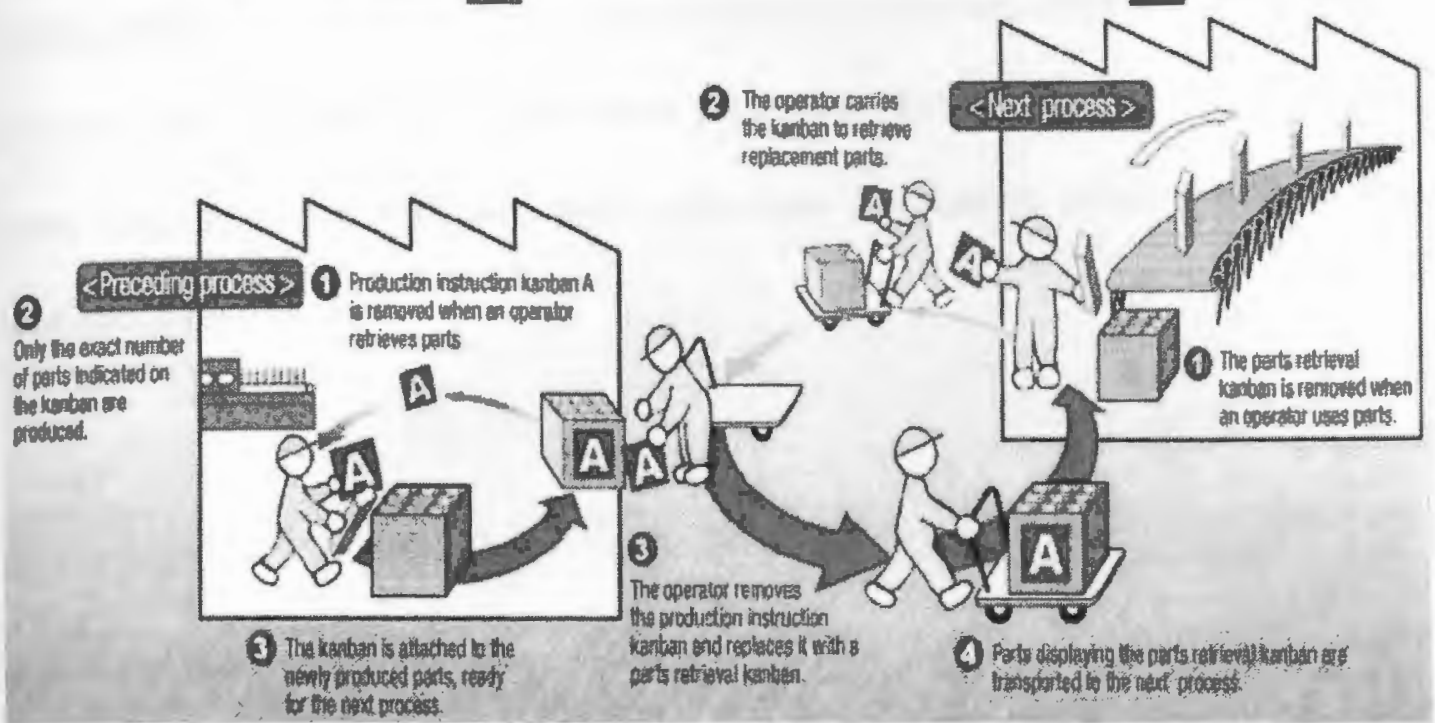

Figure 5. Conceptual Diagram of the Kanban System (Toyota Motor Co. @)

While the Kanban system appears simple, it is important to realize that understanding and calculating the optimal number of Kanbans required is difficult. A system's robustness must be studied to gain an understanding of the future environment where unexpected events such as breakdowns occur. If the Kanban system is not optimized and flexible to handle variations, production will suffer and the benefits of the just-in-time system will not be realized (Kleijen, 2003).

\subsubsection{Kaizen}

Kaizen (good change) was defined as continuing improvement in personal life, home life, social life and working life. When this definition is applied to the workplace, the kaizen philosophy is to create an environment of ongoing improvement driven by company wide involvement at all levels (Imai, 1986). The organization must create a sense of belonging to encourage employee commitment in 
order to facilitate the exchange of knowledge and ideas without fear of reprisal (Recht, 1998). Continuous improvement requires a concerted effort to identify areas of waste and propose solutions to those problems. Employees are encouraged to make suggestions on a regular basis, and these suggestions create the basis for continuous improvement.

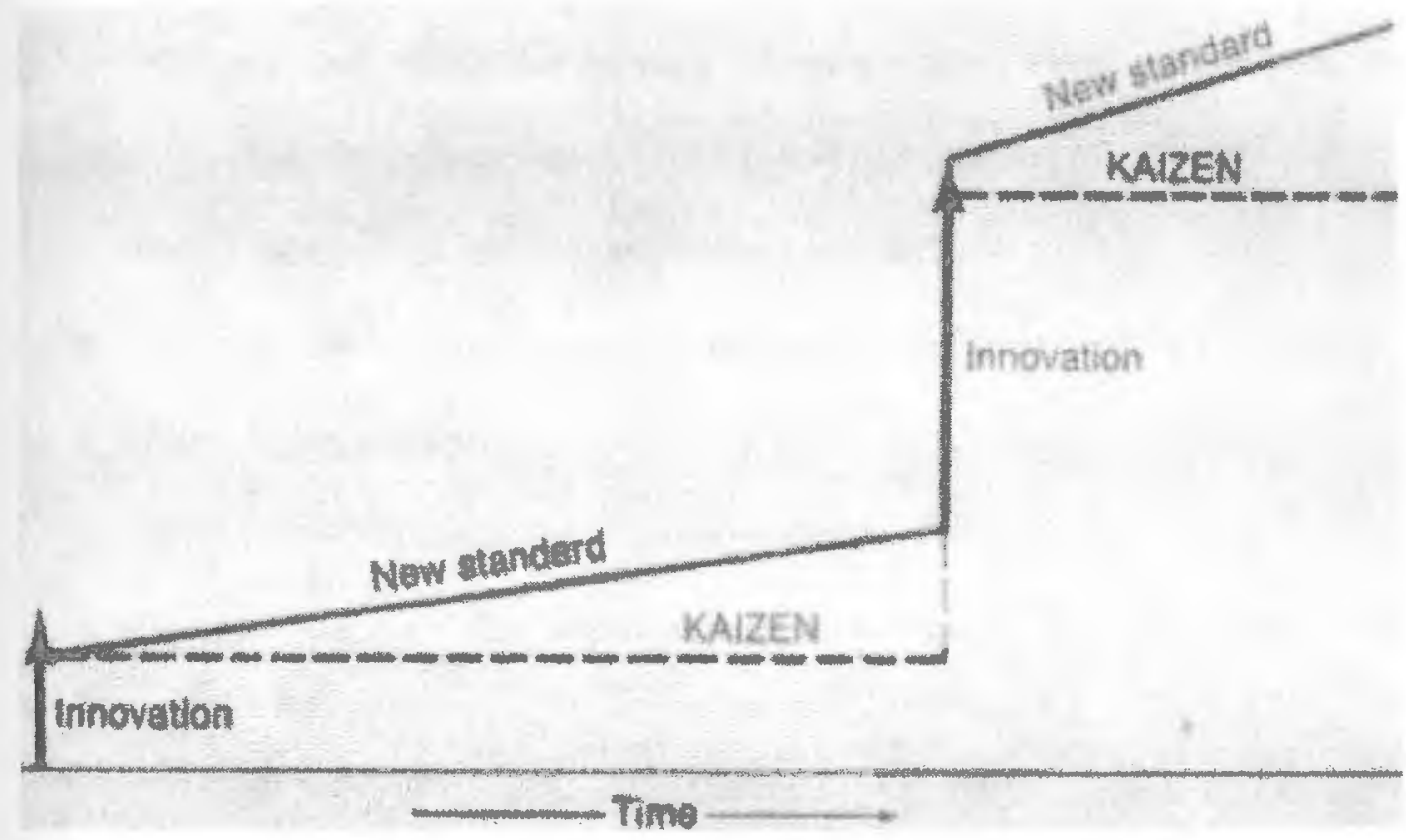

Figure 6. Comparison of innovation and Kaizen improvement (Imai, 1986)

Figure 6 compares innovation and Kaizen as complimentary means to achieve improvement, the $\mathrm{Y}$-axis of graph which is not shown, over time. The graph uses a dashed line to represent Kaizen as continuous improvement, a vertical arrow depicts the results of innovation or a Kaizen blitz, and the solid line, the new standard, can be seen as a result of the combined effort of these actions. The term innovation has evolved and is now known as a Kaizen event or a Kaizen blitz. The focus of the event is to improve a specified process or area in a short time period, 
through the Kaizen ideals of company wide cooperation. One expert describes the blitz as a week long event where a group composed of the process manager and personnel outside the department analyzes the current state of the process or area of focuses, address the problem, and implements the changes (Liker, 2004). By using both approaches, continuous improvement can be sustained both short and long term.

" $5 \mathrm{~s}$ " is a tool which can be used during a Kaizen event to reduce hidden wastes in the plant through a cleanup activity, and is comprised of:

1. Sort- Organize and remove unnecessary materials.

2. Stabilize- Improve orderliness by designating proper spaces for everything.

3. Shine- Clean the area.

4. Standardize- Standards are clear and understood.

5. Sustain- Maintain the improvements and changes that have been made (Allen, 2001). 


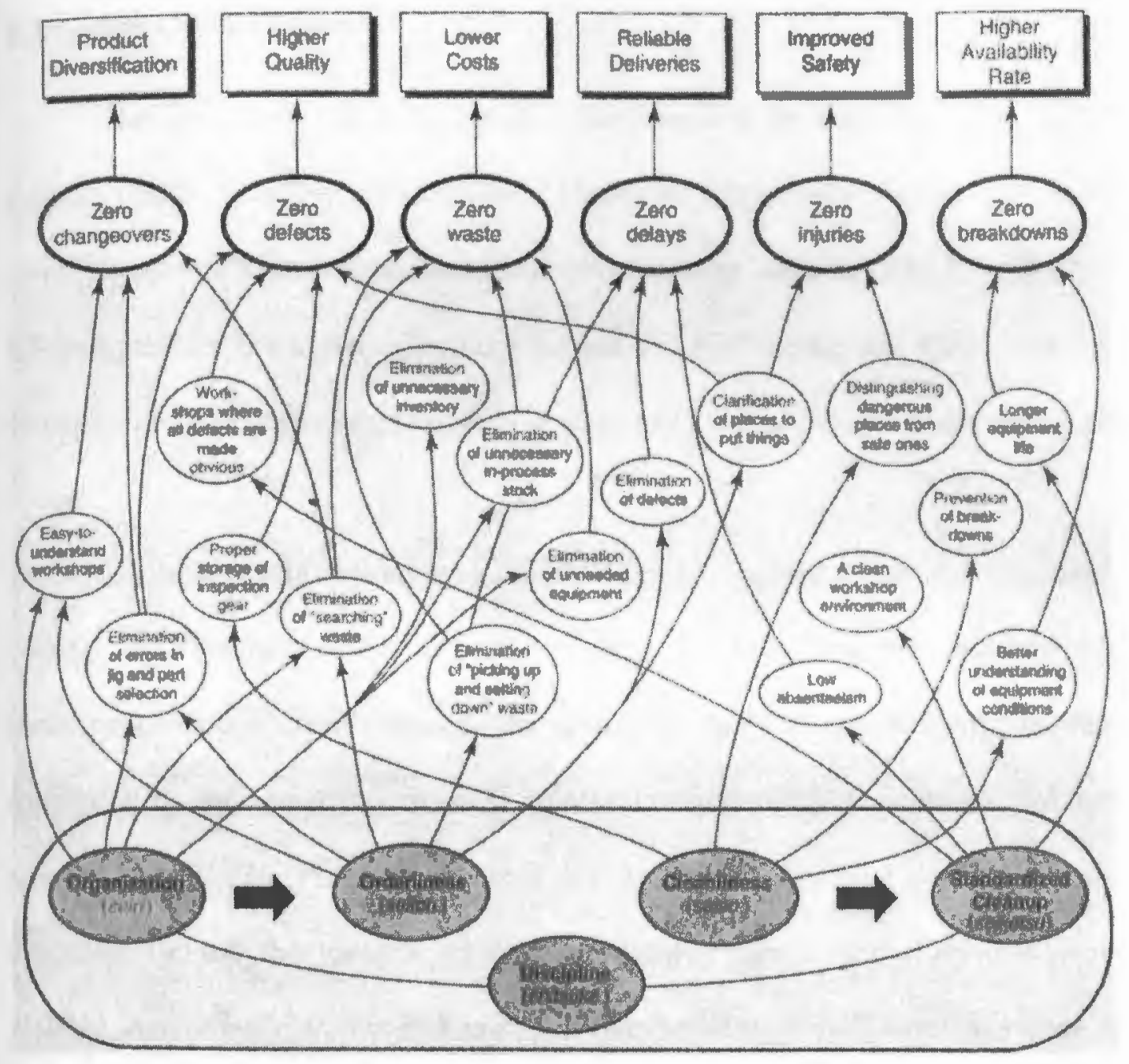

Figure 7. Overview of areas of improvement and benefits of using 5S (Hirano, 1995)

Figure 7 is an overview of direct and indirect benefits of $5 \mathrm{~s}$ in the pursuit of removing waste, defects and maintaining safe working conditions which is the ultimate goal of lean manufacturing. 5S improvements will result in: 1. Product diversification. 2. Higher quality products. 3. Lower manufacturing costs. 4 . Reliable product deliveries. 5. Improved worker safety and 6. Higher equipment availability (Hirano, 1995). 


\subsection{System Configurations}

The statement "An hour lost at a bottleneck is an hour out of the entire system" (Goldratt, 2004) embodies the "Theory of Constraints". It is essential to identify a system's bottlenecks and focus on improving them in order to realize the full potential of the system. In order to address bottlenecks and meet customer demands, manufacturers must be flexible, especially when changes occur with little notice.

Machine configurations ranging from serial to hybrid to parallel have been studied to determine their impacts on key metrics. Research investigating performance was defined through the following metrics: productivity, quality, convertibility and scalability to evaluate each configuration of equipment (MaierSperedelozzi, 2002). Findings indicated that a completely parallel configuration of machines yielded the greatest performance improvements, with hybrid systems yielding greater performance measurements than serial systems. While this work is encouraging, parallel machining is not a "cure-all" approach, as research has also shown that other configurations have their own advantages. Quality analysis has shown that serial machining had the smallest standard deviation, and different hybrid configurations had the smallest mean deviation and greatest convertibility (Zhong, 2000). The complexity and needs of the system must be addressed for each individual facility, equipment and product. Additionally, the cost of parallel machining must be considered, especially for equipment with long setup and change over times. 


\subsection{Chapter Review}

The basic concepts of selected lean manufacturing tools and other practices used in outside industries were addressed in this chapter. The overall goal of manufacturing lean is the elimination of waste, as this principle is applicable to every industry. It is important to identify where practices are applicable in the pharmaceutical industry. 


\section{Chapter 3}

\subsection{Pharmaceutical Manufacturing Background}

Chapter 3 will address the current state of pharmaceutical regulations by the FDA through cGMP's. This chapter will discuss Process Analytical Techniques (PAT), a guidance approved in 2004, and regulations to improve innovation and competitiveness, while giving examples of this technology currently in use. Additionally, regulations regarding over the counter (OTC) products will be discussed as an appealing area for advancing manufacturing based research. Finally, opportunities for pharmaceutical manufacturers to take advantage of the new regulations will be discussed.

\subsection{Current State of Pharmaceutical Regulations for Manufacturing}

Current pharmaceutical leaders have recognized the shortcomings of cGMP's; examples include dubious and repetitive product testing, validation procedures and extensive documentation for well understood process changes. Inflexible regulations have hindered process improvements in the past and became the object of industry and FDA focus for change (Hussain, 2002). In response, the FDA has recently released new Guidance for Industry which addresses the use of PAT (FDA, 2004a) and Pharmaceutical cGMP's for the $21^{\text {st }}$ century (FDA, 2004b). These documents are supported by a number of cGMP's including: Q8 Guideline on Pharmaceutical Development (FDA, 2006b), Q9 Guideline on Quality Risk Management (FDA, 2006c) and Q10 Guideline on Quality Systems which is still 
under development (Joneckis, 2006) to encourage innovation in the pharmaceutical industry.

\section{The FDA defines PAT as:}

A scientific, risk-based framework intended to support innovation and efficiency in pharmaceutical development, manufacturing, and quality assurance. The framework is founded on process understanding to facilitate innovation and risk-based regulatory decisions by industry and the Agency. The framework has two components: (1) a set of scientific principles and tools supporting innovation and (2) a strategy for regulatory implementation that will accommodate innovation (FDA, 2004a).

The definition for PAT presented does not define the overall strategy of the initiative, but serves as an introduction to the regulatory practice. A practical definition of PAT is given as "systems for continuous analysis and control of manufacturing processes based on real-time measurements, or rapid measurements during processing, of quality and performance attributes of raw and in-process materials and processes to assure acceptable end product quality at the completion of the process" (Hussain, 2002). These revised guidance documents have created a new era for the pharmaceutical industry. The documents shift away from conventional thinking, where process changes are discouraged due to the substantial financial and scientific resources required to fulfill FDA documentation requirements. The new focus is to understand the product, the manufacturing process, and operations. This approach has been described as the "design space", defined by the FDA as:

...the multidimensional combination and interaction of input variables and process parameters that have been demonstrated to provide assurance of quality. Working within the design space is not considered as a change. Movement out of the design space is considered to be a change and would normally initiate a regulatory postapproval change process. 
Design space is proposed by the applicant and is subject to regulatory assessment and approval (FDA, 2006a).

Within the design space, the control space has been described as a: "Multidimensional space that encompasses process operating parameters and component quality measurements that assure process or product quality. It is a subset of the design space" (Desai, 2006). Exploration and understanding of these areas will lead to the identification of critical parameters, as well as metrics and methods to capture their impact on the process, enabling quality management through a risk based approach. A new control strategy aims to minimize risks associated with failures when critical and non-critical process parameters fall outside the control space but remain within the design space.

The FDA has recognized, similarly to outside industries, that quality must be built into the design of the product, and that it cannot be achieved through testing or inspection alone. Throughout the development and product life cycle, changes in formulation and manufacturing practices offer opportunities to gain greater knowledge of product characteristics and performance under various conditions. Inclusion and analysis of all relevant experimental and experiential information can be used to create, support, and expand the control and design spaces. While absolute operational and process understanding is impossible, it is important to recognize what is known and operate within those parameters. Figure 8 depicts a conceptual representation of the importance of experimental data to provide the framework for creating and supporting the control and design spaces as defined by the manufacturer and approved by the FDA. 


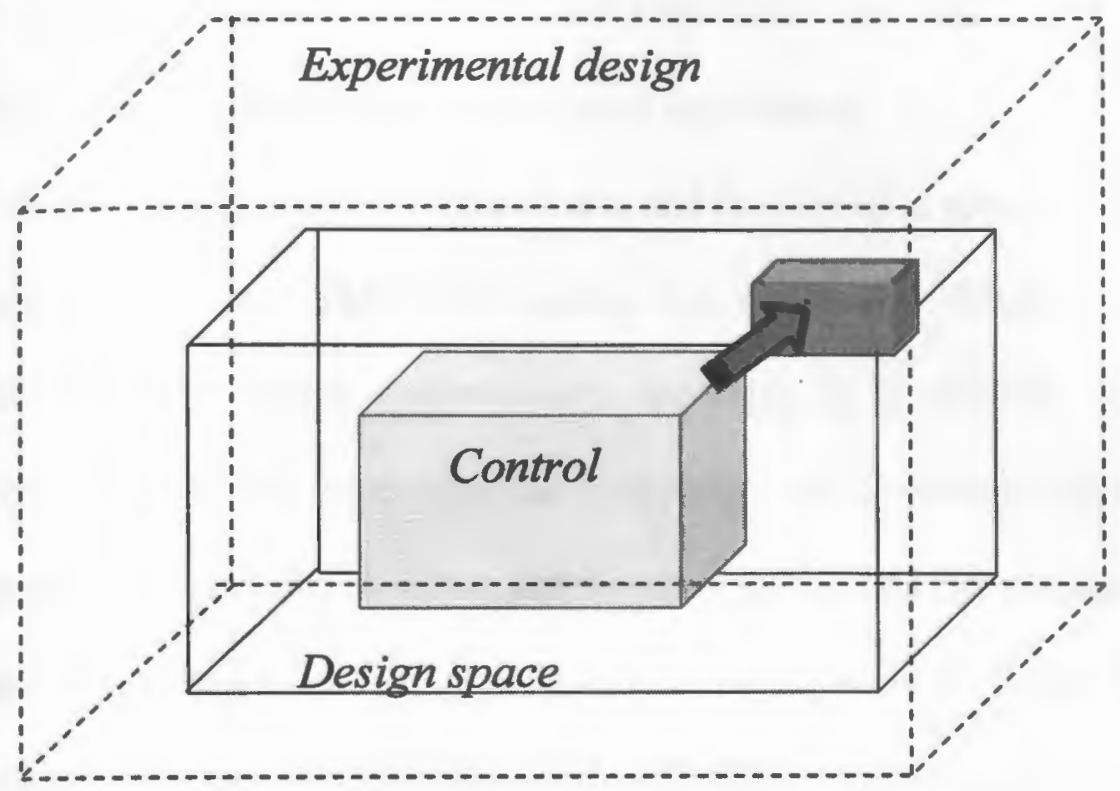

Figure 8. Hierarchy of manufacturing control strategy (Low, 2006)

The FDA has given the pharmaceutical industry an opportunity to enter the $21^{\text {st }}$ century of manufacturing by expanding the control space of their operations while still staying within safe operating conditions in the design space. PAT has excited many in the pharmaceutical industry, who see the potential to continuously improve processes as they occur in other manufacturing industries.

This drastic change in the regulatory mindset has raised many questions regarding feasibility and practicality. PAT has become an industry "buzzword" with much of the knowledge only attainable through consultants, and/or is guarded closely within the industry. Current seminars and workshops address very specific ideas of using novel techniques for limited areas, such as specific assays used during processing to verify quality (Tyler, 2006). Many consultants propose vague "buzzword" laden approaches to improvements without scientific background and 
appear to be more oriented to selling their services. Adoption of PAT has been slow due to a lack of technical knowledge and trepidation over regulations, as PAT is currently only a guidance document and not a requirement.

PAT is still in its early stages of use, and there is wide spread skepticism and uncertainty of how the FDA will regulate this new area. While the long term benefits of manufacturing improvements are clear, it is difficult to make the argument for a sizable investment in innovation on a product currently being developed for fear of clinical failure and the uncertainties of FDA product approvals. Further, if a product will be approved, companies want to avoid delaying or jeopardizing the approval process due to changes in manufacturing approaches. Additionally, there are concerns over technological limitations, which prevent online process monitoring and understanding for complex products such as protein drugs (Glaser, 2006). Others have addressed some of these concerns in outside industries and it is important to learn from their successes and failures.

\subsection{Examples of Current PAT Use}

Near infrared (NIR) spectrometry has been studied extensively for the use of online monitoring of pharmaceutical products. This non-invasive and nondestructive technique has been studied for a number of different potential uses during manufacturing. This method can identify and differentiate between differently formulated products even if they appear identical, across a wide variety of dosage forms (tablets, solutions, capsules, etc) (Medendorp, 2006). NIR has been studied throughout the manufacturing process, from raw material qualification and 
quantification, in line monitoring processes and final packaging identification systems. Some monitoring applications include moisture content, active pharmaceutical ingredient (API) concentrations, blending homogeneity, coating thickness and tablet hardness (Swarbick, 2006).

Raman spectroscopy utilizes an energy source, such as a laser or ultra violet (UV) light, to excite molecules from their original states into an excited state, and measures the vibrational level required for the shift (Raman, 1928). This tool has been used in the identification, monitoring of homogeneity, and quantification of different drug products. Polymorphs, defined as a drug substance existing as two or more crystal chemical structures which may have different chemical and physical properties than the original structure (FDA, 2002), have been identified as an opportunity for processing improvements. Continuous monitoring of polymorphic transformation secondary to high sheer granulation in formulations for encapsulation and the solubilization of API in inactive ingredients (excipients) has been studied (Jayawickrama, 2006). Raman probes have been placed in different machinery during production to determine that this technique was viable for monitoring process deviations, which negatively affect the product. Monitoring and adjusting processing to prevent undesirable polymorph formations through online Raman monitoring to retain formulation homogeneity is an important tool for manufacturing acceptable products (LaPlant, 2005). Currently, Raman and Infrared techniques are limited to process monitoring but future developments should aim to incorporate autonomation principles such as automatic processing adjustments when deviations occur and automatic shut downs if adjustments do not solve the problem. 
There are a number of other methods of utilizing analytical and process instrumentation to identify acceptable processing and product specifications. A few examples are included here: Mass spectroscopy has been proposed to monitor moisture content of drug products during lyophilization to ensure acceptable processing conditions to yield less than $1 \%$ water content (Wiggenhorn, 2005). Cell density probes have been utilized to monitor the fermentation process of protein drugs, to reduce potential quality issues, process variability and meet the desired target density with fewer deviations (Low, 2006).

Pharmaceutical manufacturing requires that strict processing and formulation specifications must be met prior to the release of the product. Currently, manufacturers must "test in" quality by sampling a number of randomly selected finished products prior to their release, known as end product testing. By monitoring important metrics during production with a demonstrated correlation with end product quality, one could conceivably avoid end product testing and utilize inprocess (parametric) release testing. In 1987, The FDA approved parametric release only for terminally heat sterilized drug products. Parametric release is defined as "a sterility release procedure based upon effective control, monitoring, and documentation of a validated sterilization process cycle in lieu of release based upon end-product sterility testing. All parameters within the procedure must be met before the lot is released (FDA, 1987)." This regulation only applies to certain large volume parenteral (LVP) products and requires a supplemental new drug application for approval. Currently several manufacturers have gained approval for parametric release using moist heat sterilization (autoclave) methods, but it has not been adopted 
widely due to the extensive documentation and validation procedures required (Stevens-Riley, 2005). Chemical, ionic, and thermal methods of terminal sterilization for many drug products to avoid end product sterility testing and allow parametric release have been discussed by members of the United States Pharmacopeia (USP) for FDA approval (Tirumalai, 2005).

\subsection{Over-The-Counter Product Regulations}

There are more than 100,000 over-the-counter (OTC) products and 800 active ingredients, encompassing over 100 therapeutic classes currently for sale in the US (FDA, 2000). There are two methods to get an OTC product on the market to sell to the general public without a prescription. Similar to new prescription drugs, a New Drug Application (NDA) for a specific product must be approved prior to marketing which may require clinical studies, mandated FDA review timelines and postapproval maintenance (Christl, 2006). An alternative method is to be in compliance with an FDA approved drug monograph. Monographs specify active ingredients which must comply with standards that have been found "generally recognized as safe and effective" (GRASE), and must comply with the monograph with regard to the formulation, labeling, and testing requirements (FDA, 2006d). The United States Pharmacopeial Convention is an independent volunteer organization recognized by the FDA to set monograph standards for active and inactive pharmaceutical ingredients, dosage forms, and medical devices (USP, 2007). Monograph products do not require pre-approval or clinical trials; they have common labeling for all similar drugs and are publicly available without exclusive marketing rights. The 
similarities between NDA and monograph products include: safety and efficacy standards, manufacturing and GMP inspections, labeling requirements and advertising regulations (Hilfiker, 2006).

OTC monograph products represent an opportunity to investigate new manufacturing techniques. Formulation, dosage form, concentration requirements and labeling are the key monograph factors (Hilfiker, 2004), while manufacturing processes are generally left to the manufacturers. This flexibility allows manufacturers to individualize specific processes to create their own version of the product. During the approval process for a prescription drug, clinical or bioequivalence studies are required and the manufacturing processes used during this period must remain the same after approval. If there is a significant change to the production process, it must be validated and documented in a supplemental document. The financial and time constraints cause pressure to gain an expedient approval, and can later result in non optimal processes which are not changed for fear of negative FDA action. As a manufacturing model, it would be more feasible to use an OTC monograph product because it has been characterized and studied. While monographed products still require validation for changes during manufacturing, there is a greater flexibility and information available during the initial production process planning.

\subsection{Opportunities for Pharmaceutical Manufacturing}

There is considerable opportunity to investigate the implementation of current practices and knowledge found outside the pharmaceutical industry for 
incorporation into novel processes in line with the FDA's cGMP's and PAT regulations. The concept of the incorporation of external industries has been proposed (Crosby, 2006), but research focused on these principles and their effects on manufacturing operations and pharmaceutical product development has not been explored. It is important to approach improvements to manufacturing while still complying with cGMP and FDA regulations. Each product and manufacturer should asses whether changes in their regulatory requirements are necessary if changes are made.

\subsubsection{Batch vs. Continuous Processing}

One of the most apparent areas that could be improved in the pharmaceutical industry is a change from batch manufacturing to a continuous manufacturing approach. Currently the metal industry has utilized continuous manufacturing for metal matrix composite wires, among other products. Originally the wire was manufactured by batching, but long processing times and extended heat exposure was detrimental to the final product. The process was redesigned addressing the critical parameters required for a quality product, and thorough experimentation was performed in order to identify the optimal operating parameters of the new process. The new process yielded lower throughput times and lower exposure times which had resulted in heat damage to the metal and an unacceptable product (Blucher, 2001)

Some areas of pharmaceutical production have considered continuous production methods. Tablet, transdermal patch and biotechnology product 
manufacturing have been studied to determine the potential advantages of continuous manufacturing practices. Granulation is a method to increase powder flow and compressibility (Ansel, 1999), and is often a bottleneck in tablet manufacturing. Some continuous production methods which have been considered to overcome this problem include: fluid bed agglomeration, spray-drying, extrusion, instant agglomeration, roller compaction and semi-continuous granulation. Continuous transdermal patch manufacturing using hot melt extrusion principles has been studied (Wolff, 2000). Spray drying techniques, used extensively in the dairy industry, have been used in the biopharmaceutical industry but have been increasingly displaced by lyophilization, a batch process. Ease of automation, lower material handling, in-process controls, flexible manufacturing and avoidance of scale-up are some advantages of a continuous system (Vervaet, 2005). It is important to consider that continuous practices are not a "one size fits all" application, and individual products must be critically evaluated. This methodology can be applied early on in the development phase, when considering formulations, but it is critical to evaluate the formula's performance during the manufacturing process, in vitro and in vivo. If production.volumes are kept constant, continuous manufacturing would require significantly smaller space and equipment, potentially yielding a several fold cost reduction (Cini, 2006).

Currently there are technical and regulatory barriers which must be addressed prior to the commercial institution of continuous manufacturing. Few manufacturing systems can be easily adapted to a continuous process without significant capital investment. Publications in this area are sparse, and narrowly focused on a single 
product, requiring expansive experimentation to gain the information required to change. Additionally, some products are made in small quantities and production goals can be met in a single batch. The FDA has given manufacturers theoretical guidance, and the industry is unsure of the regulatory agent's interpretations of the new documents. Manufacturers should not overlook previously discussed lean techniques which could be evaluated and applied to the pharmaceutical industry now for results in the near future.

\subsubsection{Lean Techniques}

Currently, setup times are very long for equipment and result in large batch processing to preserve their economy of scale. The Toyota Single Minute Exchange of Die (SMED) concept is focused on reducing the setup time for equipment which had traditionally taken several hours to less than ten minutes. This significant accomplishment occurred through continuous improvement by employees at Toyota ${ }^{\circledR}$. Continuous improvements in setups in pharmaceutical companies could be achieved utilizing shadow boarding, a visual control technique, which creates an outline for mechanics tools and parts required for assembly of equipment, to ensure that parts are not missing or incorrect. Currently, standard operating procedures (SOP's) are required by the FDA, but may be unclear when compared to visual controls used in many automotive manufacturing facilities. Standardized work and error proofing techniques are aimed to aide manufacturers through simplification and visualization of the process. While many SOP's may include sample graphs or tables with information, they often do not utilize pictures or simple drawings to 
instruct the operator. SOP's can be technical and difficult to understand resulting in operator deviations. Simplification of the process, such as color coded setup components, or creating one way assemblies of parts can simplify the setup and change over tasks, while reducing the chance of an erroneous setup resulting in damage to the machine or the product.

A pull system could be used to increase product flow through the manufacturing facility and movement towards one piece flow. Predominantly the formulation aspect of pharmaceutical products requires a batch process to generate the bulk drug. The following stages could utilize a semi continuous approach to decrease batch sizes similar to Toyota ${ }^{\bigotimes}$ production method. Batch splitting or mini batching could be explored to increase flow and flexibility in the remaining operations. Kanban cards could be used to facilitate the pull system, especially since the master batch record currently travels with the product throughout processing and acts as a production Kanban. Retrieval Kanbans could be used to help create greater visualization of where equipment and material should be placed to support the flow of production.

\subsubsection{Design for Manufacturing}

Design for Manufacturing (DfM) principles have been studied extensively for products such as wiring harnesses, electronics, machining of metal components, powder metal processing, plastic injection molding, sheet metalworking, casting, and final assembly (Bralla, 1986; Boothroyd, 2002; Otto, 2001). There are opportunities to develop similar principles for the development of drugs and medical device 
products. Traditional development methodologies are concerned only with creating a safe and efficacious product. The product is then given to the manufacturing department and is expected to be produced rapidly, despite the fact that manufacturability was not considered at all during the design process. In reality, the transition from development to manufacturing is a difficult and complex process.

Using principles from DfM to guide experimentation during formulation, identification of factors that are critical to the manufacturability of the product will support expansion of the design space to allow more flexible manufacturing.

Examples of experimental focal points include raw material properties, variation of formulation characteristics and delivery device components.

\subsubsection{Simulation}

Simulation has been used throughout many industries to gain insight into current conditions and hypothetical future states. Mathematical models and simulations have been used in operations research for many years to solve operational, warehousing, transportation, distribution and logistical problems (Chung, 2004). Simulation has been expanded to address a wide array of problematic areas for industries outside of manufacturing. Lean manufacturing principles have been studied to determine suitability for specific industries in order to evaluate conceptual improvements that could be made through its implementation (Abdulmalek and Rajgopal, 2007). By creating a value stream map as the foundation of their simulation model, Abdulmalek and Rajgopal evaluated implementing lean techniques to a steel manufacturer and determined which improvements were 
feasible. The simulation allowed the researchers to monitor WIP and production lead time as their primary metrics, while creating a visual product for management to encourage changes where needed.

\subsubsection{Other Manufacturing Tools}

Parallel and flexible machining could also be used in many of the processes after the bulk drug has been formulated. Filling bulk product into its container, cartoning of filled drug product and boxing of finished goods are all strong candidates for parallel machining. Utilizing flexible routing and reconfigurable machines can reduce throughput time and minimize the effects of downtimes. Also, resources required for production may be shared, and have a synergistic effect on production rate and setup times.

Online and in line sensing methodology is continuously evolving and has the potential to change the way processes are monitored. Unfortunately the current limitations are sensitivity issues and equipment can not accurately analyze all aspects of the manufacturing processes. As the sensing and analytical technology improves, manufacturers can rely greater on processing parameters and less on end product tests.

\subsection{Chapter Review}

The current state of the regulatory influences guiding the pharmaceutical industry was addressed in this chapter. New guidance documentation and the opportunities which have arisen for the industry were addressed. The opportunities addressed may not apply to all pharmaceutical manufacturers, and it should be noted 
that there is varying commitment to lean manufacturing throughout the industry. Particularly small and medium companies with more limited resources may need to explore these techniques. 


\section{Chapter 4}

\subsection{Methodology and Procedures}

Chapter four will describe the methods and procedures used to gain an understanding of a product throughout the current system of the company used in this study. Collected empirical data are defined as model inputs to accurately portray the product in the system. A simulation model will be employed to allow visualization of the process and for identification of problematic areas. A theoretical future state will be created in ProModel ${ }^{\circledR}$ software and compared against the original current state to identify which changes to the system yield a significant impact.

\subsection{Phase I - Current State of Pharmaceutical Manufacturing}

Phase I will evaluate a manufacturing facility that produces pharmaceutical products under current Good Manufacturing Practices to gain a "baseline" understanding of current manufacturing systems. This phase will develop a model of the system to identify critical and problematic areas, to identify potential opportunities for processing and formulation improvements.

\subsubsection{Evaluation of the Current System}

The current manufacturing system will be evaluated by "walking the line" and "gemba" (go and see) lean manufacturing techniques (Meier, 2001) to create an

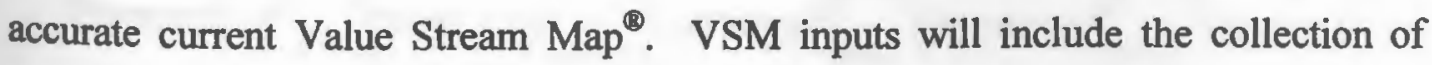
direct measurements, historical data and empirical information. Manufacturing data will be collected through direct and indirect methods, including time and motion 
studies and the measurement of factors such as Work In Process (WIP) throughout the system, productivity, rework/scrap rates and other critical manufacturing indicators (Hopp, 2001). An AutoCAD drawing of the layout will be used to measure distances traveled by personnel and materials. Detailed employee shifts with breaks will be collected to measure total work hours in a day. Delivery times and quantities will be documented to monitor the flow of materials into and out of the production facility.

Direct methods:

- Measuring throughput time, cycle time and change over/setup times.

- Counting materials, components, Work in Process (WIP) and finished goods throughout the system.

- Machine utilization/uptime and operators required.

- Counting defects, rework and scrap rates.

Indirect Methods:

- Quality Control Master Batch Records.

- Other documentation recorded during the manufacturing process.

\subsubsection{Simulation Modeling}

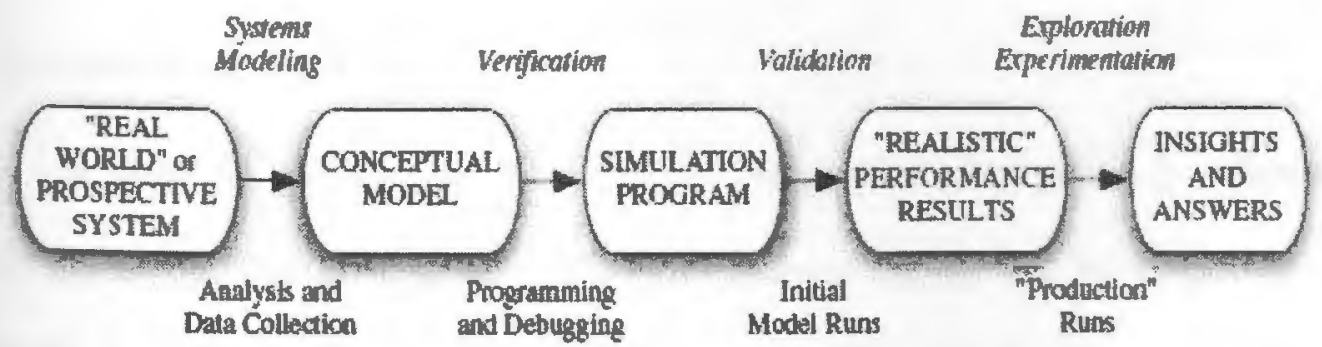

Figure 9. Simulation Overview (Sanchez, 2006) 
Figure 9 gives an overview of the steps required to create an accurate simulation and how experimentation can be performed to gain insight into "real world" problems in the current system. ProModel ${ }^{\circledR}$ software is a tool for simulating and analyzing diverse production systems including assembly lines, transfer lines, flexible manufacturing systems, job shops and Just-In Time systems. Resource utilization, production capacity, efficiency, inventory levels, etc. are some of the elements which can be modeled (PROMODEL, 2003). This software will allow experimentation with numerous variables, such as equipment, personnel, and layout with only conceptual alterations to the manufacturing facility. Data collected will be analyzed to identify trends, which enhance production metrics, (throughput, Work in Process, cycle time, etc.) (Hopp, 2001) and those that are detrimental to efficient production. Simulation will allow visualization and will incorporate detailed information about the system while closely conforming to the individual aspects, (Askin, 1993) facilitating experimentation with theoretical scenarios to identify problematic areas and potential failures. Phase one will result in the characterization and creation of a simulation model of the existing manufacturing system to identify the current manufacturing state.

\subsubsection{Statistical Methods}

In order to identify the most critical parameters after phase I, statistical analysis will be used to determine factors of interest which will be tested during phase II. A quality by design (QbD) method using a Box-Behnken design has been recently employed by Zidan et al. (2006), and will serve as a model. Critical factors 
will be identified in phase I and ranked according to perceived impact and an appropriate statistical design will be chosen based on the number and type of factors. The top factors, approximately three or four, will then become the statistical focus of the phase II simulation, with each of the factors containing appropriate levels for thorough study. Examples of potential critical areas include identification of bottleneck workstations, problem areas (defect/scrap rates) and unreliable operations/operators. The significance of interactions between independent and dependent factors will be evaluated through analysis of variance (ANOVA), with graphs to enhancing visualization where appropriate (NIST, 2006). Minitab Statistical software, Minitab Inc. Pennsylvania, USA (or equivalent) will be used for all statistical analysis and generation of appropriate tables, graphs and charts.

\subsection{Phase II - Future State of Pharmaceutical Manufacturing}

Phase II will utilize the information gained in phase I to compare current drug processing with a model of a theoretically and experimentally based "improved" system. Improved systems will address the critical processing parameters identified in phase one, and employ concepts adapted from alternative industries to gauge feasibility and potential outcomes.

\subsubsection{Development of the Future State Model}

To address the identified critical parameters, manufacturing tools from across all industries will be utilized including The Toyota Production System ${ }^{\circledR}$, flexible manufacturing system designs, continuous processing methods, in-line product testing and additional manufacturing tools. New processing and techniques for 
manufacturing will be analyzed to determine feasibility, using simulation to understand the impacts. Experimentation comparing alternative layouts and theoretical flexible systems to enhance production while potentially minimizing space and expenses will be performed using simulation (Askin, 1993).

A design of experiment using a factorial design was chosen in order to identify which interactions and factors achieve statistical significance. Table 1 describes the $2^{3}$ factorial design employed to compare the different simulation models. There are three factors where the current state for each factor is denoted as zero, and the future state is denoted as 1 . Therefore, run 1 depicts the current state of the system and run 8 is the most radically changed future state. In order to evaluate which areas of the future state are significant, six other intermediate simulations will be run, where some factors will be modified while others remain the same.

Table 1. Overview of Experimental Design

\begin{tabular}{|r|r|r|r|}
\hline & & Factors & \\
\hline Scenarios & A & B & C \\
\hline 1 & 0 & 0 & 0 \\
\hline 2 & 0 & 0 & 1 \\
\hline 3 & 0 & 1 & 0 \\
\hline 4 & 0 & 1 & 1 \\
\hline 5 & 1 & 0 & 0 \\
\hline 6 & 1 & 0 & 1 \\
\hline 7 & 1 & 1 & 0 \\
\hline 8 & 1 & 1 & 1 \\
\hline
\end{tabular}

\subsection{Chapter Review}

This chapter describes the methodology that will be used to evaluate a pharmaceutical manufacturer and a specific product. Using simulation and lean 
tools, identification of problem areas and solutions will be evaluated. Additionally, by using a statistical design, interactions between factors can be evaluated for significance. 


\section{Chapter 5}

\subsection{Case Study}

Chapter five will describe a pharmaceutical company which was selected as a case study for manufacturing improvements. The current manufacturing processes of a product chosen as the focal point of the study will be described and evaluated. A value stream map will guide the reader through the process and indicate where value and non value added time is expended on the product. The data collected and used to prepare the value stream map and the ProModel ${ }^{\otimes}$ simulation model will be described in this chapter.

\subsection{Background of the Pharmaceutical Company Selected for Study}

The pharmaceutical company chosen for this study will be referred to as XYZ Pharma in order to maintain their anonymity. While the company produces a few proprietary and prescription products, it primarily serves as an OTC contract manufacturer, producing over 100 human and veterinary products. Management currently describes that they are slightly behind schedule to meet customer deadlines, but feel that they are one of the more reliable and capable contract manufacturers in their market area.

\subsubsection{Facility}

The facility has the capacity to produce oral products such as liquids and suspensions, and topical products including gels, creams, liquids, adhesives and more. This study will focus on issues affecting topical gels and their manufacturing. 
The company is comprised of a $25,000 \mathrm{sq} . / \mathrm{ft}$. production facility and a $75,000 \mathrm{sq} . / \mathrm{ft}$. detached warehouse building, approximately $1 / 10^{\text {th }}$ of a mile away. The production facility layout can be seen in Appendix II, while the warehouse building, (not shown) is not considered the primary area of study. Unlike many other manufacturers with dedicated manufacturing equipment and personnel, XYZ Pharma is a self described pharmaceutical "job-shop". At any given point they are manufacturing between five and seven different products simultaneously throughout the production facility in various formulation, filling and packaging areas. The company does not have a yearly shut down period and strives to meet customer needs in a flexible and timely manner.

Due to the high volume of products being manufactured and the need to meet deadlines, the overall maintenance of the facility is lacking. While there is an employee dedicated to cleaning and waste removal, large amount of cardboard boxes can be found throughout the facility. Additionally, empty chemical containers, usually 55 gallon drums, can be found in large numbers, 60-90 at any given time. These barrels are removed by a recycling company which compensates XYZ Pharma at an approximate rate of $\$ 2$ per barrel. Currently, the recycling company will remove all unwanted drums at the request of XYZ Pharma, which occurs occasionally every 10-14 days. Materials waiting for recycling are stored in the loading dock area, and often monopolize $75 \%$ of that area, creating obstructions during loading and unloading of trucks. Material handlers must frequently move raw materials and finished goods multiple times to access blocked pallets. 


\subsubsection{Personnel}

There are approximately 55 employees. Many employees are temporary, but permanent employees have between 5 and 15 years of experience at their position. There are three overlapping shifts: shift 1 starts at 5:00am and ends at 2:00pm, shift 2 begins at 7:30am and ends at 4:00pm, and shift 3 begins at 2:00pm and ends at 10:30pm. Each shift is entitled to two 15 minute breaks and a 30 minute lunch period. There are currently two mechanics who service all of the filling and packaging lines in the facility, with a third mechanic in training. Two manufacturing specialists formulate all topical products. There is currently one "dishwasher" responsible for sanitizing parts and components for equipment, but he feels there is need for another full time washer. Two material handlers move most of the components and trash in the facility, but often assist in other areas when needed. There are between 20 and 30 operators during the shifts to run the filling and packaging machines. Only a select group of operators have been trained on the newest filling machine, and their operating times are limited to the second shift (7:30am - 4:00 pm). During slow periods, operators build inventories of boxes or they are sent home. There is currently a surplus of operators, who are occasionally given time off due to lack of work.

\subsubsection{Quality Control}

The quality control (QC) department functions to ensure that all shipments received and products exiting the plant meet quality specifications. The QC department consists of a laboratory based group with five analysts. All incoming raw 
chemical ingredients and packaging materials must be placed into a "quarantine" area. This designation identifies that the materials have not been tested to ensure that they meet the required specifications. A QC analyst must sample the quarantined material and upon successful testing, the material is released to the general production warehouse area or production facility. Raw materials will generally spend between one and two weeks under quarantine before they are released for use. This group is also responsible for all analytical testing of the bulk formulated drug substance, the final product filled into packaging and stability studies required to determine expiry periods.

The other function of the QC department is the monitoring of all manufacturing operations and documentation. This section of the QC department is comprised of 6 inspectors and a supervisor. There are 12 total QC employees responsible for ensuring quality and proper documentation at XYZ Pharma. Inspectors rotate around the facility to monitor a number of processes at once and must record their findings in the master batch record. The master batch record captures manufacturing and formulation data and is vital for the manufacturer to prove to the FDA that all SOP's, and cGMP's were followed. All equipment must be inspected by QC prior to machine setups to ensure that proper cleaning has occurred and there are no residual materials on the parts. To ensure proper formulation, QC is required to initial the batch record along with the manufacturing specialist after every step in the process. Tube filling is monitored by checking the weight of 5 tubes every half hour to ensure accurate fill weights. Filled tubes placed into cartons must be inspected every half hour to ensure the machine is producing a 
legible lot number and expiration date on the cartons. This monitoring is in addition to visual and weight measurements taken by the operators and supervisors to make adjustments to the machines on a regular basis, approximately every 15 minutes. Finally, it is the responsibility of a separate dedicated QC inspector to reconcile all of the batches manufactured. Finished goods are considered to be quarantined again until the product has been fully tested and the shipping release has been completed, which may take up to a day or two. All packaging components, raw materials, defects and finished goods must be counted. All of the inventory must be accounted for and finished goods production must be within $10 \%$ of the desired goal. The QC supervisor then must compile the master batch record with the reconciliation documents and acceptable test results from the QC laboratory group's quality tests. When all of these documents are compiled, the shipping release sheet is created and signed by the supervisor in compliance with FDA regulations. The batch is then released, removed from the quarantine area and ready to be shipped out to the customer.

\subsubsection{Deliveries}

One driver is responsible for operating and filling XYZ Pharma's truck, which travels between the main warehouse building and the production warehouse area in the production facility with raw materials, finished goods and recyclables. If material handlers are available, they will assist the driver in loading or unloading the truck. The truck is on a continuous delivery schedule beginning at 7:30am and ending at 4:00pm. Occasionally, the truck will make deliveries or pickup materials 
from an outside company and material will buildup in both buildings. The truck completes one trip where it is loaded and unloaded between the two buildings in one and half to two hours. These milk runs create a steady flow of materials entering and exiting the system. Currently, the truck is not always filled before it departs from the production facility loading dock. Poorly marked components for return or the unknown status of a finished good prevents the driver from independently making return decisions. If cardboard is to be recycled, it will be taken to the warehouse if the pallet has been wrapped by the pallet wrapper and placed in the loading dock or storage facility, but the driver will not actively search for additional return materials. Instead, a warehouse supervisor must instruct the driver what to remove. Additionally, the last truck load at 4:00pm leaving the production facility is empty and stored at the warehouse building's loading area.

The external shipping truck, operated by a freight company, arrives at the warehouse production area daily between $1: 00 \mathrm{pm}$ and $3: 30 \mathrm{pm}$, and serves to ship finished goods inventory or deliver small packages of raw materials. Small packages of raw materials are generally less than $5 \mathrm{Kg}$ and are stored in a designated area of the production building for easy access by manufacturing specialists during formulation. Large quantities of incoming materials from the external shipper arrive at the warehouse building daily. Outgoing shipments of large finished good orders are removed to the warehouse building as well, where there is ample storage room to organize and store the order. Lead times for raw materials vary, with readily available chemicals arriving daily with a 1-2 week lead time. This is in stark contrast to custom printed plastic tubes and packaging materials which arrive once every 4 
months due to their long lead times of 8-12 weeks. Long lead times for materials, coupled with time spent in quarantine results in XYZ Pharma holding a large amount of raw materials inventory in order to meet variable customer demand.

\subsection{Current State for Manufacturing of Product X}

This study will evaluate the manufacturing of a poloxamer based topical gel, referred to as product $\mathrm{X}$, sold in a one ounce tube with an average yearly production of 120,000 tubes per year, produced in 30,000 tube batch sizes as requested by the customer. This product is similar in formulation and manufacturing processes too many other products manufactured at $\mathrm{XYZ}$ Pharma and is representative of the system.

Production schedules are generally made weekly in response to customer purchase orders, but last minute changes occur if customer deadlines are missed or the order is changed. In response to the schedule, a material requisition and a packaging requisition are sent to the production warehouse area where raw chemical ingredients and packaging components, such as tubes and cardboard boxes, are primarily stored. The materials requisition indicates the type and quantity of chemicals that are required for the formulation of the product. The packaging requisition indicates the type and quantity of components required to package the formulated material. All ingredients and components are held in quarantine until verified by quality control $(\mathrm{QC})$ through an identification assay to ensure identity and potency, or compliance with specification limits for components. The individual components are weighed and product is then formulated by a manufacturing 
specialist and filled into a large storage vessel. Unused raw materials that are no longer needed for formulation are returned to the production warehouse area, where they are returned to the main warehouse building. Theoretically, a sample of the bulk formulated product from the vessel should be assayed before filling into tubes. However, the bulk is often assayed by QC at a later time, while the product is filled into tubes and concurrently undergoing end product QC testing of finished goods. The vessel may be taken to the filling machines for immediate tube filling but is more commonly stored until a machine is available. The vat is then moved to the filling machine, where tubes are filled and crimp sealed. The filled tubes are stored near the cartoning machine or intermediate manufacturing holding area until the batch is finished or nearing completion. The manufacturing process has undergone a validation procedure, which requires only one tube selected at random to be tested by QC for end product release testing. The tubes are then loaded into cardboard cartons and filled into boxes with preprinted company labels. Filled boxes are loaded onto pallets and wrapped in protective plastic, before being moved to a quarantine area. After all QC assays, reconciliation, and necessary documentation are complete, a shipping release form is completed and the product is ready to be shipped to the customer. A schematic overview of the process and the material flow through the buildings in which they take place can be seen in figure 10 . 
Figure 10. Material Flow Chart

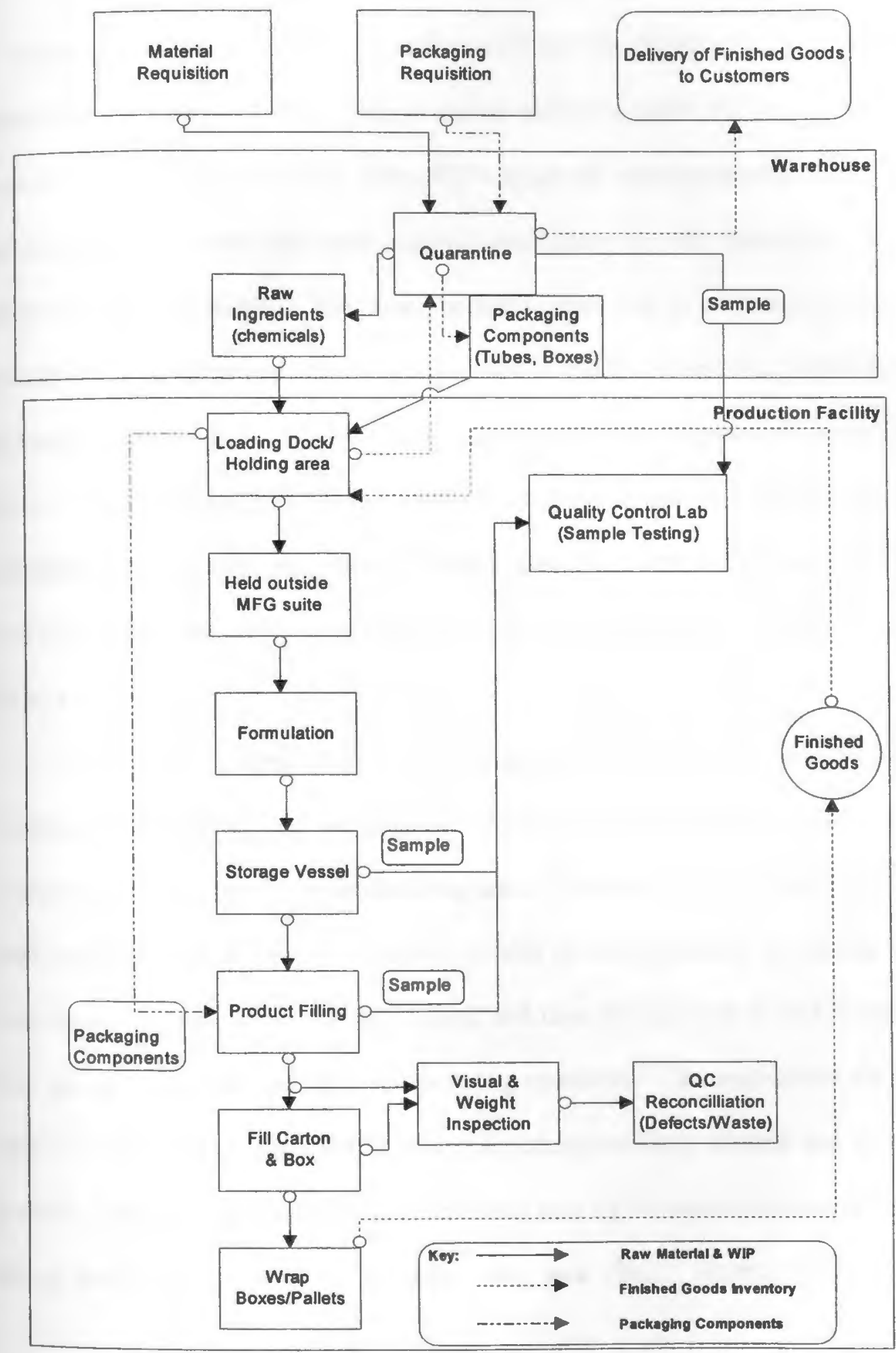




\subsubsection{Formulation of Product $X$}

Prior to formulation, all equipment, parts, and the manufacturing area must be inspected and documented for cleanliness by the QC department.., Visual and smell tests have been validated with chemical analysis support to identify residual materials from previous batches. Upon QC's approval, equipment setup begins and the manufacturing specialist assembles the machinery for use depending on the product to be produced. The manufacturing specialist is responsible for all formulation equipment and other materials such as pumps, tubes, etc. There is one equipment washer who works during the second shift and is responsible for cleaning the machine parts. When he is not working, or if the cleaner is overwhelmed, the manufacturing specialist must clean the parts needed for setup. This may result in used kettles left over night, or weekends until the manufacturer is available to clean the area.

Product $\mathrm{X}$ is comprised of six ingredients which are brought from the warehouse, while deionized water is hard piped and validated for purity to meet necessary standards into the manufacturing area. Chemicals are stored outside of the manufacturing area, if space is available, or held in the production warehouse area. Each ingredient must be weighed, checked, and then documented to be accurate by both the QC inspector and the manufacturing specialist. The ingredients are then added in a four phase approach to ensure a pharmaceutically elegant and accurate product. Empty drums are taken to the cleaning area by the manufacturing specialist during production to keep the manufacturing area clear. Excess raw chemical 
ingredients are placed outside of the manufacturing area for return to the warehouse, or future use.

Product $\mathrm{X}$ is formulated in a $1000 \mathrm{~L}$ capacity Lee Kettle ${ }^{\circledR}$ equipped with a sweep mixer and a built in Toledo ${ }^{\circledR}$ scale. A smaller $300 \mathrm{~L}^{\text {Hubert }}{ }^{\circledR}$ mixing vat is used for high shear mixing and solubilization of material prior to transfer with an air pump into the Lee Kettle ${ }^{\circledR}$. The product undergoes a 23 step formulation process, which is described specifically in the Master Batch Record and that can be categorized as weighing and addition of ingredients, mixing, heating, milling, material transfers and de-aeration (settling). During the production period, the QC inspector periodically checks on the manufacturing specialist dependent on which step he is performing to verify his work and sign the master batch record. The product is completed when it has been entirely transferred into a stainless steel storage vat through a milling process. Table 2 gives the data collected through time studies. The value added time has been identified and serves as the basis for the calculations of the formulation kettle's uptime.

Table 2. Data of Formulation Time for Batch \#2

\begin{tabular}{|r|l|l|l|l|}
\hline Formulation & & Action & $\begin{array}{l}\text { Value } \\
\text { Added } \\
\text { (Min) }\end{array}$ & $\begin{array}{l}\text { Non Value } \\
\text { Added } \\
\text { (Min) }\end{array}$ \\
\hline & & Change Over & & 662 \\
\hline $10: 21$ & Start & & 24 & \\
\hline $10: 45$ & Stop & Went to get Scale & & 3 \\
\hline $10: 48$ & Start & & 21 & \\
\hline $11: 09$ & Stop & $\begin{array}{l}\text { Went to Dispensory for } \\
\text { Chemical }\end{array}$ & & 6 \\
\hline $11: 15$ & Start & & 56 & \\
\hline $12: 19$ & Stop & Lunch & & 41 \\
\hline $1: 00$ & Start & & 25 & \\
\hline $1: 25$ & Stop & Waiting for QC & & \\
\hline $1: 30$ & Start & & 25 & \\
\hline $1: 55$ & Stop & Went to get Scooper & & \\
\hline
\end{tabular}




\begin{tabular}{|r|r|l|r|r|}
\hline $1: 59$ & Start & & 198 & \\
\hline $5: 17$ & Stop & & 120 & \\
\hline & & Milling Transfer & 469 & 721 \\
\hline Total & & & & \\
\hline
\end{tabular}

\subsubsection{Filling of Product $X$}

A mechanic is responsible for the setup of the filling equipment and must have a QC inspector check all of the parts for cleanliness prior to setup of the machine. The mechanic performs the machine setup, and must prime the machine with product to make adjustments and ensure accurate filling within specifications. Product $\mathrm{X}$ is filled into the hopper from the storage vessel using a transfer pump. Common adjustment issues include misfed tubes due to incorrect carousel or loader settings, inaccurate fill amounts requiring adjustments to the filling mechanism, poor crimp seal due to inaccurate heights of the tube holder or dirty crimping surfaces and tubes jamming.

The company currently has two different types of tube filling machines; they have three older Kalex ${ }^{\circledR a c h i n e s}$ and one new IWKA ${ }^{\circledR}$ Packaging system. Product $\mathrm{X}$ has been manufactured on both types of machines on separate occasions. The Kalex ${ }^{\circledast}$ machines have been used extensively for many years in the plant and the majority of employees are trained on the machines which can be run on all three shifts with only minor adjustments after the initial setup. Additionally, the Kalex machines are less complex than the new IWKA ${ }^{\circledR}$ machine and can be setup faster by the mechanics. The new IWKA ${ }^{\circledast}$ system is only run by a select number of operators and generally runs during the 7:30am to $4: 00 \mathrm{pm}$ shift, but will run longer to meet a 
deadline if the operators are available. The Kalex ${ }^{\circledR a c h i n e s ~ a r e ~ c a p a b l e ~ o f ~}$ producing 35 tubes per minute of product $\mathrm{X}$ using two to three operators. The IWKA $^{\circledR}$ system can produce 70 tubes per minute using between two and four operators. Data collected during the filling of product $\mathrm{X}$ is presented in table 3, with both value added and non-value added time.

Table 3. Data for Tube Filling Batch \#3

\begin{tabular}{|c|c|c|c|c|}
\hline $\begin{array}{l}\text { Tube } \\
\text { Filling }\end{array}$ & & Action & $\begin{array}{l}\text { Value Added } \\
\text { (Min) }\end{array}$ & $\begin{array}{l}\text { Non Value } \\
\text { Added (Min) }\end{array}$ \\
\hline IWKA & & Change Over & & 300 \\
\hline $8: 45$ & Start & & 45 & \\
\hline $9: 30$ & Break & & & 20 \\
\hline $9: 50$ & Start & & 5 & \\
\hline $9: 55$ & Stop & Mechanic adjust & & 5 \\
\hline $10: 00$ & Start & & 2 & \\
\hline $10: 02$ & Stop & Cleaning & & 1 \\
\hline $10: 03$ & Start & & 5 & \\
\hline $10: 08$ & Stop & Tube Loading & & 4 \\
\hline $10: 12$ & Start & & 1 & \\
\hline $10: 13$ & Stop & $\begin{array}{l}\text { Not Sealing } \\
\text { Properly }\end{array}$ & & 1 \\
\hline $10: 14$ & Start & & 1 & \\
\hline $10: 15$ & Stop & Adjustments & & 1 \\
\hline $10: 16$ & Start & & 7 & \\
\hline $10: 23$ & Stop & Fill Adjustments & & 3 \\
\hline $10: 26$ & Start & & 19 & \\
\hline $10: 45$ & Stop & Cleaning & & 2 \\
\hline $10: 47$ & Start & & 1 & \\
\hline $10: 48$ & Stop & Fill Adjustments & & 2 \\
\hline $10: 50$ & Start & & 11 & \\
\hline 11:01 & Stop & Adjustments & & 7 \\
\hline $11: 08$ & Start & & 4 & \\
\hline $11: 12$ & Stop & Crimp Defects & & 7 \\
\hline $11: 19$ & Start & & 34 & \\
\hline $11: 53$ & Stop & Cleaning & & 7 \\
\hline $12: 00$ & Lunch & & & 30 \\
\hline $12: 30$ & Start & & 12 & \\
\hline $12: 42$ & Stop & Hopper Overflow & & 8 \\
\hline $12: 50$ & Start & & 107 & \\
\hline $2: 37$ & Stop & Cleaning & & 3 \\
\hline
\end{tabular}




\begin{tabular}{|r|l|l|r|r|}
\hline $2: 40$ & Break & & & 15 \\
\hline $2: 55$ & Start & & 58 & \\
\hline $3: 57$ & Stop & Cleaning & & 12 \\
\hline $4: 00$ & Break & & & 1 \\
\hline $4: 12$ & Start & & 7 & 1 \\
\hline $4: 19$ & Stop & Jam & 80 & \\
\hline $4: 20$ & Start & & 399 & 432 \\
\hline $6: 40$ & Stop & Job Complete & & \\
\hline
\end{tabular}

Regardless of the filling machine used, a QC inspector must monitor the fill weights of five random tubes every half hour. A calibrated balance is kept within six feet of the filling machine and is used to weigh the tubes. If one of the tubes does not meet the weight specification, there must be an adjustment and five more tubes are tested. If tubes are not able to be brought into specifications, the machine is stopped for further adjustments and testing. Tubes manufactured during this time are weighed individually to determine if they are within specification, if they fall outside of a $+/-10 \%$ range, they must be rejected. This in-process testing aims to minimize the number of out of specification products that are produced. Although this system is relatively crude and does not adhere to statistical process control ideas, it does give QC an indication of gross errors.

Operators are responsible for loading empty tubes into the chamber to ensure a continuous supply of tubes for filling. The hopper is fed with formulated material by operators periodically adding the bulk drug through the transfer pump from the storage vat. The hopper has been overfilled by accident, especially when the machine is run with fewer operators. This error requires operator cleanup, machine shutdown and wasted bulk product. 
After tubes are filled and crimp sealed they are ejected from the machine and inspected by operators. Each tube must be squeeze tested and visually inspected to ensure a visible lot number and expiration date. If a tube fails either of these criteria it is thrown into a rejection tote which generally consists of $<1 \%$ of total production. If the tube passes the inspection criteria, it is put into a plastic storage tote on a pallet.

Each pallet holds up to 20 plastic totes, and the company owns 52 totes. When the totes are full, boxes are assembled (boxes are later reused for other products) by operators and filled in place of totes if the next process, cartoning, is not yet running. This occurs when the slower machine is used because the cartoner runs at a significantly higher rate and they want to prevent machine starvation. Therefore, the batch is completed to build up inventory and stored near the cartoning machine until it is ready to be cartoned. In contrast, they have overlapped the IWKA ${ }^{\circledast n}$ and the cartoning machine with a buildup of approximately $6,000-8,000$ tubes of WIP and were able to reuse totes and avoid using cardboard boxes for WIP storage.

\subsubsection{Cartoning of Product $X$}

A mechanic must setup and adjust the Jones ${ }^{\circledR}$ cartoner to accommodate the size of the carton, the feed rate of cartons into the machine and the tape machine (a subsystem of the Jones ${ }^{\infty}$ cartoner) to fit the different cardboard box sizes. Additionally, the mechanic must setup the machine to produce an accurate and visible lot number and expiration date. A QC inspector must check and document that the lot number and expiration date is correct and visible prior to beginning 
cartoning. Before production begins, three to four operators assemble large quantities of preprinted cardboard boxes which are readily available to be filled with cartoned product.

Cartoning occurs at a load rate of $78-82$ cartons per minute. The machine can operate through all three shifts and run with between six and eight operators. Cartons are manually loaded by the supervisor into the feeder, which then is automatically loaded onto a conveyor which opens the carton. The opened carton travels around a circular track and two or three operators manually drop filled tubes of product into the open cartons. The filled cartons are then closed while in the cartoner and collected into groups of six after exiting the machine by an operator. The groups of cartons are then covered in plastic by a Shanklin seal wrapper machine by an operator before being sent through the Clamco ${ }^{\circledR}$ heat sealer. An operator fills the plastic sealed packs into cardboard boxes, which are then sealed with a $3 \mathrm{M}^{-}$taping machine. Taped boxes are placed on pallets and taken to the Lantech $^{\text {}}$ pallet wrapper. Finished goods are placed in the production holding area under quarantine to await final assay results and reconciliation of quantities. The product may be moved via an internal shipping truck to the warehouse facility to await final shipping release if the $\mathrm{QC}$ operator has documented the quantity produced. Time studies collected during cartoning of product $\mathrm{X}$ is presented in table 4, with value added and non value added time described. 
Table 4. Jones Cartoner Data Collection for Batch \#3

\begin{tabular}{|c|c|c|c|c|}
\hline Cartoner & & & $\begin{array}{l}\begin{array}{l}\text { Value } \\
\text { (Min) }\end{array} \\
\end{array}$ & $\begin{array}{l}\text { Non Value Added } \\
\text { (Min) }\end{array}$ \\
\hline & & Change Over & & 240 \\
\hline & & Building Boxes & & 120 \\
\hline $4: 20$ & Start & & 8 & \\
\hline $4: 28$ & Stop & Catching up & & 2 \\
\hline $4: 30$ & Start & & 31 & \\
\hline $5: 01$ & Stop & Adjustments & & 2 \\
\hline $5: 03$ & Start & & 22 & \\
\hline $5: 25$ & Stop & Catching up & & 1 \\
\hline $5: 26$ & Start & & 14 & \\
\hline $5: 40$ & Stop & Fixing & & 6 \\
\hline $5: 46$ & Start & & 74 & \\
\hline $7: 00$ & Stop & Dinner & & 30 \\
\hline $7: 30$ & Start & & 42 & \\
\hline $8: 12$ & Stop & Adjustments & & 2 \\
\hline $8: 14$ & Start & & 46 & \\
\hline $9: 00$ & Stop & Break & & 15 \\
\hline 9:15 & Start & & 22 & \\
\hline $9: 37$ & Stop & & & 3 \\
\hline $9: 40$ & Start & Fixing & 35 & \\
\hline 10:15 & Stop & For Night & & \\
\hline \multicolumn{5}{|l|}{$\begin{array}{l}\text { Next } \\
\text { Day }\end{array}$} \\
\hline $5: 45$ & Start & & 75 & \\
\hline $7: 30$ & Stop & Break & & 15 \\
\hline $7: 45$ & Start & & 60 & \\
\hline $8: 45$ & Stop & Job Complete & 454 & 436 \\
\hline Total & & & & \\
\hline
\end{tabular}

\subsubsection{Current State Value Stream Map}

Data for the current state map of the system for product $\mathrm{X}$ at XYZ Pharma was collected through time studies and is presented in Tables 1 through 4 . Additional data was retrieved from the master batch records of four recent production runs of Product $\mathrm{X}$, as shown as in table 5. Uptime percentage was calculated by dividing the value added time (of the batch) by total production time, 
both value and non value added. Non value added time was comprised of breaks, lunch, machine breakdowns and setup/change over times. Table 5 compiles data from four batches of product $\mathrm{X}$. The batches of the first two columns were filled with the slower filling machine and waiting times designated as **, were not included because they are not accurate representations of the system when the newer machines are used. Additionally, one of data points for vat storage designated as *, was not included because it was unusually long.

Table 5. Overview of Batch Records of Product X

\begin{tabular}{|l|l|l|l|l|l|l|}
\hline & Kalex & Kalex & IWKA & IWKA & AVG & Std Dev \\
\hline Batches & 1 & 2 & 3 & 4 & & \\
\hline $\begin{array}{l}\text { Formulation/mill } \\
\text { Time }\end{array}$ & 520 & 524 & 505 & 535 & 521 & 12.4 \\
\hline Storage in Vat & $11805^{*}$ & 1110 & 4965 & 3945 & 3340 & 1997.4 \\
\hline Filling Time & 998 & 1055 & 525 & 465 & 495 & 308.7 \\
\hline $\begin{array}{l}\text { Filling Scrap } \\
(\%)\end{array}$ & 0.2 & 1.9 & 0.9 & 3.2 & & 1.3 \\
\hline $\begin{array}{l}\text { Time Waiting } \\
\text { for Carton }\end{array}$ & $* *$ & $* *$ & 360 & 150 & 255 & 148.5 \\
\hline Cartoning Time & 545 & 530 & 470 & 480 & 506.25 & 36.8 \\
\hline $\begin{array}{l}\text { Cartoning Scrap } \\
\text { (\%) }\end{array}$ & 1.64 & 0.6 & 0.5 & 0.3 & 0.76 & 0.6 \\
\hline $\begin{array}{l}\text { Wait Time To } \\
\text { shipping }\end{array}$ & & 900 & 3330 & 2715 & 2315 & 1263.4 \\
\hline Total (Min) & & 4121 & 10,156 & 8294 & 7433 & \\
\hline Total (Hrs) & & 68.68 & 169.27 & 138.23 & 123.88 & \\
\hline
\end{tabular}

The current state value map, shown in figure 11 , gives the cycle time (CT) of an individual tube through processing, except during formulation where the batch is undergoing value added work at the same time. The map shows that the greatest wastes of time are the buildup of WIP in the systems before the filling line and after the cartoning process, where finished goods pallets are stored until the entire batch is 
complete and ready for shipment. The lead time of the system was calculated to be $7925 \mathrm{~min}$ and $50 \mathrm{sec}$. When divided by the total amount of operational hours from 5:00am to $10: 30 \mathrm{pm}$ ( 17.5 hours) the lead time is roughly 7.5 days. The current state is based on a five day work week, with Saturday and Sunday as days off. This translates into a "real world" lead time of 9.5 calendar days for one batch. An order for this product generally consists of three batches requiring minimal inter-batch changes, resulting in decreased holding times to avoid starving down process machines. Therefore the second and third batches are produced faster, and the entire three batch process requires approximately 11 days of processing or 15 calendar days. 
Figure 11. Current State Value Stream Map

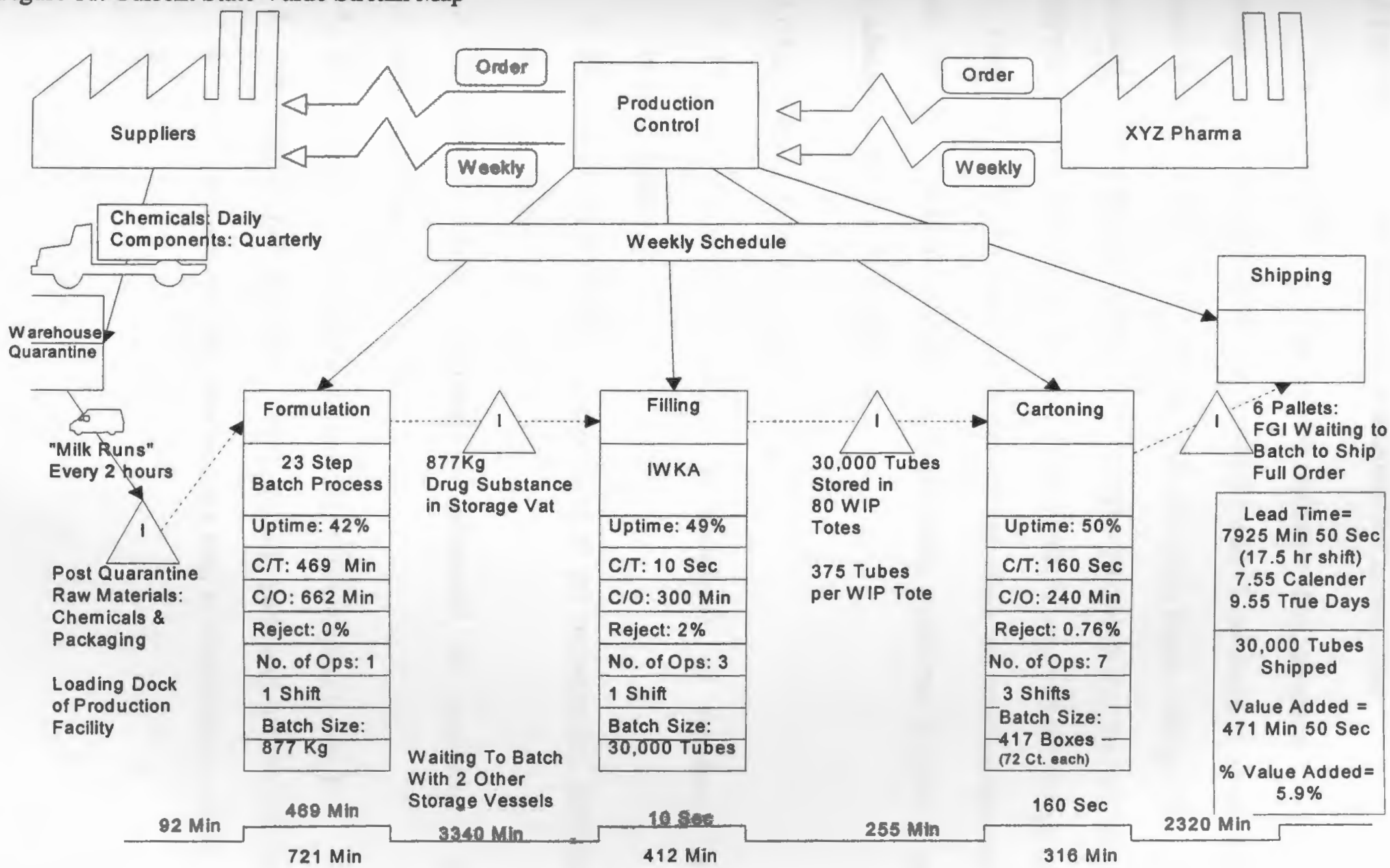




\subsection{Development of the ProModel ${ }^{\circledR}$ Simulation of Current State}

The ProModel ${ }^{\circledR}$ simulation utilizes collected data presented in tables 1 through 4 and compiled master batch records, table 5, to create a model which depicts the current state of the system. All processing times, waiting times, and personnel assignments have been created through observation and verified through company documentation. A full text version of the model can be found in Appendix III. Figure 12 shows the layout of the facility and where the locations have been built. The flow of materials follows the current stream value map in figure 11 and the schematic material flow in figure 10.

\subsubsection{Current State Model Assumptions}

1. $1^{\text {st }}$ shift $(5: 00 \mathrm{am}-2: 00 \mathrm{pm})$ is comprised of operator_1 and material_handler_1.

2. $2^{\text {nd }}$ shift $(7: 30 \mathrm{am}-4: 00 \mathrm{pm})$ is comprised of the manufacturer, mechanic, driver and operator.

3. $3^{\text {rd }}$ Shift $(2: 00 \mathrm{pm}-10: 30 \mathrm{pm})$ is comprised of operator 2 and material_handler_2.

4. The Truck Driver has the sole responsibility of (un)loading the truck.

5. Shipments of raw ingredients arrive on one truck and are of sufficient quantity to manufacture three batches for a total of 30,000 tubes of Product $\mathrm{X}$. 
6. Raw ingredients are taken directly to the manufacturing area, excess is first stored in the formulation holding area and the remainder is kept in the production warehouse area.

7. Each batch of formulated bulk requires 2 pallets of Raw_Ingredients_Drum and 2 pallets of Raw_Boxed_Ingredients to be combined.

8. After a batch of formulated bulk drug has been removed, the manufacturer immediately begins the next batch without a setup, until all batches have been formulated.

9. Mechanic setups of the filling machine begin after the stored bulk drug vessel has been brought to the filling area.

10. Filling using the IWKA ${ }^{\circledR}$ machine is completed by the "operator", which consists of three operators specially trained on the machine who only work during the second shift (7:30am - 4:00pm).

11. The filling machine fills 84 WIP totes, which contain 375 tubes per tote to account for a small batch overage.

12. Mechanic setups of the cartoning machine begins after the entire batch of tubes has been filled into WIP totes and moved to the Jones ${ }^{\circledR}$ WIP feed area.

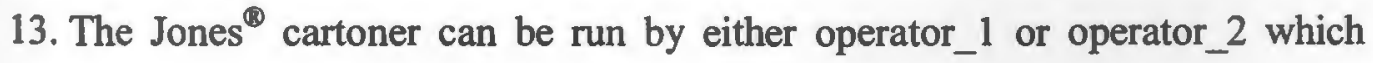
both consist of 7 operators each and operate in the first and third shifts respectively.

14. Finished goods are packed into 72 count boxes before they are palletized as 70 boxes to a pallet. 
15. Material handling is performed by one material handler during the first shift and a designated material handler during the second shift which is normally an operator or supervisor.

16. Each completed batch yields 6 pallets of finished goods inventory. When 6 batches are completed, the QC reconciliation process begins prior to shipping. 
Figure 12. Current State ProModel® Simulation Layout

히

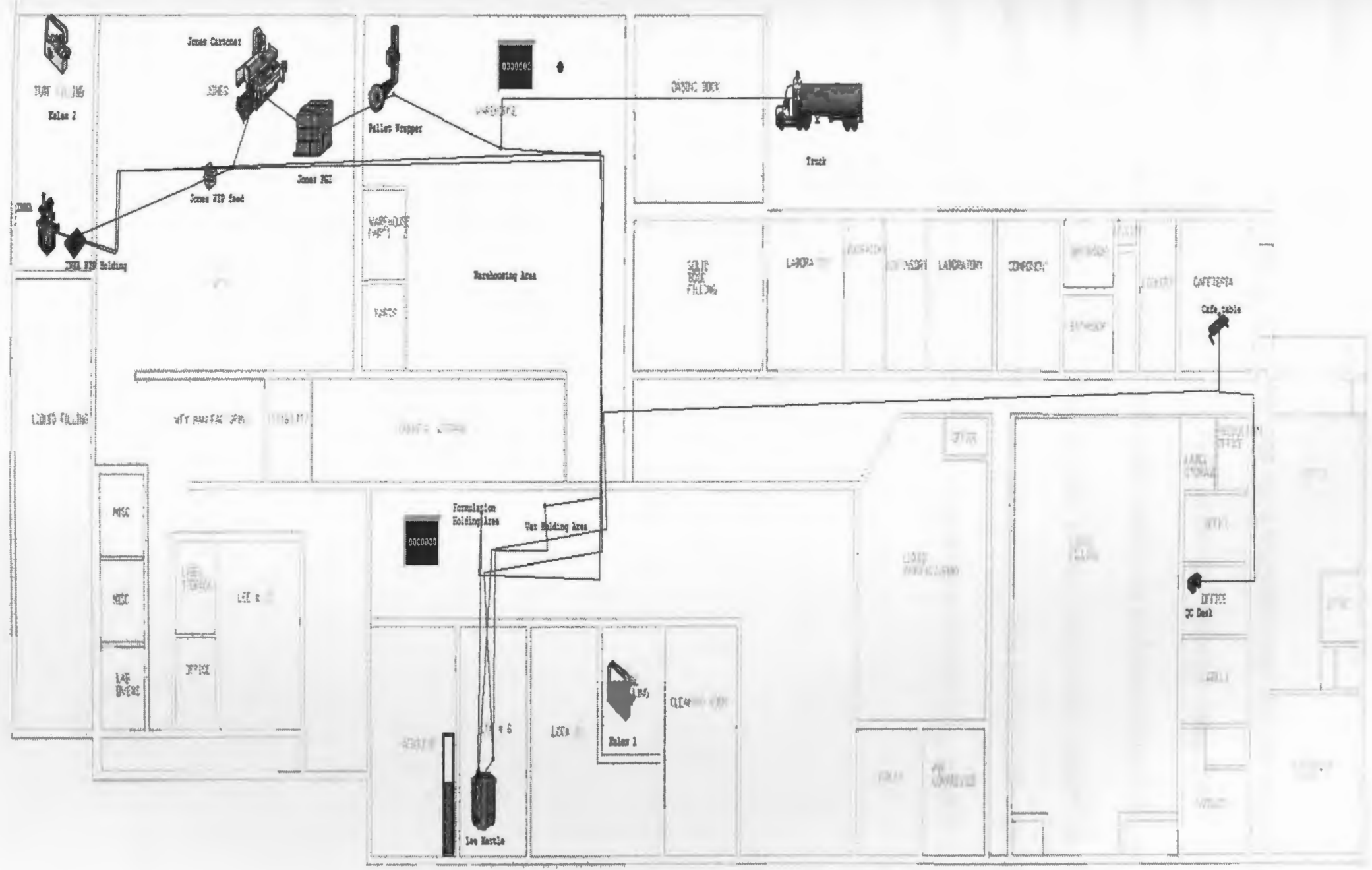




\subsection{Chapter Review}

This chapter introduced XYZ Pharma as a manufacturer and described the system required to produce Product X. Data collected through time studies and master batch records were presented to give the reader an understanding of how the product is currently manufactured. The current stream value map helped in the identification of problematic areas throughout the system. The results of the current and altered future state ProModel ${ }^{\circledR}$ simulations are presented in the next chapter. 


\section{Chapter 6}

\subsection{Results}

This chapter will present possible areas for improvement to the current system based on the ProModel ${ }^{\circledR}$ simulation and current stream value map. Three of these areas for improvement are modeled in a future state. The primary study, metric, that was chosen, was the minimization of throughput time to improve meeting deadlines for contract customers. The results of these future state simulations were analyzed for statistically significant factors and interactions.

\subsection{Results of the Current State ProModel ${ }^{\circledR}$ Simulation}

The data tables presented are separated into two groups: inventory and transfer holding locations and equipment locations. The equipment locations are areas that processing of WIP occurs, while the inventory and transfer holding locations are all of the supporting locations for the manufacturing systems. Table 6 shows the results of the current state simulation to gain an understanding of the steady state of the system. Unlike the value stream map, the simulation runs overnight and on the weekends, to describe a more realistic picture. The calculated average throughput time through the system for 999 replications of the simulation was 370.92 hours or 15.45 days. In order to ensure that the simulation adequately represented the real world conditions the average time per batch, 123.88 hours (from table 5), is multiplied by three to give a total order time of 371.65 hours. The average time from the simulations is divided by the average time from the master batch records and is $99.8 \%$ similar. It is important to consider that time value is 
averaged and does not account for overlapping production of batches which may occur.

The IWKA@ filling machine has the highest percent utilization of processing equipment while the pallet wrapper has the lowest. The largest periods of non value added time are when the operation waits to batch. The time the formulated bulk drug product spends in the transfer vat waiting to be brought to the filling line is very long. Also the time spent waiting for the batch of wrapped and palletized finished goods is considerable. Due to the infinite capacity of the production warehouse area in the model, the utilization percent is not calculated, this was purposely avoided to prevent blockage of incoming, outgoing and stored materials which would require a separate in depth material handling study out of this project's scope.

Table 6. Results of the Current State ProModel ${ }^{\circledR}$ Simulation

\begin{tabular}{|l|l|l|}
\hline Location Name & Avg Time Per Entry (MIN) & \% Utilization \\
\hline $\begin{array}{l}\text { Inventory Transfer and } \\
\text { Holding }\end{array}$ & & \\
\hline Production Warehouse Area & 3081.99 & 0 \\
\hline Formulation Holding Area & 934.16 & 12.79 \\
\hline Storage Vat Load & 977.77 & 13.39 \\
\hline Vat Holding Area & 7097.92 & 31.64 \\
\hline IWKA WIP Holding & 54.86 & 0.64 \\
\hline Jones WIP feed & 353.97 & 4.06 \\
\hline Jones FGI & 203.02 & 14.32 \\
\hline Equipment & & \\
\hline Lee Kettle & 1397.93 & 19.14 \\
\hline IWKA & 1816.03 & 24.58 \\
\hline Jones Cartoner & 142.85 & 16.49 \\
\hline Pallet Wrapper & 27.14 & 2.26 \\
\hline & & \\
\hline $\begin{array}{l}\text { Total System Throughput } \\
\text { Time }\end{array}$ & 370.92 hrs & 15.45 days \\
\hline
\end{tabular}


The average time per entry ( $\mathrm{min})$, is the average time an entry spends at a location. The utilization percentage is defined as the percentage of capacity occupied. The utilization percentages appear lower than the uptime calculated by hand for the current stream map because physical capacities were not always fixed or clearly defined. The simulation calculates utilization over the course of the entire run and is different from the value stream map which calculated the uptime for each machine to process the first unit of the product. For the production warehouse area an infinite capacity was assigned to prevent the blockage of incoming or outgoing material; therefore, there is no calculation of the utilization \%.

Table 6 shows that the two highest utilization percentages of equipment or inventory transfer and holding are the vat holding area and the IWKA ${ }^{\circledR}$ filling machine, respectively. These areas appear to be bottlenecks in the current system and should be viewed as areas for improvement for the future state. While the production warehouse area does not have a calculated utilization percent, the average time per entry is the second highest and should also be considered as a potential area for improvement.

\subsection{Areas for Improvement}

All of the areas for improvement suggestions considered in this paper are from an efficiency approach. cGMP's must be followed for each product and manufacturer considering changes. Experimentation and validation may be required to implement the proposed changes. The FDA and appropriate regulatory documents should always be consulted if there is uncertainty in a regulatory area. 


\subsubsection{Quality Contral}

\subsubsection{Testing}

Testing bulk at the same time as finished goods is double end product testing. This is a common practice where management is confident that its process will result in an accurate product because it has been rigorously validated, but it does leave the company vulnerable if the assay fails because many tubes have already been filled by this point. A bulk drug product can be "reworked" to meet specifications if a deviation report is filed, but once the product is filled and crimped into tubes, it is far too labor intensive and cost prohibitive to empty each one for rework.

\subsubsection{JT QC}

The quality control department is responsible for reconciling (counting) all materials that have been used, defects produced and finished goods for release. The majority of finished goods may not be released from "quarantine" until the product has successfully passed shipping release testing for quality and QC reconciliation to meet FDA requirements. Finished goods can be shipped under "quarantine" if the reconciliation documents have been completed for the materials shipped and a sample has been taken for testing. Upon successful testing of the product, the customer is faxed confirmation of the test results and the product is removed from "quarantine." This practice would shorten lead times and could be considered for low risk products to ensure that a batch is not defective. Often the QC inspector will wait until the entire batch is completed before counting the finished goods inventory and compiling the final batch release documentation. Due to space limitations in the 
production facility warehouse, quarantined finished goods may be moved to the larger warehouse building until they pass shipping release parameters. Unfortunately, the QC inspector is often unaware if a pallet of quarantined finished goods has been moved to the other building and can cause delays and errors during reconciliation. Conversely, if the inspector does count a portion of the finished goods and they are available to be moved to the main warehouse, it will not be moved by the material handlers unless the warehouse supervisor instructs them. By having the QC inspector keep an ongoing count of finished goods pallets as they are produced and placing a marking such as a neon sticker onto the pallets, the material handlers will know to put the pallets on the milk run truck. This will free up space in the production warehouse area and decrease the time required for reconciliation after production is complete.

\subsubsection{Deliveries}

"Milk-Run" Truck Efficiency Improvement

Currently the "milk run" truck runs between buildings approximately every one and a half to two hours. The truck is not always full, and leaves the production facility empty on its last run at 4:00pm. This is surprising considering the production building warehouse is normally very congested and items are usually blocking each other. Cardboard generated during manufacturing can be found throughout the facility and is only removed occasionally. Excess raw ingredients and components often stay in the production warehouse area for a few days after they could have been removed. By utilizing the proposed QC improvements above, the truck will have 
excess material to load throughout the day and can fill the truck more often. Storing the truck at the production facility overnight will allow late shift employees to place materials directly into the truck and avoid the production warehouse area completely.

\subsubsection{Inventories}

\subsubsection{Decreasing Storage Vessel Batch Sizes}

The steps involved in the formulation of bulk drug can not easily be changed, as the process has been given by the customer and validated by XYZ Pharma. A significant change in the formulation would require revalidating the process for the FDA. This product is relatively complex and requires many processing steps, many of which have been developed with current batching equipment in mind. Until development of continuous formulation methods and equipment improve, the product is not currently a strong candidate to make the transition from batching. However, after the bulk drug has been formulated, there are opportunities to decrease the batch sizes of the WIP in the system. Currently, all $877 \mathrm{Kg}$ of the bulk drug is milled directly from the Lee Kettle ${ }^{\circledR}$ to a large stainless steel transfer vat. This process takes an average of two hours and the transfer vat is then available for the mechanic to prime the next process, the filling machine and complete the setup process. The transfer vat is on wheels and is moved by the manufacturing specialist to the storage area while the mechanic moves the transfer vat to the filling machine and must be carefully navigated through the production facility. The stainless steel transfer vat could be replaced with four 55 gallon drums, fitted with a non reactive plastic liner validated to avoid chemical reactivity and degradation. The drums have 
capacities of $225 \mathrm{Kg}$ each which would allow the mechanic could complete the filling machine's setup, and begin filling an hour and a half sooner. Each drum would contain approximately $25 \%$ of the quantity of the transfer vat, and could be filled in half an hour. The drums are individually transported with a drum dolly by material handlers or the mechanic and are more maneuverable, occupying far less floor space than the transfer vat. The viscosity of product $\mathrm{X}$ allows direct transfer from the drum to the hopper via a compressed air pump and would free up a transfer vat, which are often in short supply.

\subsubsection{Decreasing WIP Buffers}

Currently tubes are filled with product $\mathrm{X}$ and then put into plastic totes. Totes contain an average of 375 tubes and are stacked 20 totes to a pallet. Full pallets are then removed from the filling area and are stored near the next machine, the cartoner. The cartoner is not started until filling is complete or very near completion. This buildup in WIP is in response to the cartoner running slightly faster than the filling machine. The cartoner loads 80 cartons per minute, each carton is filled with one tube of product X, while the IWKA ${ }^{\circledR}$ filling machine loads 70 tubes per minute. The filling machine generates a new WIP tote every 5 minutes and 21 seconds and the cartoner consumes 1 WIP tote every 4 minutes and 30 seconds. If one WIP tote was delivered to the cartoner every six minutes, to account for travel time, the cartoner would run at a deficit of 1050 tubes per hour, if the system ran optimally at 80 cartons per minute. The current average wait time between finishing the filling process and beginning the cartoning process is 255 
minutes. If a one hour buffer of 4200 tubes was generated while the cartoner was finishing its last hour of its four hour setup and a newly completed WIP tote was brought every six minutes, the cartoner could run for four hours. Regardless of the time of day, there is a 15 minute break every two to two and a half hours, and a lunch/dinner break every four to four and a half hours. If more operators were trained on the filling machine, they could keep the machine running during the two 15 minute breaks and 30 minute lunches to create new buffers, while the operators on the cartoner shut down during their breaks. This coverage through breaks would result in 1050 tubes during break periods and 2100 tubes during lunch for a steady replenishment of the buffer stock to ensure smooth production.

\subsubsection{Facilities}

\subsubsection{1 $5 \mathrm{~s}$ for Facility}

FDA regulations require that the manufacturing areas be clean (shine) and follow SOP's (standardize), which leads many in the pharmaceutical industry to feel that only the remaining $3 \mathrm{~s}$ applies. Storage areas are less strictly monitored and $\mathrm{XYZ}$ Pharma is in dire need of a 5 s plan for its production warehouse area. Although the wall does contain signs to indicate where incoming and outgoing material belongs, it is rarely followed due to the lack of free space. There are pallets with materials that do not belong there which should be returned to long term storage or other locations. There are no markings on the floor to alert material handlers where materials can safely be stored without obstructing walkways. Material handlers waste movements when they must repeatedly move materials to access 
blocked pallets. Usually materials that are blocked tend to be left in the storage area long after they have been used or needed, which may be considered an inappropriate long term storage area by the FDA.

Sort: By evaluating the contents of the current production warehouse area and removing unnecessary materials, the flow of the product will be greatly improved. Stabilize: Creation of designated "homes" for raw materials, finished goods, pallet trucks, recyclables, etc. will facilitate the rapid identification of materials that are out of place or in need of attention. Shine: All of the cardboard boxes and empty material drums should be removed and the loading dock and production warehouse area should be power washed. Standardize: Create standard operating procedures, which are based on visual information, such as simple diagrams and cartoons to indicate the proper method to store and remove material. Create a regular schedule, every three to four days, for empty drum removal. Sustain: Create a reward system for maintaining the area and following the standardized work. Incorporate cleaning and organization into employee's jobs, and utilize down times to ensure the work place is maintained.

\subsubsection{Equipment}

\subsubsection{Visual controls to decrease setup times}

Incorporate visual control techniques into the equipment and manufacturing areas. Use shadowboards for mechanics tools and for parts used in equipment setups (tubes, valves). Some setups have over 50 individual components that are placed on a moving cart where QC inspects them, but QC is unable to identify whether parts 
are missing or in excess. If parts are missing, the setup process is disrupted and results in the mechanic having to track down the proper tool or part. Additionally, manufacturers can easily assemble kettle components, such as rubber blades of the sweep mixer incorrectly, which can have severe impact on the product. While the manufacturers and mechanics are highly trained, these suggestions would benefit new employees being trained and help the current staff avoid errors. These measures would facilitate cross training of employees and give more employees a broader system's perspective.

\subsubsection{Autonomation}

The incorporation of autonomation to a number of locations at XYZ Pharma would result in improved product quality and fewer operators needed on machines. Currently, the beverage industry commonly uses online sensors to monitor filling rates and accuracy during production, thereby removing the need for end product content uniformity testing which is currently a time consuming and labor intensive FDA requirement (Jeffries, 2003). The addition of online sensors to the filling machines at XYZ Pharma would allow operators more freedom to attend to other tasks and decrease the total number of operators required. These operators could be reassigned to other areas or serve to cover break periods.

Specifically, the IWKA ${ }^{\circledR}$ is pre-wired but not equipped with a sensor to monitor the loading of empty tubes. The sensor would automatically shutdown the machine in the event of a misfeed or a tube jam. This is a common problem which currently requires an operator to monitor tube feeding. The hopper is also 
susceptible to bulk product overflow, where currently a mirror is the only equipment used to monitor the fill height. Ultrasonic sensors have been employed for a number of years by biotechnology, oil, food and other industries for processing monitoring and control, automotive techniques and chemical analysis. (Hauptmann, 1998) These sensors have evolved into low cost tools which could monitor hopper fill levels, as well as monitor the bulk material viscosity and homogeneity for enhanced online monitoring.

\subsubsection{Personnel}

\subsubsection{Cross Training Personnel}

The current training of operators is performed on the job. Most operators are trained on two to three pieces of equipment and rotate when needed. While job rotation is performed, it could be expanded. The new IWKA ${ }^{\circledR}$ filling machine is operated by a select team of operators and is limited to one shift. By increasing the number of operators that can run the machinery, the overall processing time could be increased. As there is a surplus of operators, and often slow periods are used to build boxes for later use, training could be accomplished during these points. Also, by creating a rotating team of cross trained employees to cover break and lunch periods, machines would remain operational and keep pace of production at a level pace. An additional mechanic for the third shift is required to setup and maintain the filling machinery, which they are currently in the process of training.

Additional areas for cross training could include cleaning responsibilities. To alleviate both the mechanics and the manufacturers, operators could rotate into the 
cleaning area to sanitize equipment parts during changeovers. This would decrease waiting times and give mechanics and manufacturers greater time to use their skills for specialized tasks. There are only two manufacturing specialists currently operating 5 days a week. Cross training other employees in basic areas of the manufacturing specialist's responsibilities such as prep work, setup and changeover would also give the manufacturing specialist more time. If a manufacturing specialist is sick, their manufacturing area is not used which results in greater product lead times. Training additional personnel to formulate would alleviate problems arising from unexpected work absences, as well as increase the capacity to produce during the weekend.

\subsubsection{Off shift personnel}

In addition to cross training employees, off shift personnel could decrease a significant portion of non value added time that is currently experienced. A small team of personnel could perform a number of tasks during non operational hours (10:30pm $-5: 30 \mathrm{am})$ to improve flow during operational hours. Cleaning would be the primary responsibility of the team. Areas would include cleaning formulation kettles, parts for equipment setups, empty raw material drums and the facility itself. Material movement would be the other focus, such as cardboard for recycling, components for return to the production warehouse area and raw materials for production the next day. The truck for inter building deliveries could be stored at the production facility loading dock and loaded throughout the night in order to remove unneeded materials. 


\subsection{Development of the Future State ProModel ${ }^{\circledR}$ Simulation}

Table 7. $2^{3}$ Factorial Design of Three Factors Selected for Experimentation

\begin{tabular}{|l|l|l|l|}
\hline & & Factors & \\
\hline Runs & A & B & C \\
\hline 1 & 0 & 0 & 0 \\
\hline 2 & 0 & 0 & 1 \\
\hline 3 & 0 & 1 & 0 \\
\hline 4 & 0 & 1 & 1 \\
\hline 5 & 1 & 0 & 0 \\
\hline 6 & 1 & 0 & 1 \\
\hline 7 & 1 & 1 & 0 \\
\hline 8 & 1 & 1 & 1 \\
\hline
\end{tabular}

Factor $\mathrm{A}$ is the addition of the Kalex ${ }^{\circledR}$ filling machine. This machine is operated by three operator teams during the first and third shift, with a total of 17 hours of available manufacturing time. This machine operates to the specifications given in the description of the filling process of product $\mathrm{X}$. If there is no cross trained operators available, they are pulled from available Operator_1 or Operator_2 groups. If there is no change in the batching rules, the new machine will feed the current IWAK_WIP_Holding area and is moved when 21 WIP_Totes have been accumulated from the two machines on the shared pallet.

Factor B is the cross training of personnel. By training operators on all of the machinery, work assignments are made from a general pool of available operators and can cover all the hours of operation on all machines. Additionally, material handlers have been given the option of assisting the mechanic in the movement of bulk drug materials and the driver to move raw ingredients and finished goods. Mechanic_2 has been trained for the third shift, while the first mechanic has been moved from the second to the first shift. In the case of a cross training scenario 
without the addition of the second filling machine, the 3 dedicated operators from the IWKA $^{\circledast}$ will be cross trained and distributed. Operator_1 and operator_2 will each gain one operator and have 8 each; the odd operator will be removed and considered reassigned.

Factor $\mathrm{C}$ changes the batching rules during production. First, bulk drug substance is no longer transported in one large transfer vessel. Formulated bulk is now divided into four 55 gallon drums and transported individually to the filling machines. WIP totes created after filling the product into tubes are no longer batched 20 totes to a pallet prior to transfer to the cartoner. Instead, the totes are moved by any available operator or material handler after each tote is filled. Totes can be moved on wheeled carts by anyone and no longer require pallets or jacks to move them. Final QC reconciliation is no longer performed after all of the finished goods pallets have been completed. Additionally, the finished goods pallets are moved out of the production warehouse area after they have been reconciled and are shipped to the customer from the warehouse building.

\subsubsection{Assumptions of the Future State ProModel Simulation}

1. $1^{\text {st }}$ shift $(5: 00 \mathrm{am}-2: 00 \mathrm{pm})$ is comprised of the mechanic, material_handler_1, and operator_1.

2. $2^{\text {nd }} \operatorname{shift}(7: 30 \mathrm{am}-4: 00 \mathrm{pm})$ is comprised of the manufacturer and driver.

3. $3^{\text {rd }}$ shift $(2: 00 \mathrm{pm}-10: 00 \mathrm{pm})$ is comprised of mechanic_2, material_handler_2 and operator_2. 
4. The "operator" group has been reassigned and operator_1 and operator_2 consist of a pool of 10 operators each.

5. 2 pallets of Raw_Ingredients_Drum and 2 pallets of Raw_Boxed_Ingredients are delivered in each arrival and are brought directly to the manufacturing area. Excess is only stored in the formulation holding area. Additional arrivals are triggered when the formulation holding area is emptied by the manufacturer as a pull system.

6. Completed formulation of bulk drug is transferred with milling to four $\mathbf{5 5}$ gallon drums, capable of transporting up to $225 \mathrm{~kg}$ each, named Bulk_Drug_Wip_1.

7. When a Bulk_Drug_Wip_1 drum is filled, it is moved to the hopper by material_handler_1, material_handler_2, or the mechanic.

8. The hopper location serves to split the Bulk_Drug_Wip_1 into 21 parts, which are routed to the first available Kalex_2 or the IWKA filling machine by Operator_1 or Operator_2.

9. Kalex_2 and IWKA filling machines are operated from a pool of 10 general operators during the first and third shifts.

10. An operator from the Kalex_2 and IWKA filling machines move WIP totes as soon as they are filled and are not batched.

11. When the first WIP tote arrives from either filling machine, the Jones Cartoner setup begins. 
12. FGI_Pallets are reconciled by QC individually as they are placed into the production warehouse area. Upon reconciliation, they are removed by the "milk truck" to the main storage area or are shipped out to customers. 


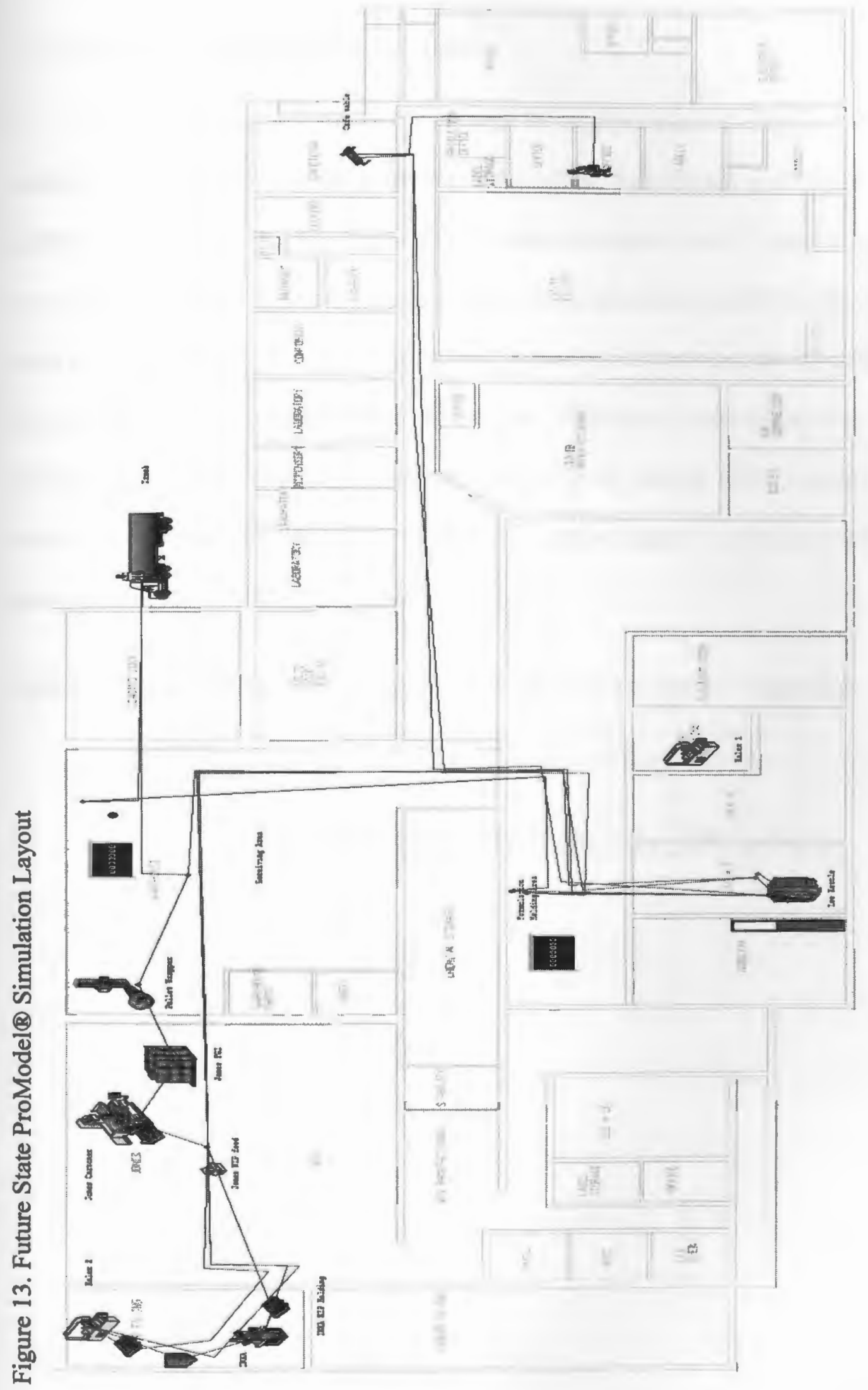




\subsection{Results of the ProModel $\circledast$ Simulations}

Table 8 and figure 13 show the average throughput times of 999 simulation replications for each of the eight ProModel $\circledast$ scenarios. Scenarios 4 and 8 show the greatest improvement over the original current state throughput time. Scenario 8 is a future state with all three factors changed, which is comprised of parallel machining, cross training and changing the batch rules. Scenario 4 is the same as scenario 8 , except it does not use parallel machining methods. Scenario 5 only utilizes parallel machining and is considerably worse than the original current state, scenario 1, which demonstrates the importance of personnel and a support system to enhance manufacturing.

Table 8. Rounded Average Throughput Times (Hr) of all ProModel ${ }^{\circledR}$ Scenarios

\begin{tabular}{|l|l|l|l|l|l|l|l|l|}
\hline Scenario & 1 & 2 & 3 & 4 & 5 & 6 & 7 & 8 \\
\hline $\begin{array}{l}\text { Avg. } \\
\text { Throughput } \\
\text { (Hr) }\end{array}$ & 371 & 189 & 284 & 105 & 406 & 161 & 290 & 110 \\
\hline
\end{tabular}


Figure 14. Average Throughput Time for all ProModel@ scenarios

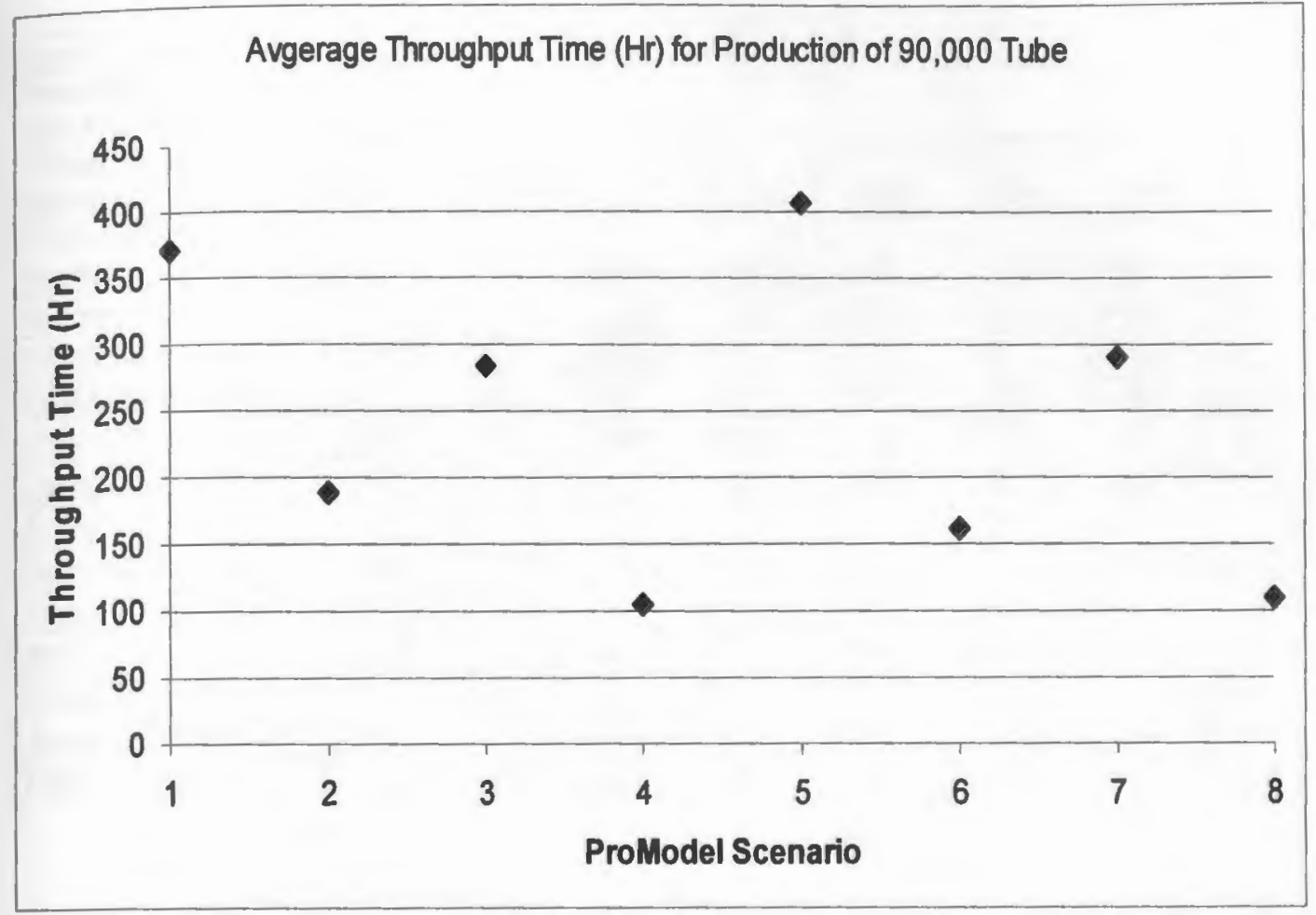

Table 9 compares all of the ProModel@ scenarios and depicts the average time per entry, which gives the average time spent by each component traveling through the system for a given location in minutes. This table is helpful to evaluate the effects of changes in scenarios on processing and holding times. It is important to consider that when batch sizes change, there are a different number of entities in the system and some locations are avoided all together. Therefore, this table is most useful to compare scenarios with similar factors and graphs are used to illustrate important differences. 
Table 9. Average Time Per Entry (Minutes) of all ProModel@ Scenarios

\begin{tabular}{|l|l|l|l|l|l|l|l|l|}
\hline Location Name & 1 & 2 & 3 & 4 & 5 & 6 & 7 & 8 \\
\hline $\begin{array}{l}\text { Inventory Transfer } \\
\text { and Holding }\end{array}$ & & & & & & & & \\
\hline $\begin{array}{l}\text { Production } \\
\text { Warehouse Area }\end{array}$ & 3082 & 598 & 2242 & 164 & 3061 & 629 & 2198 & 136 \\
\hline $\begin{array}{l}\text { Formulation } \\
\text { Holding Area }\end{array}$ & 934 & 1584 & 943 & 1458 & 939 & 1076 & 939 & 1140 \\
\hline Storage Vat Load & 978 & 631 & 986 & 154 & 979 & 119 & 980 & 87 \\
\hline Vat Holding Area & 7098 & 0 & 4537 & 0 & 8912 & 0 & 5021 & 0 \\
\hline IWKA WIP Holding & 55 & 0 & 97 & 0 & 304 & 33 & 235 & 1 \\
\hline Jones WIP feed & 354 & 11 & 493 & 33 & 1127 & 207 & 785 & 171 \\
\hline Jones FGI & 203 & 226 & 132 & 99 & 222 & 235 & 126 & 171 \\
\hline Equipment & & & & & & & & \\
\hline Lee Kettle & 1398 & 3266 & 1411 & 1909 & 1404 & 1560 & 1404 & 1576 \\
\hline Hopper & 0 & 658 & 0 & 147 & 1262 & 385 & 734 & 112 \\
\hline IWKA & 1816 & 33 & 1021 & 9 & 46 & 31 & 22 & 9 \\
\hline Kalex 2 & 0 & 0 & 0 & 0 & 44 & 27 & 32 & 20 \\
\hline Jones Cartoner & 143 & 117 & 112 & 63 & 172 & 142 & 118 & 75 \\
\hline Pallet Wrapper & 27 & 22 & 31 & 25 & 26 & 40 & 41 & 169 \\
\hline
\end{tabular}

Figures 15 and 16 compare the effects that changing batching rules has on raw ingredient storage. Interestingly, time spent in the formulation holding area which is directly adjacent to the manufacturing area is about 400 min greater on average for the continuous processing models. This increased holding time in the area may appear to be a negative finding for decreasing batch sizes, but in effect the amount of time materials spend in the production warehouse area will decrease the overall inventory and clutter. Raw materials are spending more time in the area designated for them, instead of a general "dumping area" which occurs currently for raw materials when the formulation holding area is full. By decreasing the amount of materials that are delivered to meet the formulation requirements for the day, they are decreasing the necessary time to move materials multiple times. This decreased 
material movement is particularly true when materials are blocking other items that are needed and must be moved to access them.

The effects of changing the batching rules to a more continuous approach additionally impact the outward flow of finished goods. The batch methods store materials longer in order to create a batch and subsequently cause a buildup of inventory in the production warehouse area. Figures 15 and 16 group the average time spent per entry of raw materials and palletized finished goods together for both the traditional batch processing scenarios and the future state batching rules. The differences in the approaches yield considerable time savings, occupying the production warehouse area for approximately $50 \%$ less time. This can be accounted to the JT QC approach, which would reconcile the finished goods as they are completed and would be removed by one of the "milk runs" or outside shipper. 
Figure 15. Raw Ingredients Holding Time for Batch Processing

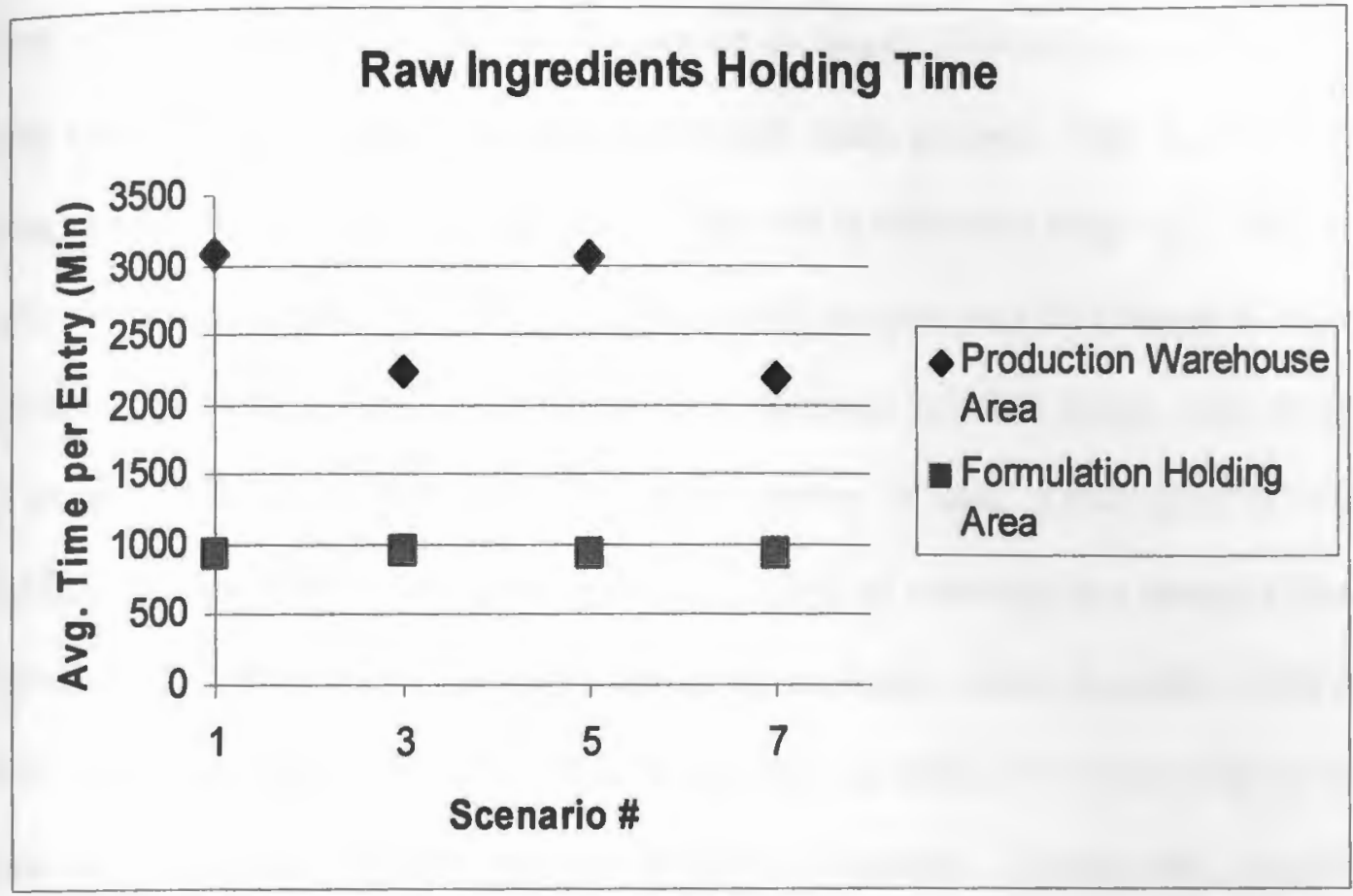

Figure 16. For scenarios implementing more Continuous Processing

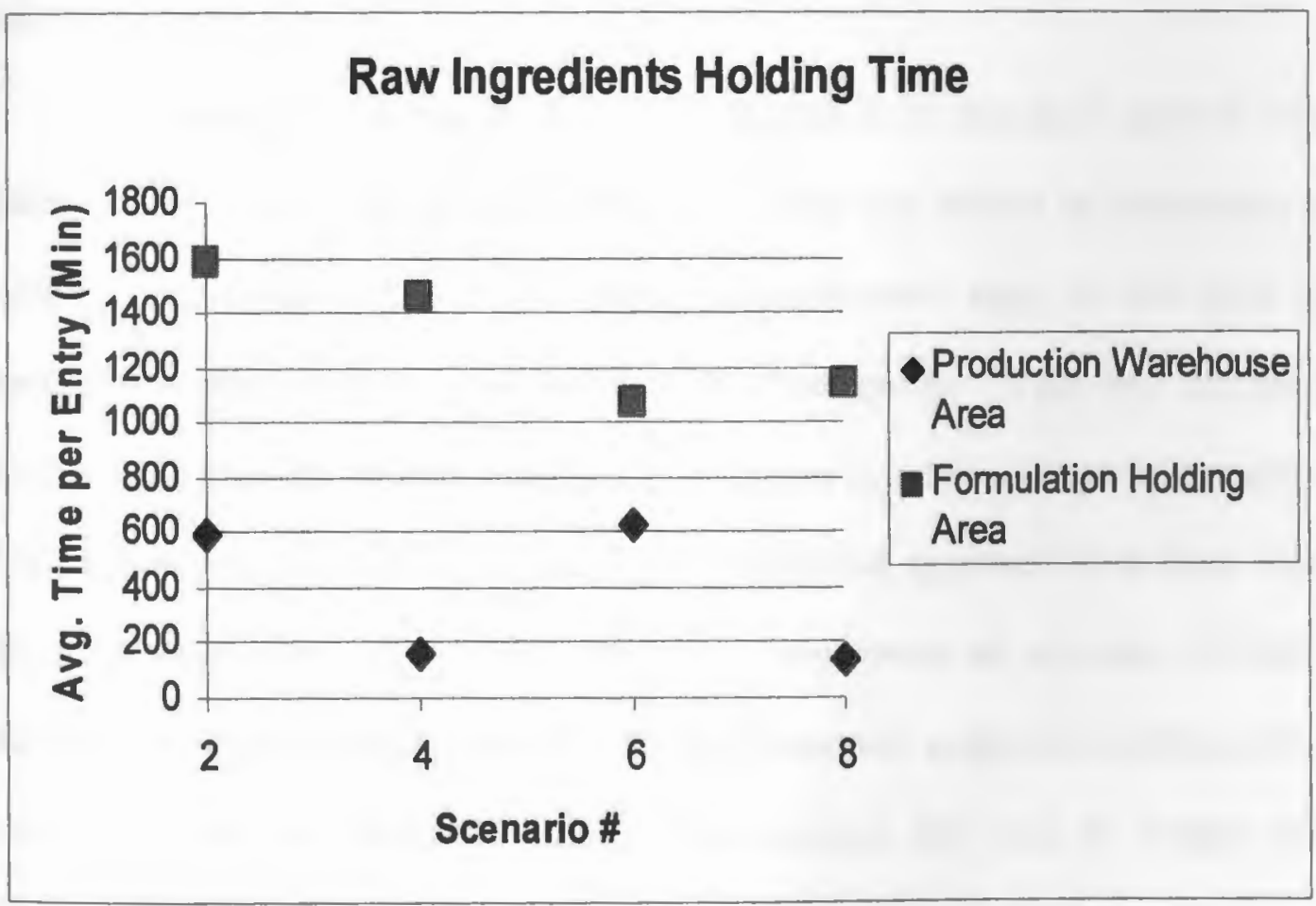


Figures 17 and 18 describe the effects changing the batching rules on the time WIP is held in the system. The two figures are on largely different scales, due to the long holding times experienced in the traditional batch process. The time the bulk drug product spends in the transfer vat holding area is extremely long. XYZ Pharma will often wait to batch and have three formulated transfer vats of Product X, ready for filling to avoid having to setup their filling machines multiple times. This results in large inventories of WIP, being held for a number of days. Other areas of WIP holding are also greatly decreased because the flow of materials has changed from pallets to WIP totes. The filling machine must no longer create an entire pallet of WIP totes prior to their transfer. Instead, as a tote is filled, it is transferred to the next station by any available operator or material handler. Additionally, material handlers are no longer necessary to move pallets of WIP totes and are free to assist other operations.

Decreasing the amount of WIP in the system is an important goal of lean manufacturing. WIP crowds the plant's floor space and should be considered a liability. Since $\mathrm{XYZ}$ Pharma is a contract manufacturer they are not paid to manufacture WIP, but are paid for their finished goods. This lean thinking challenges the manufacturer to decrease the lead times in order to make more money. This methodology is in stark contrast to the traditional approach of a large WIP inventory, which may appear to be giving the manufacturer an economy of scale. Additional inventory in the system will hide problems such as defects, inefficiencies, long setup times and long lead times, while incurring the costs of storage and delayed lead times (Liker, 2004). 
Figure 17. Holding Time for WIP in the System for Batch Processing

\section{WIP Holding Time}

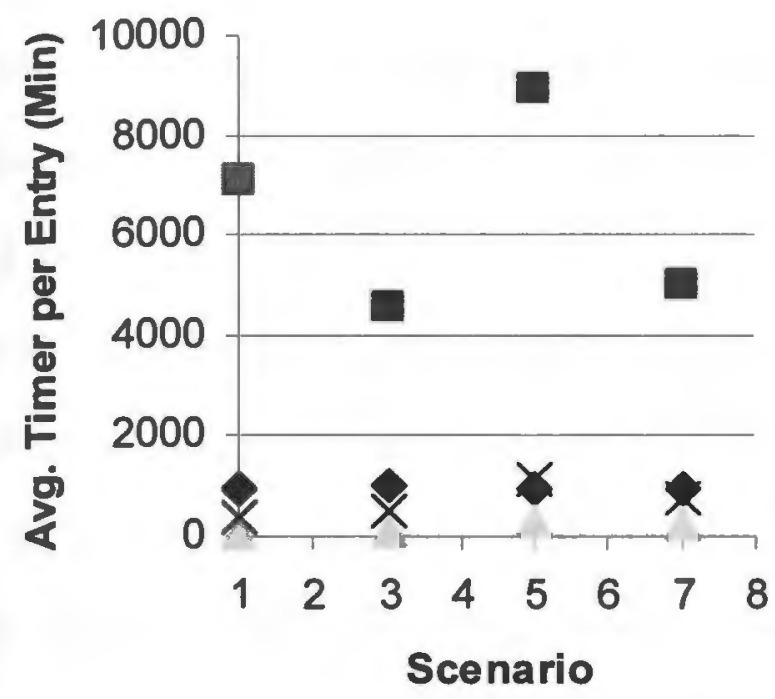

- Storage Vat Load

- Vat Holding Area

IWKA WIP Holding

$X$ Jones WIP feed

Figure 18. Holding Time for WIP in the System for more Continuous Processing

\section{WIP Holding Time}

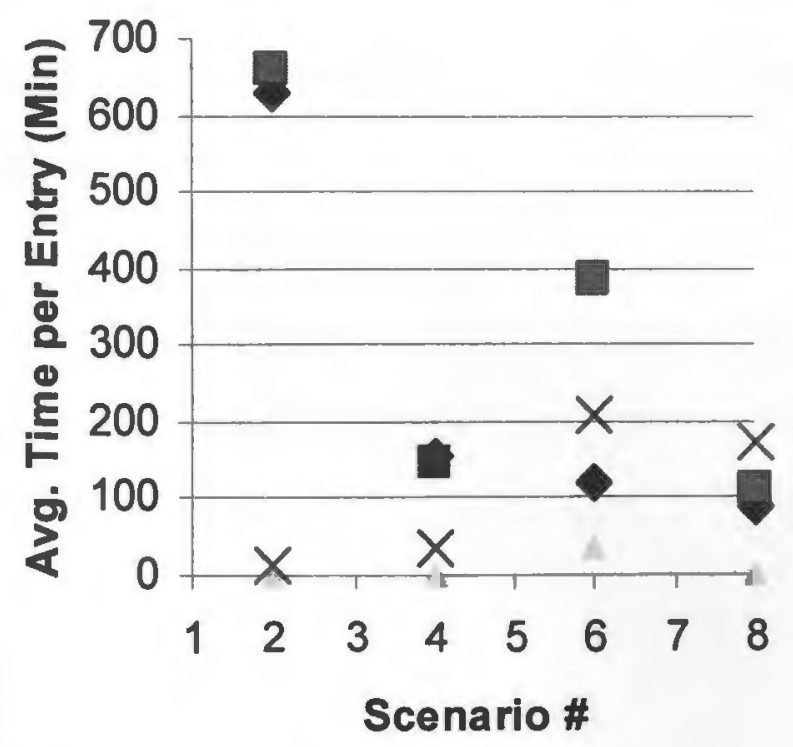

- Storage Vat Load

- Hopper

IWKA WIP Holding

$X$ Jones WIP feed 
Figure 19 compares the average time per entry $(\mathrm{min})$ that a box of finished goods inventory spends waiting after completion of operations at the Jones cartoner. The time spent on the pallet waiting to batch for the final finished goods pallet is currently unavoidable. In an ideal setting, palletizing would be an unnecessary step and boxes would be shipped as soon as they had been completed and reconciled. Unfortunately, due to $\mathrm{QC}$ testing and customer requirements decreasing shipments to single pallets instead of individual or groups of batches, 6 pallets each is the best approach. Scenario 4 spends approximately $50 \%$ of the time as the current state, scenario 1 , while scenario 8 only reduces the average time per entry $(\mathrm{min})$ by $15 \%$ of the current state. Additionally, scenarios 3 and 7 reduce the average time per entry by roughly $35 \%$ each. The common factor among these four scenarios is the cross training of employees. Since the IWKA filling machine is operated for two shifts in these scenarios, the probability that the Jones ${ }^{\text {cartoner will }}$ be waiting for material is reduced and time spent waiting to accumulate enough boxes to fill the pallets will be decreased. Cross training will result in more available material handlers, as they are assisted by the driver and operators in other areas of production. 
Figure 19. Finished Goods Inventory across all scenarios

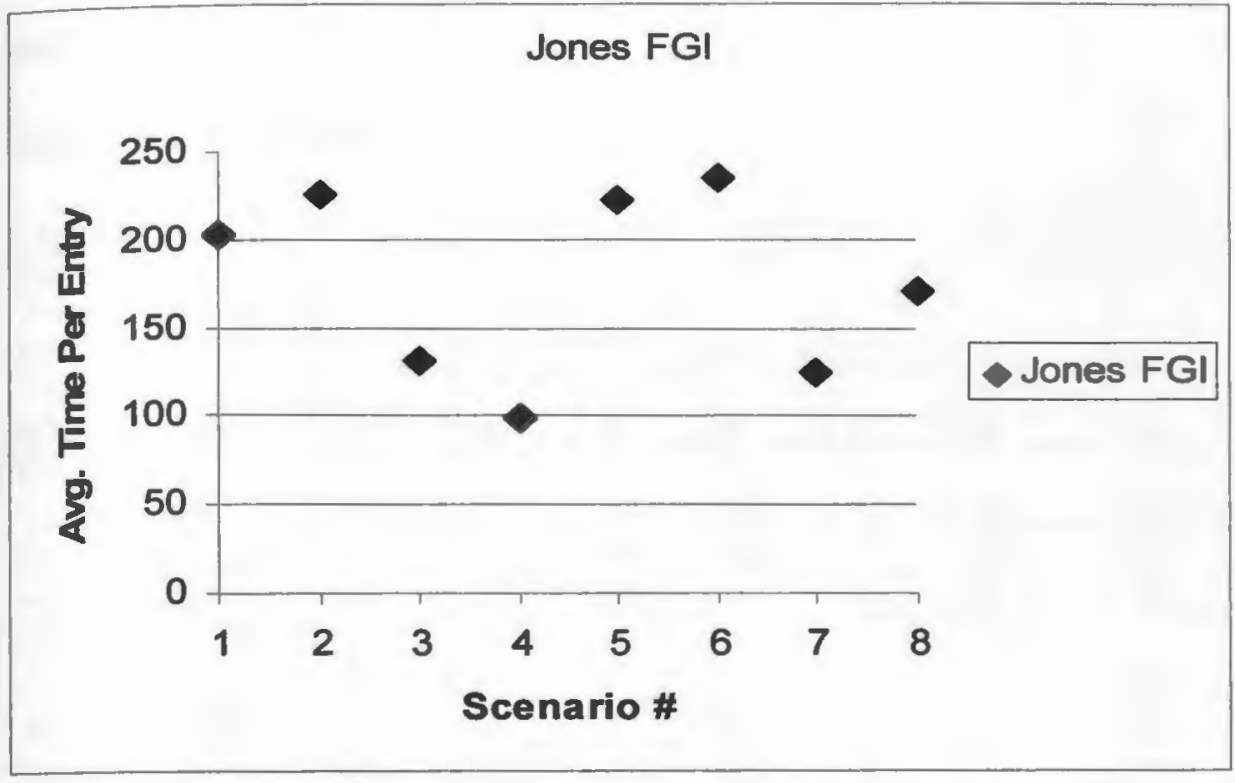

Table 10 shows the utilization (\%) of locations in the model, which is useful to identify possible new bottlenecks created in the system after changes have been made. An increase in utilization can not automatically be described as a bottleneck. "A bottleneck is any resource whose capacity is equal to or less than the demand placed upon it. And a non-bottleneck is any resource whose capacity is greater than the demand placed upon it" (Goldratt, 2004). For example, a utilization of $99 \%$ does not constitute a bottleneck if it is able to meet demand. Fluctuations and variability in the system must be accounted for with excess capacity to prevent the formation of bottlenecks throughout the system. Therefore, the utilization can be used to identify locations for further investigation. Many manufacturers strive to reach high utilization rates for expensive machinery and research has shown that this can result in a large buildup of WIP in front of the machine to avoid starvation ( $\mathrm{Li}, 2007)$. This 
buildup of WIP has negative effects on the system and can be seen from the batching used at XYZ Pharma.

Table 10. Utilization (\%) of locations

\begin{tabular}{|c|c|c|c|c|c|c|c|c|}
\hline Location Name & 1 & 2 & 3 & 4 & 5 & 6 & 7 & 8 \\
\hline \multicolumn{9}{|l|}{$\begin{array}{l}\text { Inventory } \\
\text { Transfer and } \\
\text { Holding }\end{array}$} \\
\hline $\begin{array}{l}\text { Production } \\
\text { Warehouse Area }\end{array}$ & 0 & 0 & 0 & 0 & 0 & 0 & 0 & 0 \\
\hline $\begin{array}{l}\text { Formulation } \\
\text { Holding Area }\end{array}$ & 13 & 42 & 17 & 69 & 12 & 36 & 16 & 54 \\
\hline Storage Vat Load & 13 & 67 & 18 & 30 & 12 & 16 & 17 & 17 \\
\hline Vat Holding Area & 32 & 0 & 26 & 0 & 36 & 0 & 29 & 0 \\
\hline $\begin{array}{ll}\text { IWKA } & \text { WIP } \\
\text { Holding }\end{array}$ & 1 & 0 & 1 & 0 & 3 & 0 & 4 & 0 \\
\hline Jones WIP feed & 4 & 0 & 7 & 1 & 12 & 5 & 12 & 7 \\
\hline Jones FGI & 14 & 32 & 13 & 25 & 14 & 37 & 12 & 40 \\
\hline \multicolumn{9}{|l|}{ Equipment } \\
\hline Lee Kettle & 19 & 86 & 25 & 91 & 18 & 52 & 25 & 74 \\
\hline Hopper & 0 & 70 & 0 & 28 & 16 & 13 & 13 & 23 \\
\hline IWKA & 25 & 74 & 18 & 36 & 25 & 45 & 19 & 26 \\
\hline Kalex 2 & 0 & 0 & 0 & 0 & 23 & 37 & 19 & 26 \\
\hline Jones Cartoner & 16 & 26 & 17 & 25 & 18 & 37 & 18 & 31 \\
\hline Pallet Wrapper & 2 & 3 & 3 & 7 & 2 & 8 & 4 & 45 \\
\hline
\end{tabular}

Figures 20 and 21 give a graphical representation of the effects of changes on the utilization of locations throughout all of the scenarios. Figure 20 shows the locations which are used for inventory transfer and holding. Increasing the utilization of holding and transfer areas is not the goal of lean manufacturing and implies that raw materials or WIP is occupying holding areas adding to non value added time. Therefore, utilization alone must not be misinterpreted and compared with figures 15 through 19 , the overall holding time has been decreased in scenarios utilizing changes in batching rules. Subsequently, inventory is occupying holding and transfer areas for a greater percentage of time, but is occupying the locations for 
shorter periods of time overall. In certain scenarios locations such as the transfer vat holding area, the IWKA ${ }^{\circledR}$ WIP holding area, and the Jones ${ }^{\circledR}$ WIP feed area have all been avoided or reduced to negligible utilizations.

Figure 21 describes the utilization (\%) of the plant's processing equipment. All scenarios except scenario 5, showed increased utilization of the Lee Kettle, regardless of the factors changed. The greatest increases in utilization of the kettle occur when the batching rules are changed, as can be seen in scenarios 2, 4,6 and 8 . The usage of drums to transport the materials results in down line processing beginning sooner. Because utilization is calculated as the percent of the location capacity occupied and little has been changed to alter the formulation procedure, other than the arrivals of raw materials, the same amount of formulation time appears as a greater percentage when the system throughput times are decreased. 
Figure 20. Utilization (\%) of Inventory Transfers and Holding

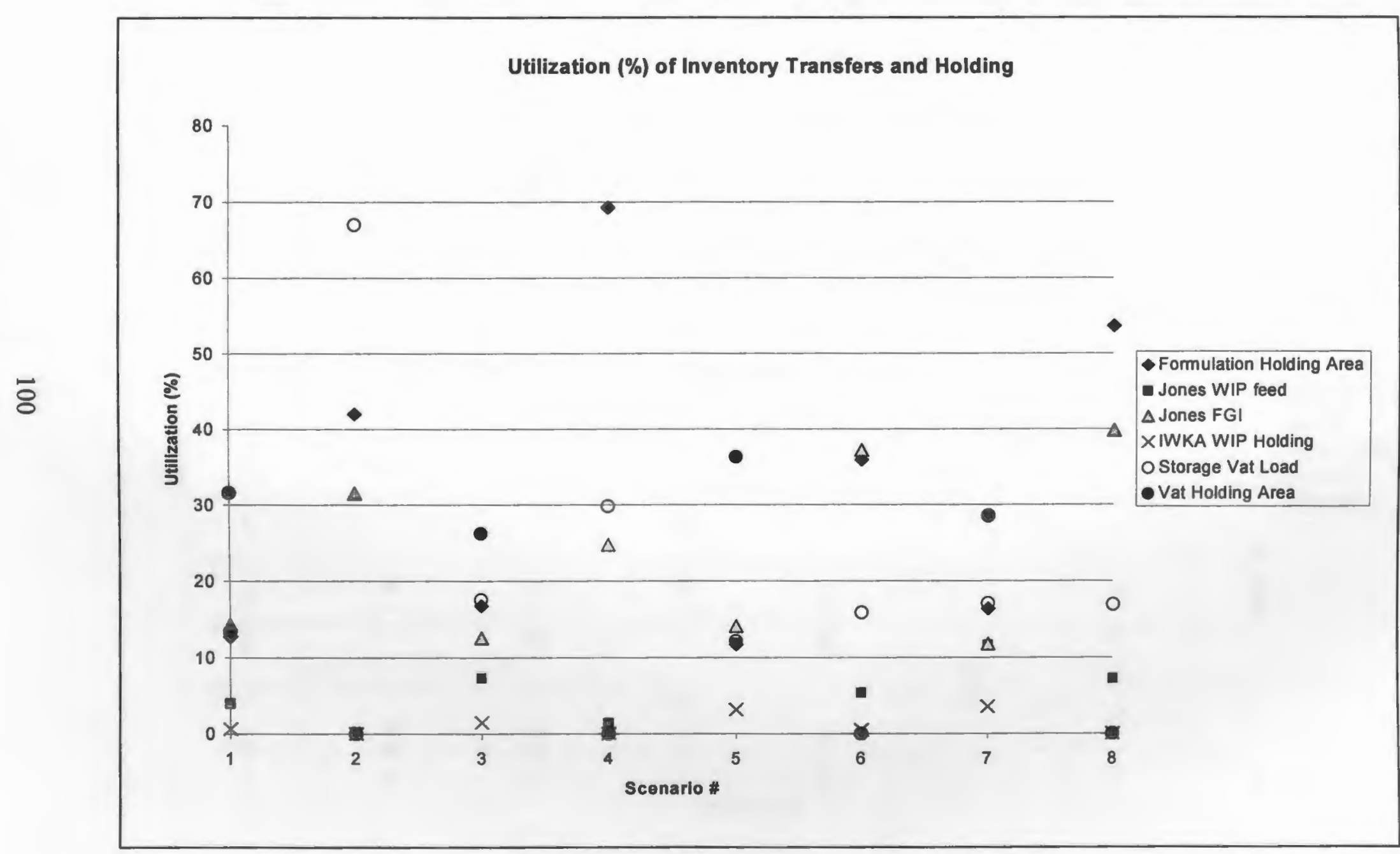


Figure 21. Utilization (\%) Equipment

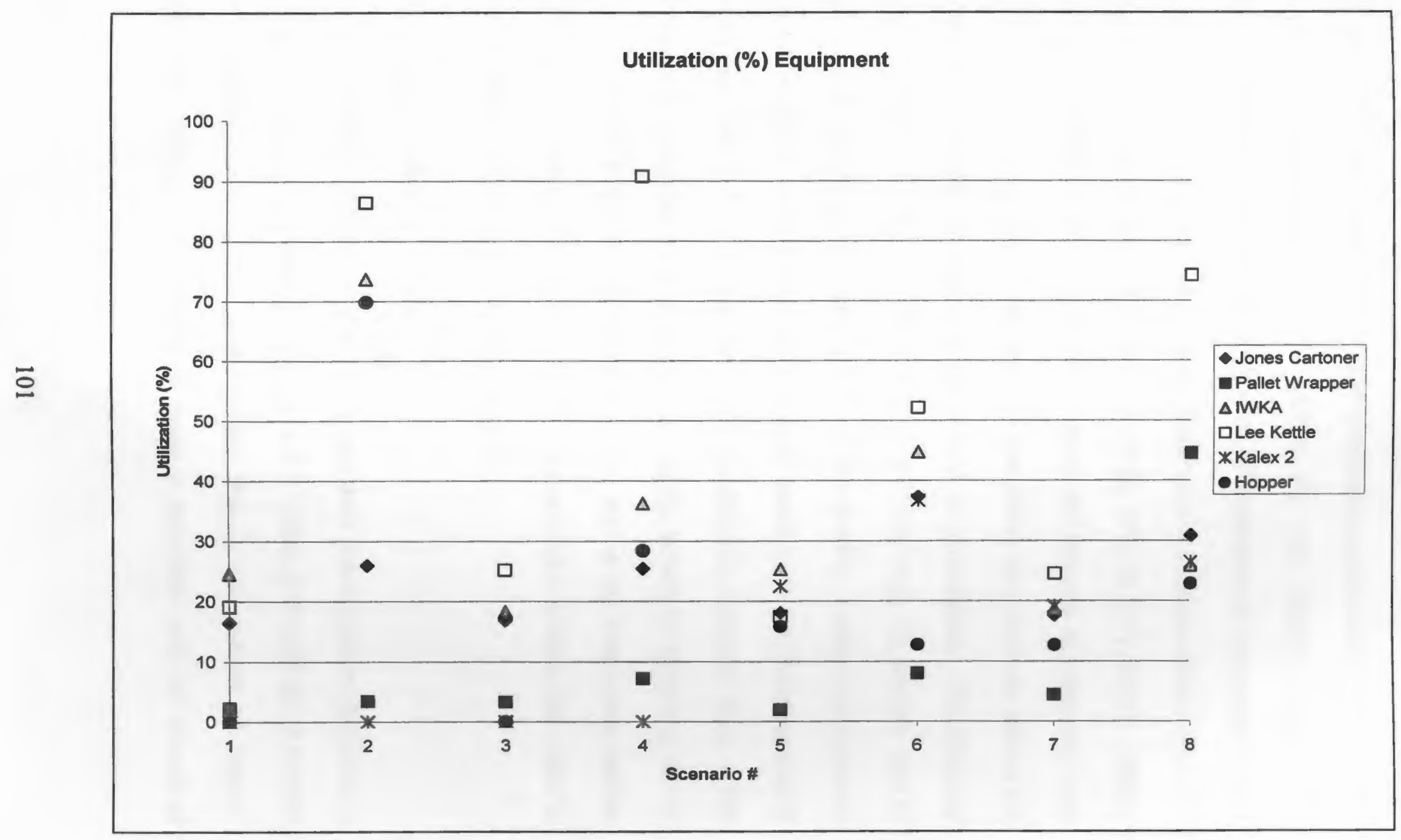


Scenario 4 has been identified as providing the lowest throughput time ( $\mathrm{Hr})$ out of the 8 tested scenarios. Following the continuous improvement philosophy, the next phase of improvements would address the new locations which have subsequently become bottlenecks in the system. The addition of cross training and a change in the batching rules has shifted the bottleneck to the formulation step. The utilization of the Lee ${ }^{\circledast}$ Kettle has increased from $19 \%$ to $91 \%$, which strongly suggests further improvements to setups, cleaning and removal of other non value added operations. If minimization of non value added time does not relieve the formulation bottleneck, parallel machining should be investigated. The inventory transfer and holding areas experience a large increase from the current state in utilization of the formulation holding area from $13 \%$ to $69 \%$. Further improvements would consist of a more precise JIT system, which would bring the correct amount of materials for formulation at the time the manufacturer required them. The improvements in scenario 4 improve upon the current system by spreading out the arrivals of the raw materials, but inventory is still held in the formulation holding area. If this JIT system was instated, the current formulation holding area could be converted into a processing area, or other purposes.

\subsubsection{Statistical Analysis of Results}

To determine whether the three factors and their interactions are significant a full factorial design was analyzed. The adjusted $R^{2}$ value is defined as, "a statistic that is adjusted for the 'size' of the model, that is, the number of factors" (Montgomery, 2005a). The adjusted $\mathrm{R}^{2}$ value is correlated with the amount of 
explained variability. Adjusted $\mathrm{R}^{2}$ was calculated to be .89 , which indicates that model is expected to explain $89 \%$ of the variability in the data. This value is given in Table 11, along with the unadjusted $\mathrm{R}^{2}$, number of observations and the root mean square error. The summary of fit and the lack of fit tests are statistical methods to determine whether there is an unacceptably high level of variability in the system due to factors which do not belong in the model.

Table 11. Summary of Fit

\begin{tabular}{|l|l|}
\hline RSquare & 0.891288 \\
\hline RSquare Adj & 0.891207 \\
\hline Root Mean Square Error & 37.63837 \\
\hline Mean of Response & 239.5579 \\
\hline Observations & 7992 \\
\hline
\end{tabular}

Table 12 shows that the calculated maximum $\mathrm{R}^{2}, .896$, is very similar to the summary of fit's adjusted $\mathrm{R}^{2}$ which indicates that the model does not have a lack of fit. The calculated $P$ value is less than .05 ; therefore, the hypothesis that this model is adequate has less than a $5 \%$ chance of being rejected (NIST, 2006).

\section{Table 12. Lack Of Fit}

\begin{tabular}{|l|l|l|l|l|}
\hline Source & DF & Sum of Squares & Mean Square & F Ratio \\
\hline Lack Of Fit & 1 & 491648 & 491648 & 362.7742 \\
\hline Pure Error & 7984 & 10820280 & 1355 & Prob $>$ F \\
\hline Total Error & 7985 & 11311928 & & $<.0001$ \\
\hline & & & Max RSq & 0.8960 \\
\hline
\end{tabular}

Table 13 is the analysis of variance (ANOVA), "tells us whether there is a difference among means. It does not tell us which means differ" (Montgomery, 2005b). The $P$ value is given as zero, which indicates that the difference in means is 
statistically significant. In order to determine which factors differ and if it is significant the effects test was performed in table 14.

Table 13. Analysis of Variance

\begin{tabular}{|l|l|l|l|l|}
\hline Source & DF & Sum of Squares & Mean Square & F Ratio \\
\hline Model & 6 & 92742617 & 15457103 & 10911.05 \\
\hline Error & 7985 & 11311928 & 1416.6472 & Prob $>$ F \\
\hline C. Total & 7991 & 104054545 & & 0.0000 \\
\hline
\end{tabular}

Table 14. Effect Tests

\begin{tabular}{|l|l|l|l|l|l|}
\hline Source & Nparm & DF & Sum of Squares & F Ratio & Prob > F \\
\hline Parallel MFG & 1 & 1 & 40767 & 28.7772 & $<.0001$ \\
\hline Cross Train & 1 & 1 & 14217695 & 10036.16 & 0.0000 \\
\hline Batch & 1 & 1 & 77386070 & 54626.21 & 0.0000 \\
\hline $\begin{array}{l}\text { Parallel MFG*Cross } \\
\text { Train }\end{array}$ & 1 & 1 & 1147 & 0.8099 & 0.3682 \\
\hline Parallel MFG*Batch & 1 & 1 & 514934 & 363.4881 & $<.0001$ \\
\hline Cross Train*Batch & 1 & 1 & 582003 & 410.8311 & $<.0001$ \\
\hline
\end{tabular}

The effects test in table 14 shows that all three main factors, parallel manufacturing, cross training personnel and a change in batching are significant. The interaction between each of these factors is also examined by this statistical method. The interaction between parallel manufacturing, changing batching rules, the interaction between cross training personnel and changing the batching rules are both significant interactions. While the interaction between parallel machining and cross training are not a significant interaction. The non significant interaction is most likely due to the overpowering effect of changing the batching rules. Changing the batching rules has the strongest effect on the outcome which is demonstrated in 
the prediction profiler, figure 22 and the Pareto chart, figure 23. This dominant factor effect results in significant interactions with the other factors.

Figure 22. Prediction Profiler of the Factors

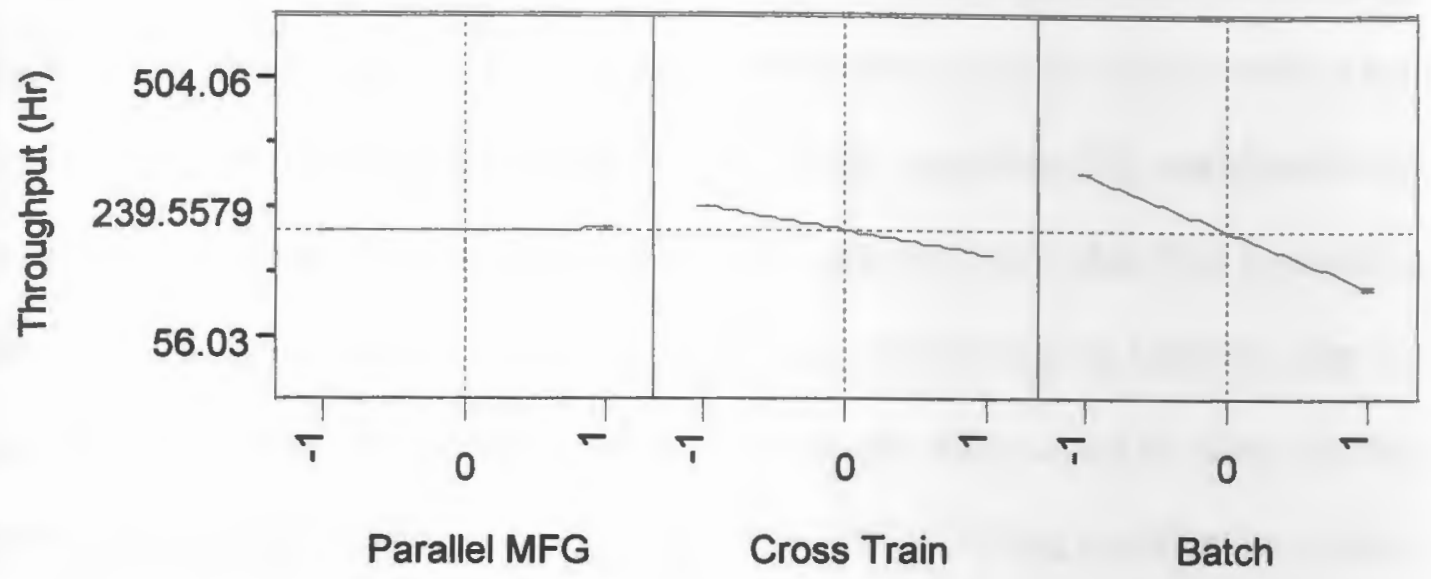

Figure 23. Pareto Plot of Estimates

\begin{tabular}{|c|c|}
\hline Term & Estimate \\
\hline Batch & -98.40194 \\
\hline Cross Train & -42.17809 \\
\hline Cross Train*Batch & 8.53365 \\
\hline Parallel MFG*Batch & -8.02691 \\
\hline Parallel MFG & 2.25854 \\
\hline Parallel MFG*Cross Train & 0.37890 \\
\hline
\end{tabular}

Even though all of the factors and interactions except one, parallel manufacturing and cross training, are statistically significant, that does not imply that they all have the same effect on the outcome. Figure 22 shows parallel manufacturing having virtually no effect on the throughput time, while cross training 
and batching changes have greater impacts. Figure 23, the Pareto chart, quantifies and ranks the effects of each of the terms and interactions.

\subsection{Future State Value Stream Map}

The future state value stream map was created based upon results found from scenario 4. This scenario yields the lowest simulation throughput time which is the primary goal for a contract manufacturer. In contract manufacturing overproduction is not a concern because company XYZ Pharma only produces what their customers have ordered. This scenario utilizes cross training and change in batching rules to decrease lead times. Differences from the current state with regard to cross training are the increase in shifts that are available for the IWKA ${ }^{\circledR}$ filling machine to operate, due to a greater number of operators able to run the machine. The most significant factor that was found through the statistical analysis was the batching rule changes. These changes affect the entire process from arrivals to departures of finished goods inventories. Arrivals of raw ingredients are limited to quantities required for formulation of bulk drug at that time and are stored directly outside of the manufacturing areas. The replacement of the transfer vat with more flexible and mobile drum has decreased waiting times during transfers and setups, subsequently decreasing the cycle time by approximately 90 minutes. Another benefit of earlier bulk drug substance arrivals are the completion of final adjustments to the filling equipment sooner. Waiting times have also been decreased because WIP is no longer waiting to batch prior to movement. Bulk drug in drums, WIP totes and finished goods pallets are all moved individually, and require fewer quantities to be 
moved. The cumulative effects of these changes result in a lead time of approximately 2130 minutes which is about a $75 \%$ reduction of time. It is important to note that this future state finds the time to produce the first pallet of finished goods inventory. The future state no longer waits to batch the finished goods prior to shipping; therefore, this estimate is useful to determine how quickly finished goods would be ready to begin shipping if there was flexibility with the customers to receive goods in more frequent smaller delivery amounts.

This future state is based upon the scenario with the lowest throughput time from the 8 scenarios tested. This throughput time can be considered a conservative estimate. Many of the effects of the suggested improvements to areas of need could not be readily quantified or modeled. Many of the other lean techniques discussed earlier in the areas for improvement would further impact the lead time. One example is implementing quick changeovers to decrease setup and adjustment times have been shown to decrease the necessary time by $20-40 \%$ (Centers and West, 2001), which could also help XYZ Pharma. While these improvements would be qualitative, they could have both direct and indirect impacts on the total throughput time of the system. 
Figure 24. Future State Value Stream Map based on Scenario 4

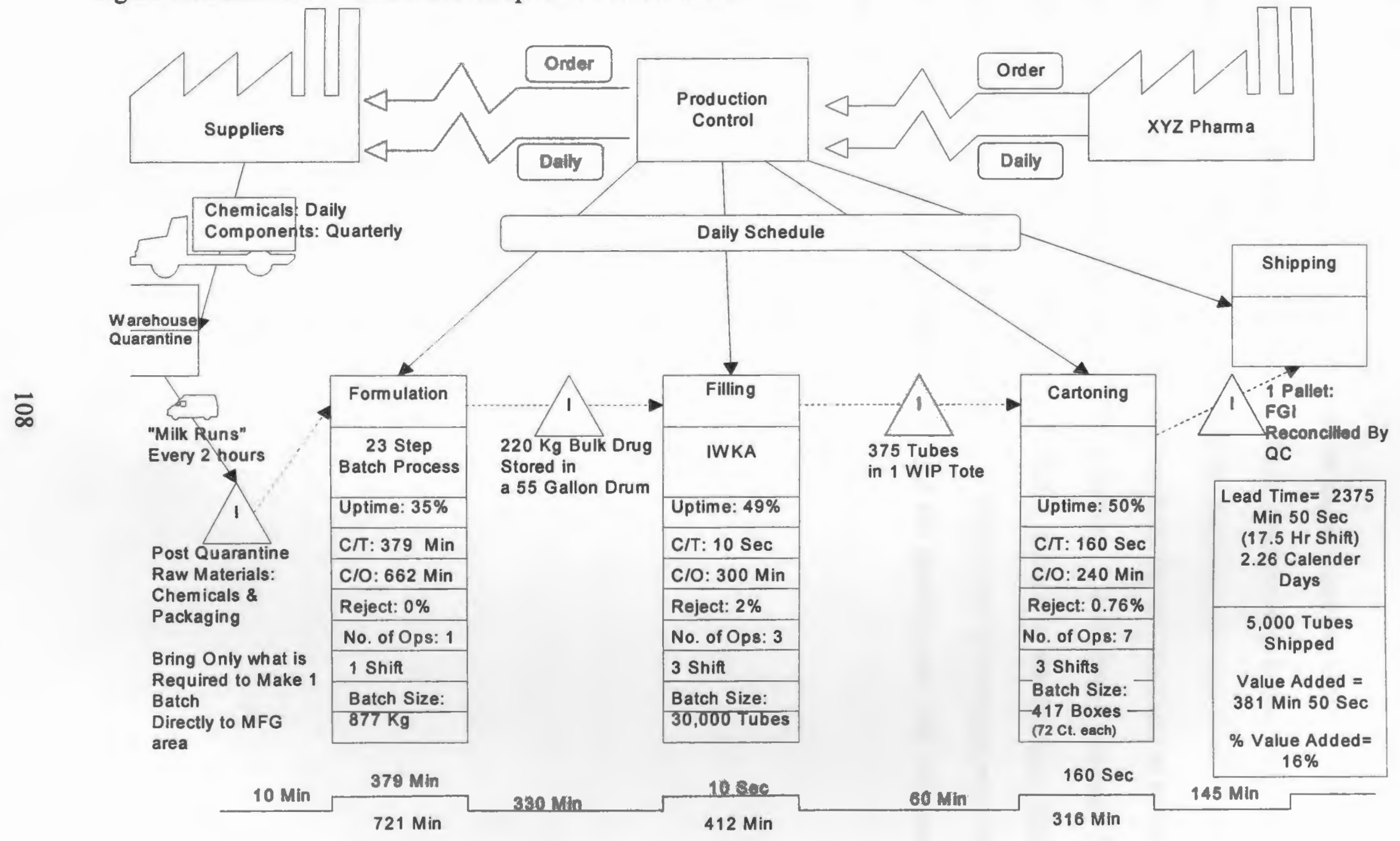




\subsection{Chapter Review}

This chapter presented the results of the current state ProModel ${ }^{\text {simulation }}$ and the theoretical future state simulations. While all of the three factors tested were found to be statistically significant, changing the batching rules was found to have the greatest effect. Only one of the interactions of the factors was found to be non significant, parallel manufacturing and cross training. Interestingly, scenario 4, which incorporated cross training methods and a change in the batching rules, yielded the lowest simulated throughput time. A future state value stream map was created to help visualize the improvements and the specific areas that had been changed. 


\section{Chapter 7}

\subsection{Conclusions}

Lean manufacturing techniques should be explored in the pharmaceutical industry to improve current systems and utilized early on in the development of new systems. This case study represents a number of possible opportunities for specific areas of improvement as well as suggesting an overall change in manufacturing mindset. The pharmaceutical industry can learn a great deal from outside industries where competitiveness is required to ensure solvency.

\subsection{Linking Pharmaceutical Manufacturing to Outside Industries:}

\subsubsection{Approach to Manufacturing}

Contract manufacturers of pharmaceuticals only make what is ordered by their customers and use a general pull production system. Usually extra finished goods are not manufactured or warehoused, due to the chance of expiration, loss of contract, or removal from the market. With many of their products having only a two to three year expiry period and products spending weeks to months traveling through complex distribution chains, especially for larger national retailers, the window of opportunity to sell their products is narrow. Also, preprinted tubing is shipped by the customer to be filled with product, resulting in a finite number of products which can be manufactured, thus limiting the temptation for overproduction. 
While orders are made to meet customer orders, the internal flow of product is pushed through the system. This is due to batch processing which results in materials being pushed onto down stream machinery. This method then results in manufacturing of as much of the order as possible in their shift, which is then batched to move to the next process. There is a lack of production leveling which results in uneven production of materials.

\subsubsection{Quality}

The focus on product quality is extremely high in the pharmaceutical industry to avoid potentially fatal and costly defects. While PAT is an emerging resource, many tools are used to ensure that the product meets the rigorous specifications required to be safe and efficacious. The pharmaceutical industry is in the process of moving away from end product testing and toward in process testing which has been used for many years by other industries.

Product quality for pharmaceuticals comes at a price. The pharmaceutical industry carries a large amount of inventory "just in case" and face problems other manufacturing industries may not. Large quantities are held in inventory for two reasons, 1. The average lead time for custom components is $4-6$ weeks and for materials is $1-2$ weeks and a last minute increase in the order size would result in a long lead time. Additionally, components from the customer are not purchased and may incur the cost of holding which is then build to the customer if held for long periods of time and 2. All batches of incoming materials and components are quarantined and require identity conformation. Regardless of the size of an 
incoming order, only one test is required and is regarded as more convenient by quality control. Component manufacturers are not willing to change to a more JT approach and experience many similar problems due to their batch mentality. Quarantine is not an issue for most other manufacturers and requires an additional inventory buffer to ensure that proper quantities of raw materials are readily available. With only a small number of capable and reliable specialized pharmaceutical component manufacturers, they are able to dictate long lead times without losing business.

\subsubsection{Equipment}

cGMP compliance requires many elements that other industries do not face. Validated methods for cleaning of equipment and manufacturing areas are important to decrease the chance of unsafe levels of contamination from the environment and personnel. The cleaning required between products is rigorous in order to decrease the chance for cross contamination between products. This results in longer time required for setups and changeovers. If setup times are addressed as a problem and visual controls are instituted, any significant changes to the physical equipment may require validation from the FDA. If the process has undergone validation, the use of two parallel machines is acceptable, but must be evaluated carefully due to long setup times and cleaning requirements.

\subsubsection{Facility}

Some production facilities have a "Job Shop" layout, with all formulation equipment grouped near each other and products transported in large vats for filling 
and palletized totes of WIP. A redesigned layout would place all the equipment in proximity to each other in order of flow. During formulation, the general area is kept clean for manufacturing and is designed for ease of cleanability. While filling operations, it tends to generate far more scrap materials. Due to cGMP regulations, certain layouts may not be feasible for fear of contamination to the product. An improvement to the flow of material within the guidance can still be investigated.

Another facility problem is the storage of components and chemicals. Storage areas for raw material and finished goods can become cluttered due to the quarantine process and the large quantities required for batch processing. This is in contrast to a JIT system which would remove finished goods upon completion and store needed components close to the manufacturing line.

\subsection{Study Limitations}

Every effort was made to accurately capture the current state of manufacturing for product $\mathrm{X}$. Data for the model was based on four batches with two batches using the older filling machine and two batches using the newer filling machine. The future state model data was based on assumptions derived from observations and were not data collected after implementation of the suggested improvements. This case study does not accurately represent the entire pharmaceutical industry, especially some of the larger companies which have greater financial resources to investigate lean and alternative techniques. 


\subsection{Future Work}

Further studies using ProModel ${ }^{\circledR}$ simulation software should be conducted to improve the process understanding and diagnosis of problems. Future areas of study addressing DfM, failure modes effects analysis (FMEA) and design of experiments should be addressed. Experimenting with continuous manufacturing equipment during the formulation process and process development should be considered, especially for large scale and volume products. The methods and findings from this study could be tested to see their applicability to product dedicated equipment and facilities. 


\section{Appendix I: Definitions of current value stream map example (US EPA, 2006b)}

CiT Cycle time

Cio Changeovertime

A

Inventor;

WK

Truck shipment

External sources isuppilers. customers. etc:

Electronic information flow

Hovement of production material

Supermarket ia controlled in:entor; of parts;

Withdrawal cull of materials. usually from a supermarket?

Production kanban icard or device that signals to a process how many of what to produce:

Signal kanban ishows when a batch of parts is needed:

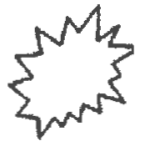

Kaizen staßurst identfies improvement needs: 


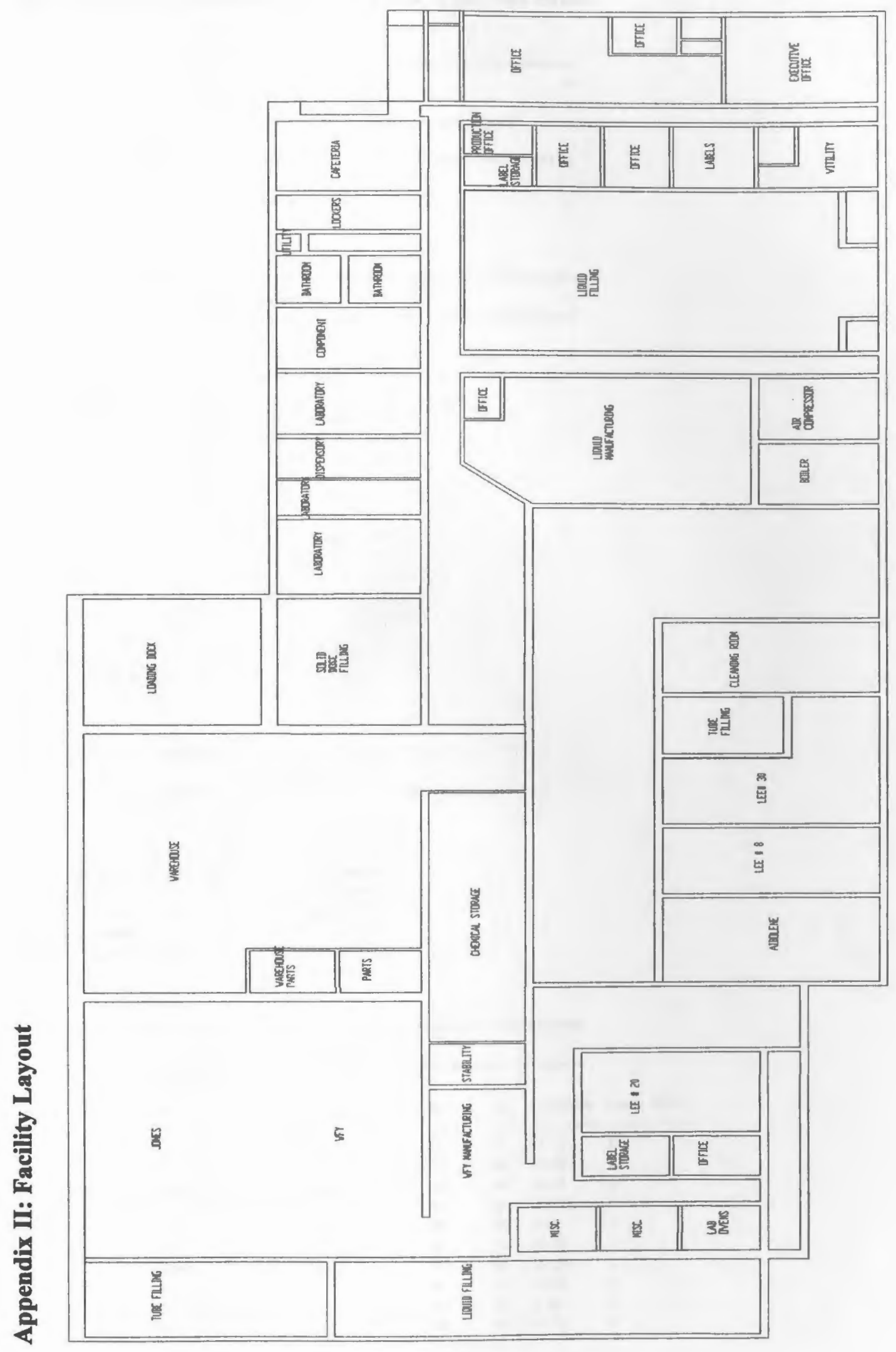




\section{Appendix III: ProModel ${ }^{\circledR}$ Simulation- Current State}

Scrma:ted listing 6 Hodel

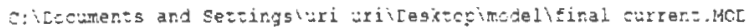

$\begin{array}{ll}\text { Time Jniis: } & \text { Minctes } \\ \text { Ciszance Jniis: } & \text { Eee: }\end{array}$

\begin{tabular}{|c|c|}
\hline & Loca=ions \\
\hline
\end{tabular}

\begin{tabular}{|c|c|c|c|c|c|c|c|}
\hline Narre & $\operatorname{Cat}$ & Inits & sta:s & & Fules & & $\cos$ \\
\hline warghnuging araa & INE & 1 & $\theta^{2}$ & Sarios & oliaget & rine. & \\
\hline Warehcüsing_Area & INF & 1 & Timo & Series & Oldest, & , Firs: & \\
\hline Form:ilation_Holdir_g_Ârea & 4 & 1 & Tine & Series & Clos: & , & \\
\hline Jenes_zirf_zeed & $10 \hat{0}$ & 1 & Time & Series & cldes: & , & \\
\hline Jeras_Carzerer & 25 & 1 & Tine & Seriös & cldes:, & , & \\
\hline Fallez_haccer & 1 & 1 & Fire & Series & cläest, & , & \\
\hline Jer.es_EGI & e: & 1 & Time & Series & cldest, & , & \\
\hline Kalex_z & 1 & 1 & Tires & Series & cldes: & , & \\
\hline inks & $i$ & 1 & Pire & Saries & cldes: & , & \\
\hline Kalex_: & 1 & : & $\operatorname{sim} 6$ & Series & Cldes: & , & \\
\hline Delivery_truck & 12 & 1 & Tine & Series & cldest, & , & \\
\hline caze_able & 20 & 1 & rime & Series & Sldes: & ， & \\
\hline Lee_Rettle & i & 1 & Inde & Eories & Gldest, & ， & \\
\hline IFKA_IF_Helding & $10 \%$ & 1 & Tine & Series & Cldes:, & , & \\
\hline stcrage_iat_Lad & 1 & $:$ & Pine & Saries & Cldes:, & , & \\
\hline †at_Frldirg_zrea & 3 & $i$ & Time & Series & clatest & . & \\
\hline Q己_Cesx & 1 & ; & Pitsa & Sories & clies=, & ， & \\
\hline
\end{tabular}

ETtizies

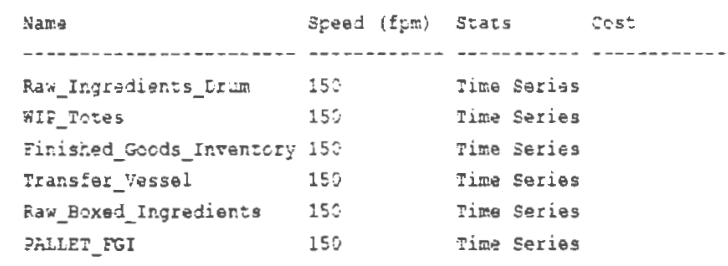

\begin{tabular}{|c|c|c|c|c|c|c|c|}
\hline \multicolumn{8}{|c|}{ zath sezwcris } \\
\hline vares & Pyç & $7: 3$ & EICI & $2=$ & $\mathrm{BI}$ & Listipin: & sţeеj Fac:er \\
\hline \multirow[t]{2}{*}{ Erizer_pazh } & zassing & Speed \& Ciszance & $x:$ & $\mathrm{s} z \vec{z}$ & Bi & $5 \hat{c} . \bar{\varepsilon}$ & $i$ \\
\hline & & & $\mathbf{y}_{\mathbf{z}}$ & $\$ 3$ & $B i$ & 27.75 & 1 \\
\hline \multirow[t]{4}{*}{ gatt._Manufarcurer } & Eassing & speed \& Listarce & $\mathrm{NI}$ & sâ & $B i$ & 35. दE & 1 \\
\hline & & & $\mathrm{x}:$ & N5 & $\mathbf{B i}$ & $2: 5.25$ & $\vdots$ \\
\hline & & & $\mathrm{N}:$ & se & Ei & 6.59 & $:$ \\
\hline & & & NE & v3 & $\mathrm{Bi}$ & $\leq 2.5$ & 1 \\
\hline \multirow[t]{4}{*}{ oversigx } & passing & skeed \& Listarce & $\mathrm{N} 1$ & $\mathrm{x} 2$ & $\underline{2 i}$ & $7 \because . \varphi_{\mathrm{E}}$ & 1 \\
\hline & & & N4 & NE & $B i$ & 32.50 & 1 \\
\hline & & & N? & ye & $\mathrm{Bi}$ & 4.95 & \pm \\
\hline & & & $\mathrm{x}$ : & 19 & $\mathrm{Bi}$ & 37.23 & 1 \\
\hline
\end{tabular}




\begin{tabular}{|c|c|c|c|}
\hline N9 & $\mathrm{NiO}$ & $\mathrm{Bi}$ & 10.41 \\
\hline $\mathrm{N}: 3$ & $\mathrm{n}: 1$ & $\bar{E} i$ & 13.84 \\
\hline$x: i$ & $\mathfrak{N}_{\mathrm{i}} \mathbf{z}$ & $\mathrm{Bi}$ & 19.14 \\
\hline NE & $\mathrm{y}$ ? & $\mathrm{Bi}$ & 4.42 \\
\hline 85 & ง 3 & $\mathrm{Bi}$ & $2: 3.39$ \\
\hline $\mathrm{N} \tilde{2}$ & $y: \hat{z}$ & $\mathrm{Bi}$ & 24.70 \\
\hline $\mathrm{N} \tilde{z}$ & N4 & $\overline{\Xi i}$ & $: 8.7 .23$ \\
\hline$y_{1}$ & $\mathrm{~s} 7$ & $\mathrm{Bi}$ & 229.69 \\
\hline $\mathrm{N}:$ ? & $\mathrm{x}: 4$ & $\bar{B} i$ & 41.36 \\
\hline 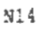 & 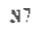 & $\mathrm{Bi}$ & $1 \Xi \pi .16$ \\
\hline$\$ 15$ & \$3 & $\mathrm{Bi}$ & 52.39 \\
\hline
\end{tabular}

Ir.terzacos

\begin{tabular}{|c|c|c|}
\hline se: & Nowe & Lccasicr. \\
\hline 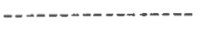 & -- & - - \\
\hline \multirow[t]{3}{*}{ Lriver_fa:h } & N! & [elivery_trute \\
\hline & $\mathrm{x}_{\hat{\sigma}}$ & Warehousirg_hrea \\
\hline & $\$ 3$ & Gralazicr_Folding_area \\
\hline \multirow[t]{5}{*}{ cath_nanifacturer } & $\$$ & Lee_Re:=16 \\
\hline & $\mathbf{s}_{2}$ & Eeraulation_pelding_frea \\
\hline & $\$ 5$ & case_tacle \\
\hline & $\$ 6$ & stcrage_vaz_zod \\
\hline & NZ & Yat_hiclding_ärea \\
\hline \multirow[t]{14}{*}{ overview } & $N:$ & Lelïgry_Truck \\
\hline & $\mathrm{N} \hat{2}$ & Warehousirg_Area \\
\hline & N4 & Formulaticn_Helding_èrea \\
\hline & sis & Iee_Rezile \\
\hline & $N ?$ & $I H R Z$ \\
\hline & NE & IWE_XIF_Holdirg \\
\hline & s9 & JCnes_mIE_feed \\
\hline & $\mathrm{N}: \mathrm{C}$ & Jeres_cartcrer \\
\hline & N:1 & Jores_EGI \\
\hline & 312 & Ealle:_frarser \\
\hline & $\$ 3$ & Cafe_table \\
\hline & $\mathrm{x} 1 ?$ & Stcrage_va:_lcad \\
\hline & N14 & Vat_yolding_Area \\
\hline & $\$ 5$ & aE_Lesk \\
\hline
\end{tabular}

Maceing

\begin{tabular}{|c|c|c|c|}
\hline Net & Eron & To & Les: \\
\hline \multirow[t]{3}{*}{ facm_manufacturer } & wi & N2 & \\
\hline & $\mathrm{NI}$ & \$5 & \\
\hline & $\mathrm{N}:$ & NE & \\
\hline \multirow[t]{13}{*}{ everview } & \$2 & 31 & \\
\hline & s4 & $\mathrm{N} \bar{z}$ & \\
\hline & $\mathrm{N5}$ & $\mathrm{Ne}$ & \\
\hline & s7 & NE & \\
\hline & $\mathrm{s}$ & NG & \\
\hline & N9 & $\mathrm{Ni} \hat{?}$ & \\
\hline & N:O & $\mathrm{NZZ}$ & \\
\hline & $N:=$ & $N: \hat{z}$ & \\
\hline & $\mathrm{N} \div 2$ & $\aleph_{2}$ & \\
\hline & $\mathrm{s}: \overline{7}$ & N5 & \\
\hline & $N: 4$ & $\mathrm{x}: 7$ & \\
\hline & $N \hat{z}$ & $\sqrt{14}$ & \\
\hline & Ni & \$5 & \\
\hline
\end{tabular}




\begin{tabular}{|c|c|}
\hline$y^{7}$ & N16 \\
\hline 85 & $\mathrm{x}^{-}$ \\
\hline $\mathrm{x} \tilde{2}$ & $\mathrm{~N} 12$ \\
\hline$x=$ & $\mathrm{N}_{\mathrm{i}}^{-7}$ \\
\hline $\mathrm{N} 5$ & $H E$ \\
\hline M:L & xy \\
\hline 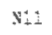 & $x:$ \\
\hline $\mathrm{xin}$ & $x:=$ \\
\hline 8:? & $\mathrm{N}: 4$ \\
\hline S:L & די \\
\hline 85 & \$3 \\
\hline
\end{tabular}

\section{Fescurres}

Res En:

\begin{tabular}{|c|c|c|c|c|c|c|c|}
\hline Xame & Inits & $s=a+s$ & Eвarch & Search. & Earh & Mosion & $\cos 5$ \\
\hline Mer:ufactureI & 1 & By Jri: & closest & Cliest & $\begin{array}{l}\text { çati__rarufacturer } \\
\text { zone: \$1 }\end{array}$ & $\begin{array}{l}\text { Empty: }: 50 \text { Egr } \\
\text { Eill: :5: :5x }\end{array}$ & \\
\hline Haterial_Eardler_a & $:$ & By ari: & Closest & Cldes: & $\begin{array}{l}\text { everviè } \\
\text { Bone: Naz }\end{array}$ & 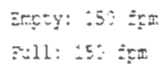 & \\
\hline Material_tancler_2 & : & $\theta_{f}$ jrit & Class9: & cices: & $\begin{array}{l}\text { crervisi } \\
\text { Sowe: } \mathrm{x}\end{array}$ & 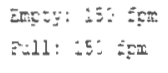 & \\
\hline [river & $\vdots$ & $\mathrm{B}_{j}{ }_{j}$ Jni: & $01=505 \%$ & clies: & $\begin{array}{l}\text { Eriver_path } \\
\text { Frme: } \mathrm{S}: \\
\text { Rezure; }\end{array}$ & 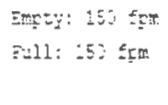 & \\
\hline Mechanic & 1 & By Jrit & closesz & cldest & $\begin{array}{l}\text { Averviey } \\
\text { Ecme: } \mathrm{v}^{-}\end{array}$ & $\begin{array}{l}\text { Entoy: } 150 \text { Erx } \\
\text { Inll: :5; Erx }\end{array}$ & \\
\hline Geveratcr: & 7 & Bit 3rit & Elcsest & Cldes: & $\begin{array}{l}\text { crervie* } \\
\text { ̈cme: } N\end{array}$ & $\begin{array}{l}\text { Inety: } 150 \text { :trm } \\
\text { Fill: : } 5: \text { : } 1 \mathrm{~m}\end{array}$ & \\
\hline Operator_z & 7 & $B_{i}$ trit & Cleses: & Glides: & $\begin{array}{l}\text { crerrigs } \\
\text { Eore: } \mathrm{Ni}^{3}\end{array}$ & 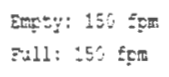 & \\
\hline greratcr & 3 & Ey trit & Elises: & clibes: & $\begin{array}{l}\text { chervidew } \\
\text { tcre: }{ }^{4}\end{array}$ & 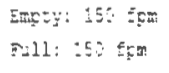 & \\
\hline$\approx$ Irspector & : & Qy Init & Cleses: & clies: & $\begin{array}{l}\text { crervisy } \\
\text { tere: } \text { x:5 }\end{array}$ & 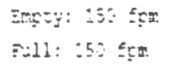 & \\
\hline
\end{tabular}

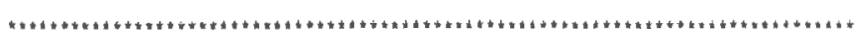

Prosess:reg

Erceess

Reisirg

\begin{tabular}{|c|c|c|c|c|c|c|}
\hline Enticy & jecation & cọerazion & $31 \mathrm{k}$ & ouret: & Lestination. & Bule \\
\hline \multirow[t]{3}{*}{ Ra:_Ingrecier:s_Irux } & feliver $\ddot{x}_{-}$Truck & $\operatorname{MEI}: 5\{2, .3\}$ & & & & \\
\hline & & JIEN "leading ceck" & & & & \\
\hline & & & 1 & RaN_Irgrecier:s_If:ix & Tazoheusing_krea & FIRST \\
\hline Ra:_Ecxed_Ir.çrecier:s & Leliver $Y_{-}$Trük & MeIT $A(.2, .3)$ & 1 & Ra'x_Eoxed_Ingradients & Wayehcusize_krea & EIRST \\
\hline \multirow[t]{3}{*}{ Ra*_Intrecients_IruT } & Haretousing_hrea & 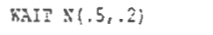 & & & & \\
\hline & & MEN "wareiouse" & & & & \\
\hline & & & 1 & Rä_Ingredierts_Lrm & Formilatier_holoira_area & EIRST \\
\hline Raw_sexod_Ingrediens & Hareionsing_azed & SXIT $x(.5, .2)$ & 1 & sak_zexod_In.grejients & Eorriulazicr_raldirg_trea & SIRET \\
\hline
\end{tabular}


ZEe_Re:Zle

Scaisire 4

I5 $202=$ :

THEN

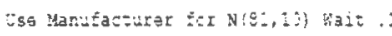

$\sum \geq 2 \hat{L}=$

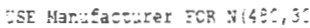

Rax_Ingredien:5_Lriun Iee_Ra:=le

Ba*_boxod Ingrodienes Lea Rezte

TIRS?

FIRS
Trar.sfer Vesse]

Frangfer_iessel

Trarsfar_Vesssl
Sterage Vi: Load

$\mathrm{Va}=$ Folding_area

I FFA

IHZA_WIF HOlOirg

Jenes_hitE_Eeed

Jones_Carzerer
Szcrage_ya_Lzad

FIRST

ZSE Nar:Eazturer ICR N $(22 \%, 3:)$

WhIT X(334:, I05T)

1 Trarszer_yessel

I Trarster Yessel

$I=S J I=$

THEN

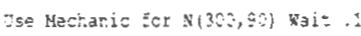

$S T=:$

Ös Cperater for $N(495,42$

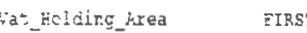

Inis

EIRST
TIE Totes

FI?_Totes

MIP_ICtes

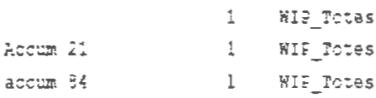
Jcres 衫 F Fot

Jcres_Carterar
FIFSI

EIRST $\operatorname{IIRSA}$

\section{IF $S: T:=0$ TRES}

ZSE mectranic for $N(245,60\}$ Rait .1

$\sin :=:$

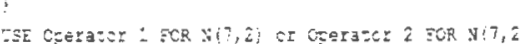




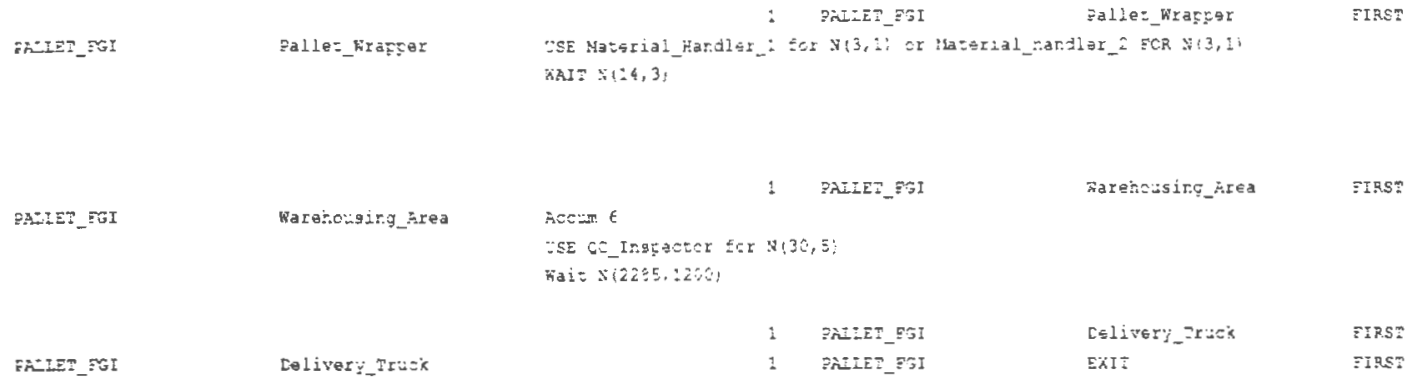

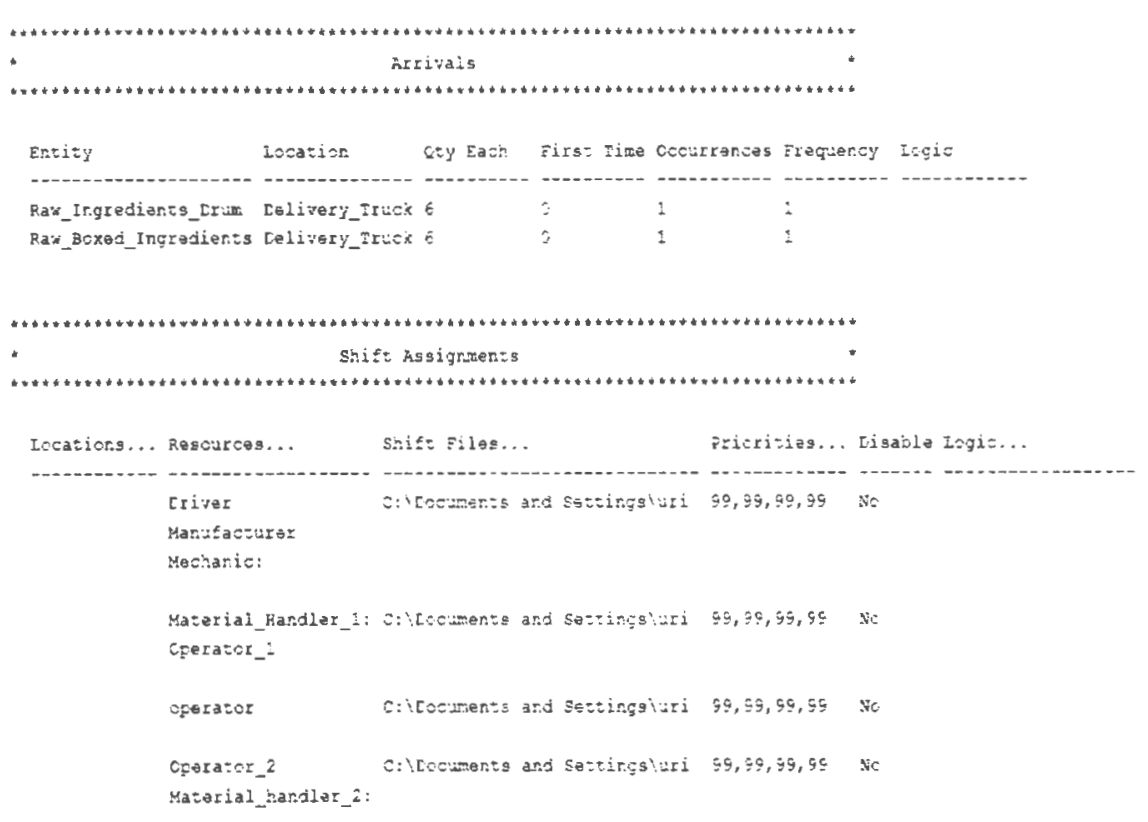

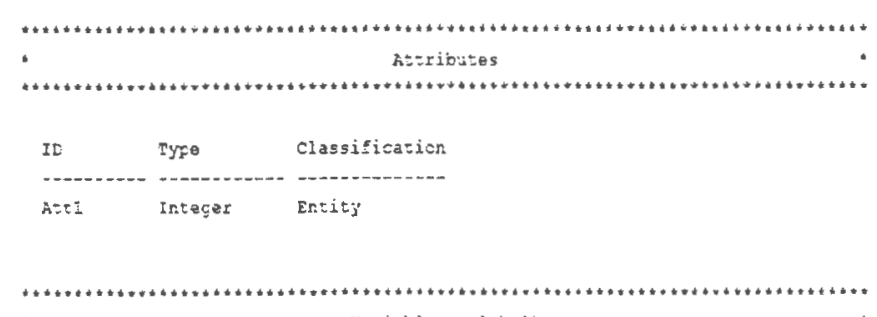

Variacles lglciaj! 


\begin{tabular}{|c|c|c|c|}
\hline II & Tipe & Initial value & scats \\
\hline $80 T$ & Ir zegex & is & Time Series \\
\hline soti & Inveger & 0 & Time Sories \\
\hline $\sin 2$ & Inceger & 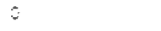 & Time Ser $i \leq s$ \\
\hline $\operatorname{Var} \hat{1}$ & Irteger & 2 & rime series \\
\hline
\end{tabular}

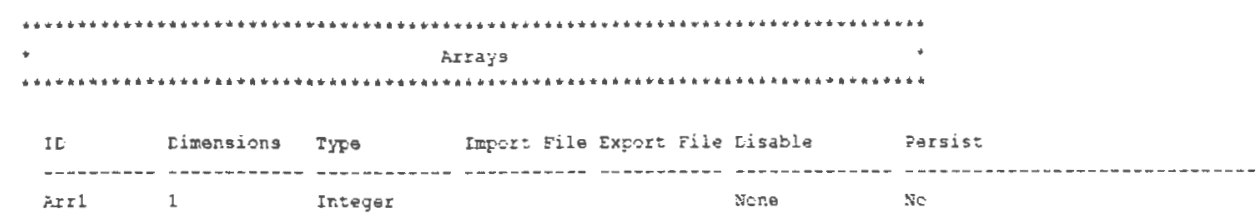

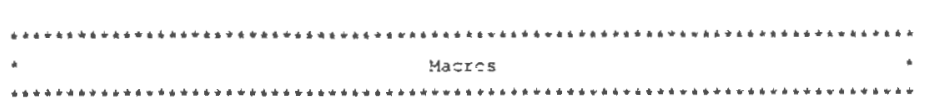

If $\quad$ Text

$\operatorname{Mac1}$

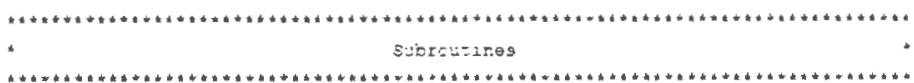

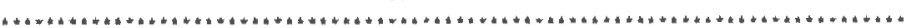

\begin{tabular}{llll} 
IL & Trife & Farameter Tyeg & Iogie \\
\hline Sit 1 & None & &
\end{tabular}

Sut 1 None

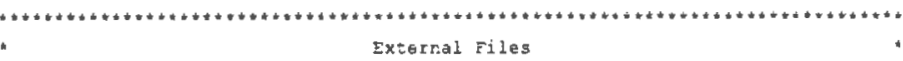

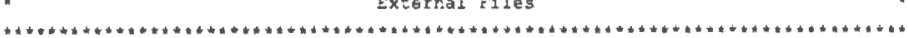

Tjice

File Name

Prame:

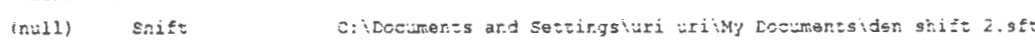

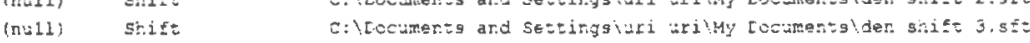

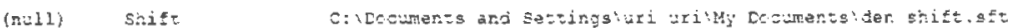




\section{Appendix IV: ProModel $^{\circledR}$ Simulation- Future State}

Eormattea Iising oz Model:

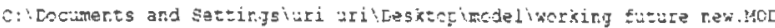

rime units:

Listares Trizs:
Minutes

Fee:

Lecations

\begin{tabular}{|c|c|c|c|c|c|}
\hline Name & aas & Jris & stats & & zoules \\
\hline Receiving_irea & INE & 1 & Tize & $S \in I i \in \underline{\theta}$ & Cldast, Eirs: \\
\hline Ecrmilaticr_ticlding_Area & 4 & 1 & Time & Series & Oddes:, \\
\hline JCr.GS_HIF_feGd & 200 & $=$ & Time & Serieg & Gides:, \\
\hline Jenes_caztrer & 12 & $\vdots$ & Time & Series & cidest, \\
\hline Falle:_Wraçer & 1 & 1 & Time & series & Oldest, \\
\hline Jones_FGI & $\varepsilon ?$ & \pm & Time & Series & oldest, \\
\hline Ralex_2 & 1 & 1 & Time & Sarias & Cldase, \\
\hline IFRA & 1 & : & Time & Series & Cldes:, \\
\hline Ralex_1 & 1 & 1 & Time & Series & Oldes:, \\
\hline Delivery_truck & 12 & ! & rime & Series & odest, \\
\hline Cafe_tabla & 20 & : & Tize & Sariss & Cldes:, \\
\hline I6e_Ket:1e & 4 & $:$ & Iire & Series & $02 d=5=$, \\
\hline Inka_FIF_tيldirg & 102 & $\stackrel{\vdots}{3}$ & rime & Series & Cides:, \\
\hline Sterage_vat_load & 1 & : & Time & Seriss & $013 \geq 5=$ \\
\hline Ralex_fiz_palle: & 20 & $\vdots$ & Tixe & Sarigs & Cidos:, \\
\hline @_Lesk & i & $i$ & Tiare & $s_{\theta} x i \neq 5$ & clces:, \\
\hline Fescer & 2: & $\vdots$ & Tize & Egrieg & Oldes:, \\
\hline
\end{tabular}

fickper

a : Tire serieg Oldeger

\begin{tabular}{|c|c|c|c|}
\hline 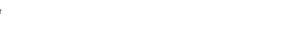 & En: & izies & \\
\hline Name & SFeed (ffm! & $s=a: s$ & ses: \\
\hline Rax_Ingredients _rum & $15:$ & Iime Series & \\
\hline WIF_Tetss & 150 & Time series & \\
\hline Firished_Gocds_Inverts $x y$ & 158 & Time series & \\
\hline Irarsfer_Jessel & 150 & Time Serios & \\
\hline Ras_Bexed_Ingredients & 155 & Time series & \\
\hline PALLET_EGI & 250 & Tíng Series & \\
\hline Bulk_Irug_gIF_? & 150 & Time Saries & \\
\hline
\end{tabular}

\begin{tabular}{|c|c|c|c|c|c|c|c|}
\hline 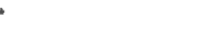 & & Fa:- Na:uerics & & & & 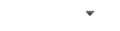 & \\
\hline \multicolumn{8}{|c|}{ 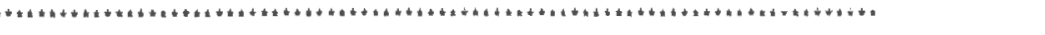 } \\
\hline Same & Tyce & I:s & Erem & it: & $5 I$ & Lis:/Zise & Spagd Factor \\
\hline 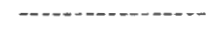 & 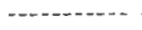 & 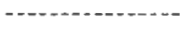 & --- & $\ldots+. . .-$ & --- & 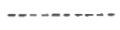 & $\cdots$ \\
\hline \multirow[t]{2}{*}{ rrivar_pazh } & zassing & Stresd: Lis:anco & $\mathrm{s}:$ & $\sqrt{2}$ & si & $5 \varepsilon .: 6$ & 1 \\
\hline & & & $\mathrm{N} 2 \hat{2}$ & $y^{2}$ & $B i$ & 87.75 & $:$ \\
\hline \multirow[t]{3}{*}{ Fath_manibacturer } & Zassing & sçed \& tiganco & $\mathrm{s:}$ & $x=$ & $5 i$ & 35.56 & i \\
\hline & & & $x$ & $\mathrm{NE}$ & Ei & $2: 5.85$ & $:$ \\
\hline & & & $s:$ & SiE & Bi & $E . E ?$ & $:$ \\
\hline \multirow[t]{3}{*}{ cverview } & Fasging & Speed o Iistance & $x:$ & $\mathfrak{x} 2$ & Ei & $7: .9 \bar{c}$ & $\vdots$ \\
\hline & & & $\$ 4$ & MS & bi & $3: .68$ & $i$ \\
\hline & & & $y^{7}$ & ye & $3 i$ & 5.53 & $\vdots$ \\
\hline
\end{tabular}




\begin{tabular}{|c|c|c|c|}
\hline $\mathrm{N}$ & $\mathrm{NG}$ & $\mathrm{Bi}$ & 37.23 \\
\hline ws & $x:=$ & $\mathrm{B} 2$ & 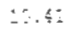 \\
\hline \$16 & $\mathrm{NH:}$ & $\overline{8}:$ & 23.24 \\
\hline$x::$ & $\mathrm{N}_{2 i}$ & $B i$ & 25.24 \\
\hline \$5 & $\mathrm{x}: 7$ & $\mathrm{Bi}$ & 4.80 \\
\hline N5 & $\$ 3$ & $5 i$ & $2: 3.3 E$ \\
\hline sz & $N: i$ & $\mathrm{Bi}$ & 24.75 \\
\hline$v_{2}$ & NG & $\mathrm{Bi}$ & $120^{7} .23$ \\
\hline$\$ 17$ & $\mathrm{x}^{7}$ & $\mathrm{Bi}$ & $228.6 E$ \\
\hline $\mathrm{N}^{7}$ ? & $\mathrm{N}: 4$ & $B i$ & 255.53 \\
\hline$N \geq 4$ & N1s & $\mathbf{E}_{i}$ & 6.75 \\
\hline $\mathrm{N}: 5$ & se & $B i$ & 62.35 \\
\hline $\mathrm{NS}$ & 13 & Bi & $5: .99$ \\
\hline$s ?$ & $x \div 8$ & Ei & $\because 2.53$ \\
\hline N:9 & $\mathrm{N}: 4$ & E! & 2.3 \\
\hline
\end{tabular}

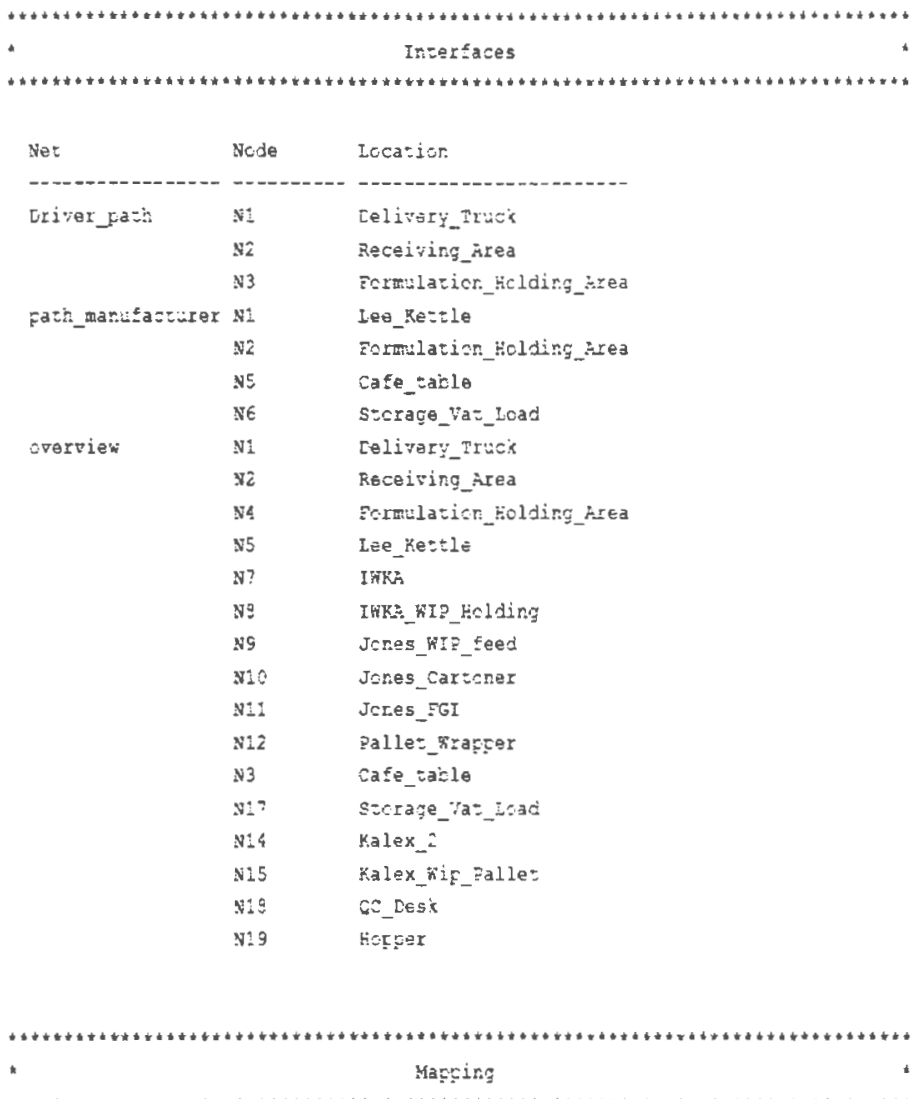

\begin{tabular}{|c|c|c|c|}
\hline Not & Srom & Is & Les: \\
\hline \multirow[t]{3}{*}{ Fath_mantzactirer } & $\mathrm{N}:$ & $\mathrm{s}_{2}$ & \\
\hline & $\mathrm{N1}$ & N5 & \\
\hline & $\mathrm{N} 1$ & Ne & \\
\hline \multirow[t]{8}{*}{ overview } & $\sqrt{ } 2$ & $\mathrm{Ni}$ & \\
\hline & $\mathrm{N}$ & $\mathrm{v} 2 \mathbf{2}$ & \\
\hline & \$S & N4 & \\
\hline & $y^{7}$ & NE & \\
\hline & NE & SE & \\
\hline & sy & $\mathrm{N}: \hat{\mathrm{n}}$ & \\
\hline & $\mathrm{N}: 0$ & $\mathrm{~N}: \mathrm{I}$ & \\
\hline & $N=1$ & $\mathrm{x}: 2$ & \\
\hline
\end{tabular}




\begin{tabular}{|c|c|}
\hline$N 12$ & $v_{2}$ \\
\hline $\mathrm{N}_{2} \mathrm{~T}$ & N5 \\
\hline$x: 4$ & v $\leq 5$ \\
\hline x15 & NS \\
\hline$x 19$ & $\mathrm{~s}^{-}$ \\
\hline$\vec{x}$ & is \\
\hline$\times 4$ & $\times 5$ \\
\hline$y$ & Y17 \\
\hline NE & $\mathrm{x}$ ? \\
\hline$x 15$ & N1d \\
\hline $\mathrm{H} 2$ & $N_{2}$ \\
\hline x5 & N1? \\
\hline ss & $\mathrm{s}$ \\
\hline$\times 10$ & xy \\
\hline $\mathrm{N}: \mathrm{i}$ & $\mathbf{N} 16$ \\
\hline$\times 12$ & $N=$ \\
\hline $\mathbf{s i}$ ? & 37 \\
\hline s5 & s3 \\
\hline ง & Nig \\
\hline$x 19$ & N14 \\
\hline so & N15 \\
\hline $\mathbb{N 1}$ & $\mathrm{N} 15$ \\
\hline
\end{tabular}

Eescirres

\begin{tabular}{|c|c|c|c|c|c|c|c|}
\hline & & & Res & En: & & & \\
\hline Same & Dnits & seats & Search & Eeareh & fath & Hozicr. & CEst \\
\hline \multirow[t]{2}{*}{ Marufacturer } & 1 & Ey Trit & cleses: & cldes: & çath_zar_asturet & Enx=y: 15: $=x \pi$ & \\
\hline & & & & & ycate: XI & Fill: :5: :trr & \\
\hline \multirow[t]{2}{*}{ Material_Eanỏler_i } & 1 & By Jri= & closest & Cldes: & stersiex & 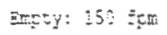 & \\
\hline & & & & & S̈cres: $\mathrm{X}$ & Fill: :5; form & \\
\hline \multirow[t]{2}{*}{ Material_tandler_a } & $i$ & 8y Dnit & Closest & Oldest & Evervie* & zmoty: 150 fex & \\
\hline & & & & & Eome: N2 & :211: :5: $\mathrm{cml}$ & \\
\hline \multirow[t]{2}{*}{ Criver } & 1 & By Jrit & Closest & Clies: & Iriter_cash & Emsty: $15:$ sto & \\
\hline & & & & & $\begin{array}{l}\text { تrce: N: } \\
\text { (Rezurr) }\end{array}$ & Rill: :5: $=\mathrm{Fm}$ & \\
\hline \multirow[t]{2}{*}{ Metiaric } & 1 & By snit & olcses: & Oldes: & crervise & Ent: $: 15 \%$ & \\
\hline & & & & & roms: $\mathrm{X}^{-}$ & Foll: : $5: \leq-\pi$ & \\
\hline \multirow[t]{2}{*}{ Macharie_2 } & 1 & By jrit & closes: & Cldes: & cyervie' & Smpig: :5: $=\mathrm{rm}$ & \\
\hline & & & & & $\ddot{s} \operatorname{cre}: \mathrm{x}$ & Fill: :5: $: p a$ & \\
\hline \multirow[t]{2}{*}{ Eperatcr:- } & 12 & By uri: & Slcses: & Cldes: & crortie & Bmety: :s: & \\
\hline & & & & & Hete: $\mathrm{s}^{-}$ & :u11: :5: Ext & \\
\hline \multirow[t]{2}{*}{ Geratcr_i } & $\therefore \hat{2}$ & Bÿ Jri: & Eleses: & cliest & sterviex & Extoy: : $::$ str & \\
\hline & & & & & Fone: $x$ & E:11: : $:$ : & \\
\hline \multirow[t]{2}{*}{$\approx$ Ir.sesetcr } & $\dot{1}$ & By Jnit & ol:ses: & clies: & crervied & Enty: $15 \div \quad$ rgm & \\
\hline & & & & & Eore: Nis & s:11: :c: fctr & \\
\hline
\end{tabular}




\begin{tabular}{|c|c|c|c|c|c|c|}
\hline Ertisy & insation & creration & $31 x$ & 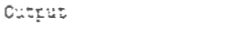 & Cestira:ior. & Rils \\
\hline \multirow[t]{3}{*}{ Ra*_Ingredients_Er:J } & Lelivery_trusis & 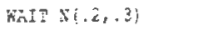 & & & & \\
\hline & & 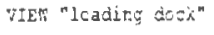 & & & & \\
\hline & & & 1 & sad_ingredignts_Lras & Exrrila=irr_H=ldir_z_kraa & SIRST \\
\hline Ra*_3exod_Irgrodier:s & Lelivary_Truek & Fits: $\times(, 2, .3\}$ & $i$ & Să̈_B:xaz_Lrgrejier::s & 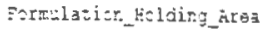 & $\operatorname{stast}$ \\
\hline \multirow[t]{4}{*}{ AI: } & Ferm:latier,_seld:rg_area & Accisis & & & & \\
\hline & & TIEi mantifacturing & crozes & & & \\
\hline & & & $\vdots$ & Bäi_Ingredier:s__[r & Lee_petile & FIRET \\
\hline & & & & 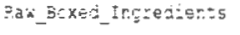 & LeE_Re:=L & FIRST \\
\hline \multirow[t]{4}{*}{$\mathrm{AL}:$} & $\therefore s \in R \in=-1 e$ & scrsine 4 & & & & \\
\hline & & $I=\sin =$ & & & & \\
\hline & & IFEN & & & & \\
\hline & & Ese Man:uazurer fo & $\$ \equiv:$ & $\therefore$ & & \\
\hline
\end{tabular}

$5+\hat{\imath}=\mathbf{3}$

ZSE Manufazurer FTR N:45:36)

\begin{tabular}{|c|c|c|c|c|c|}
\hline \multirow[b]{2}{*}{ Bulk_[rog $\left.k I z_{-}\right]$} & \multirow[b]{2}{*}{ Stcrage_ja:_lead } & \multirow{2}{*}{\multicolumn{2}{|c|}{ 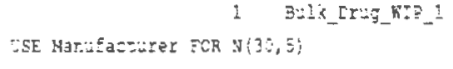 }} & \multirow[t]{2}{*}{ Szeragge_*a:_lcad } & \multirow[t]{2}{*}{ ETRT } \\
\hline & & & & & \\
\hline & & & $3: 1 c_{-}\left[r-g_{-} H: z_{-}:\right.$ & Exferer & PIRS: \\
\hline B:Ik_Lr:G_FIE_1 & Potferer & & $5: 1 K_{-}\left[r-g_{-} k I E_{-}\right.$ & recter & STRS? \\
\hline BulK_Lr & Eogter & & Suis_Lrug_hiE_ & IFY: & MOST ! \\
\hline & & & 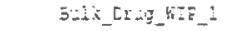 & Kalex_z & $\operatorname{MCST}$ \\
\hline
\end{tabular}

BulK_Lr:G_RIF_: IWXA

II $2 \mathrm{TTT}=$

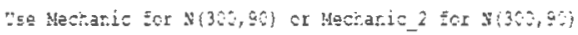

$s+2=$

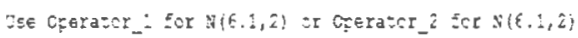

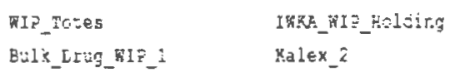

IT $\sin 3=2$

THEN

Fe Mechanio Eor $\$\{: 41,30\}$ or Mezhan:ez for $N(14:, 30)$

$5: 3=5$

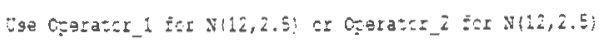

Talex_hic_zalle:

TIE_Totes

Jores_nis_togd

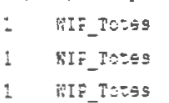

Ralex_fin_falle: IIRs?

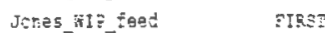

Jeras_aztcher ITKS:

Jones_carterer 


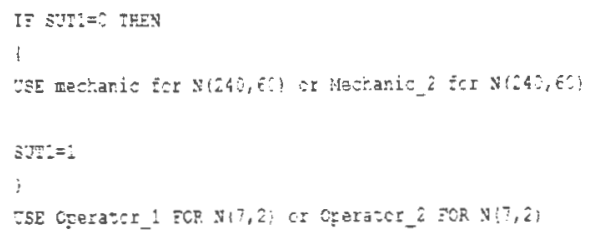

Firished_Gocds_Invertory Joneg_EGI FRIET_ET

Falle:_hirazter

Receivirg_area

PEIET_EI

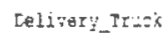

\section{$1 \quad$ Eiristed_Goods_Trwentecry jeres_For}

ercicise 70

Ealiet_nxagzer

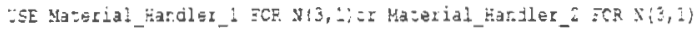
nors $x(14,3)$

Rai: $:(20,20)$

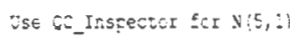

$$
1 \text { FhIET_RT Revating_hrea }
$$

Lelivery_mosk EYIT

\section{Arrivais}

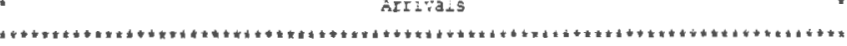

\begin{tabular}{|c|c|c|c|c|c|}
\hline Entity & Docarion & $\operatorname{cty}$ Each & Eirs: Iire & cocurrences & Exafuescy \\
\hline Rä̈ Ir.ggedierts [rue & Lelizery irusk & 2 & $?$ & 3 & \pm \\
\hline Ray_Bsx日s_Ingrediorts & Islivery_Irtek & 2 & ? & 3 & 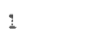 \\
\hline
\end{tabular}

\begin{tabular}{|c|c|c|c|c|}
\hline 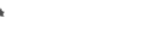 & $\operatorname{sh}$ & ift Issignaer:s & & $\star$ \\
\hline \multirow{4}{*}{ Iecations... } & Rescurces... & shife siles... & griorities... & tisaole Iogiz... \\
\hline & $\begin{array}{l}\text { Lriver } \\
\text { Hariuactirez }\end{array}$ & G: Eocuner:s ard Set:irgsiuri & $95,95, g y_{2}, g 9$ & $\mathrm{se}$ \\
\hline & $\begin{array}{l}\text { Saterial_pardler_a } \\
\text { CForazor_- } \\
\text { Marufacturer }\end{array}$ & C:icsedrents and Seztingsiuri & $99,99,99,90$ & $\mathrm{se}$ \\
\hline & $\begin{array}{l}\text { Gperaior_z } \\
\text { Ma:erial_handler_2 } \\
\text { Mecharic_2 }\end{array}$ & C:lccuger:s ard setzingsuri & $99,95,95,95$ & sc \\
\hline
\end{tabular}

\begin{tabular}{|c|c|c|c|}
\hline • & & Atzributes & - \\
\hline \multicolumn{4}{|c|}{ 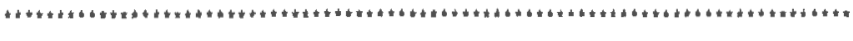 } \\
\hline IE & TyF $\theta$ & Classiřicaticn & \\
\hline$\cdots$ & -.......... & - & \\
\hline a:ti & I::EeģeI & En:ity & \\
\hline
\end{tabular}




\begin{tabular}{|c|c|c|c|}
\hline IL & Tyce & Initial ralue & $S=a \div s$ \\
\hline$\cdots+$ & $-\cdots$ & - & ----- \\
\hline $5: \pi$ & Irteger & 3 & Time serues \\
\hline St: & Irteger & $\hat{\theta}$ & Tine Series \\
\hline $\sin 2$ & Integer & $\because$ & Time Series \\
\hline $\operatorname{son}^{3}$ & In:şer & $\vdots$ & Iine series \\
\hline
\end{tabular}

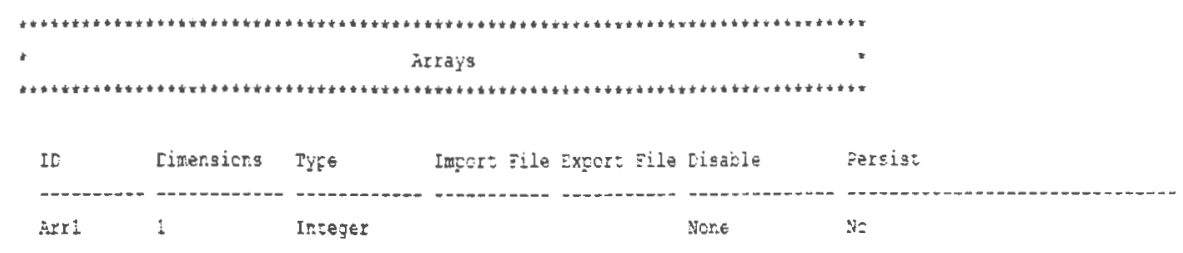

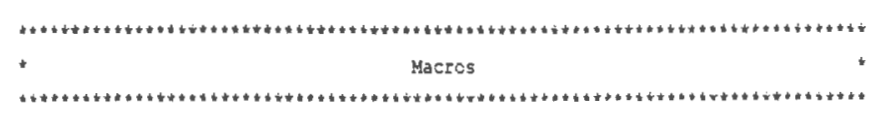

$\begin{array}{ll}\text { IL } & \text { Tex: } \\ \text { Sac: } & \end{array}$

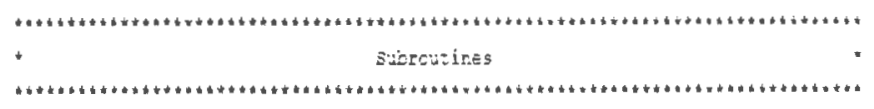

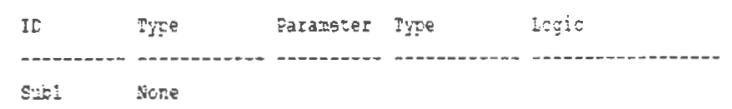

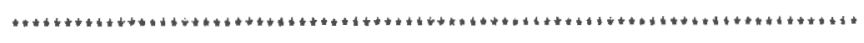

- Exrerral Files *

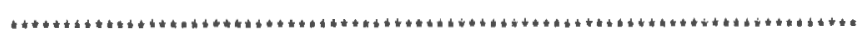

\begin{tabular}{|c|c|c|c|}
\hline If & Pyte & File sare & Erox: \\
\hline$(n: 11)$ & Shif: & 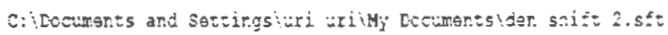 & \\
\hline (nis) & snift & 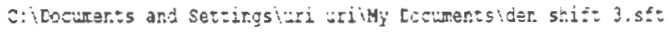 & \\
\hline$\{\sin 11\}$ & Sist: & 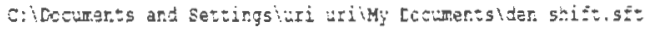 & \\
\hline
\end{tabular}




\section{Bibliography:}

Abdulamek, F. and Rajgopal, J. (2007). Analyzing the benefits of lean manufacturing and value stream mapping via simulation: A process sector case study. International Journal of Production Economics, Vol. 107, 223236.

Allen, J., and Robinson, C. (2001). Pp. xxi-xxxi in Lean Manufacturing: A Plant Floor Guide. Introduction. J. Allen, C. Robinson, D. Stewart, eds. Dearborn, Michigan: Society of Manufacturing Engineers.

Ansel, H., Allen, L., and Popovich, N. (1999). Pharmaceutical Dosage Forms and Drug Delivery Systems $7^{\text {th }}$ Ed. Philadelphia, Pennsylvania: Lippincott Williams \& Wilkins.

Askin, R., and Goldberg, J. (2002). Design and Analysis of Lean Production Systems. New York: John Wiley \& Sons, INC.

Askin, R., and Standridge, C. (1993). Modeling and Analysis of Manufacturing Systems. New York: John Wiley \& Sons, INC.

Blucher, J.T., Narusawa, U., Katsumata, M., and Nemeth, A. (2001, December). Continuous manufacturing of fiber-reinforced metal matrix composite wirestechnology and product characteristics. Composites Part A: Applied Science and Manufacturing. Vol. 32, Issue 23: 1759-1766.

Boothroyd, G., Dewhurst, P., and Knight, W. (2002). Product Design for Manufacture and Assembly ( $2^{\text {nd }}$ edition). New York: Marcel Dekker, Inc.

Bralla, J, ed. (1986). Handbook of Product Design for Manufacturing: A Practical Guideto Low-Cost Production. New York: McGraw Hill Book Company.

Centers, R., West, S. (2001). Pp. 307-323 in Lean Manufacturing: A Plant Floor Guide. Quick Changeover. J. Allen, C. Robinson, D. Stewart, eds. Dearborn, Michigan: Society of Manufacturing Engineers. 
Christl, L. (2006, November 27). Introduction to Nonprescription Products. Center for Drug Evaluation and Research: Forum for International Drug Regulatory Authorities. Rockville, Maryland.

Chung, C. (2004) Simulation Modeling Handbook A Practical Approach. Ed. by Hamid Parsaei, Boca Raton, FL. CRC Press Inc.

Cini, P. (2006, September 11-12). A study in the value of PAT. Real World Applications of PAT and QbD in Drug Process Development and Approval Workshop. American Association of Pharmaceutical Scientists. Crystal City, Virginia.

Couts, T. (2006, September 7-8). National Institute for Pharmaceutical Technology and Education: Strategic Roadmap for Research and Education. National Institute for Pharmaceutical Technology and Education Strategic Roadmap Seminar. Rockville, Maryland.

Crosby, T. (2006, January). Designing for the future of continuous processing.

Pharmaceutical Processing Online, pages 20-26.

http://www.pharmpro.com/ShowPR PUBCODE 021 ACCT 0000100 ISS UE 0601 RELTYPE PR ORIGRELTYPE ATO PRODCODE $\sim 000 \sim P R$ ODLETT A.html. 09 September 2006.

Desai, P. (2006, September 11-12). Case Study: Approach for Filing with PAT. Real World Applications of PAT and QbD in Drug Process Development and Approval Workshop. American Association of Pharmaceutical Scientists. Crystal City, Virginia.

Food and Drug Administration. (1987, October 21). Parametric Release- Terminally Heat Sterilized Drug Products (CPG 7132a.13). Compliance Policy Guides Manual Chapter 4: Human Drugs Sec 460.800 http://www.fda.gov/ora/compliance ref/cpg/cpgdrg/default.htm 21 April 2007

Food and Drug Administration. (2000, June 28-29). Questions and Answers. OverThe-Counter Drug Products Public Hearing. Gaithersburg, Maryland. 
Food and Drug Administration. (2002, October 21-22) Scientific Considerations of Polymorphism in Pharmaceutical Solids: Abbreviated New Drug Applications. Advisory Committee for Pharmaceutical Science Meeting. Rockville, MD.

Food and Drug Administration. (2004a, September). Guidance for Industry: PAT-A Framework for Innovative Pharmaceutical Development, Manufacturing, and Quality Assurance. http://www.fda.gov/cder/OPS/PAT.htm 12 October 2006.

Food and Drug Administration. (2004b, September). Pharmaceutical cGMP's for the $21^{\text {st }}$ Century-A Risk-Based Approach.

http://www.fda.gov/cder/gmp/gmp2004/GMP finalreport2004.htm

12 October 2006.

Food and Drug Administration. (2006a, April). Current Good Manufacturing Practice for Finished pharmaceuticals Title 21 Code of Federal Regulations Part 211.Revised as of April 1, 2006. http://www.accessdata.fda.gov/scripts/cdrh/cfdocs/cfcfr/CFR Search.cfm?CFRPart=211\&showFR=1. 25 September 2006.

Food and Drug Administration. (2006b, May). Guidance for Industry: $Q 8$ Pharmaceutical Development. www.fda.gov/cber/gdlns/ichq8pharm.htm. 21 April 2007.

Food and Drug Administration. (2006c, June). Guidance for Industry: $Q^{9}$ Quality Risk Management. www.fda.gov/ohrms/dockets/98fr/05d-0288-gd10002.pdf. 21 April 2007.

Food and Drug Administration. (2006d, November 22). Office of Nonprescription Products: Regulatory Mechanisms for Marketing OTC Drug Products. http://www.fda.gov/cder/Offices?OTC/reg_mechanisms.htm. 02 February 2007. 
Ghobadian, C., and Gallear, DN. (1996). Total Quality management in SME's. Omega International Journal of Management Sciences. Vol. 24, No. 1: 83106.

Gillespie, C., and Alder, K. Engineering the Revolution. Technology and Culture. Vol. 39, No. 4: 733-754.

Glaser, V. (2006, September 15). Slow Adoption of PAT for Bioprocessing: Challenges Emanate from Technology Development and Design of Process. Genetic Engineering News. Pp. 38-40.

Goldratt, E., and Cox, J. (2004). The Goal: A Process of Ongoing Improvement, Third Ed. Great Barrington, Massachusetts: North River Press.

Hall, P., High, M., McNaughton, A., and Sharma, B. (2001). Pp. 73-103 in Lean Manufacturing: A Plant Floor Guide. Mapping the Value Stream. J. Allen, C. Robinson, D. Stewart, eds. Dearborn, Michigan: Society of Manufacturing Engineers.

Hauptmann, P., Lucklum, R., Puttmer, A., and Henning, B. (1998, May 15).

Ultrasonic sensors for process monitoring and chemical analysis: state-of-theart and trends. Sensors and Actuators A: Physical. Vol. 67, Issues 1-3: 32-48.

Henry, J. (2001, November). Quick Changeover: Flexible products demand quick changes. Advanced Manufacturing. http://www.advancedmanufacturing.com/ November01/changeover.htm. 15 January 2007.

Hilfiker, D. (2005, May 11). OTC 101. Food and Drug Administration Educational Forum. www.fda.gov/cder/about/smallbiz/Presentations/4.ppt. 22 February 2007.

Hilfiker, D. (2004, June 16). OTC Drugs Today and Tomorrow. Drug Information Association Annual Meeting 2004. www.fda.gov/cder/present/DIA2004/Hilfiker.ppt. 22 February 2007. 
Hirano, H. (1987). JIT Factory Revolution: A pictorial guide to factory design of the future. English Edition ed. JT. Black. Cambridge, Massachusetts: Productivity Press.

Hirano, H. (1995). 5 Pillars of the Visual Workplace: The Sourcebook for $5 S$ Implementation. English Edition translated by B. Talbot. Portland, Oregon: Productivity Press.

Hopp, W., and Spearman, M. (2001). Factory Physics: Foundations of Manufacturing Management ( $2^{\text {nd }}$ ed.). Boston: Irwin McGraw Hill.

Hussain, A. (2002, February 25). The Subcommittee on Process Analytical Technologies (PAT): Overview and Objectives. FDA's Advisory Committee for Pharmaceutical Science. Gaithersburg, Maryland.

Imai, M. (1986). Kaizen: The keys to Japan's competitive success. New York: Random House Business Division.

Jayawickrama, D. (2006, September/October). Raman Applications in Drug Manufacturing Processes. American Pharmaceutical Review. Vol. 9, Issue 6:52-57.

Jeffries, M., Lai, M., and Hull, B. (2003). A new approach to process control in a bottling Plant. Journal of Material Processing Technology. Vol. 133: 122127.

Joneckis, C. (2006, September 12). Implementing Q8, Q9, Q10. Parenteral Drug Association/Food and Drug Administration Joint Regulatory Conference. Washington, D.C.

Kleijnen, J., and Gaury, E. (2003). Short-term robustness of production management systems: a case study. European Journal of Operational Research. Vol. 148: 452-465.

Kourkoutas, Y., Bekatorou, A., Banat, I.M., Marchant, R., and Koutinas, A.A. (2004, 
August). Immobilization technologies and support materials suitable in alcohol beverages production: a review. Food Microbiology. Vol. 21, Issue 4: 377-397.

LaPlant, F., and Zhang, X. (2005, September/October). Quantitation of Polymorphs in Drug Product by Raman Spectroscopy. American Pharmaceutical Review. Volume 8, Issue 5: 88-94.

Li, N., Zhang, M., Deng, S., Lee, Z., Zhang, L., Zheng, L. (June, 2007) Singlestation performance evaluation and improvement in semiconductor manufacturing: A graphical approach. International Journal of Production Economics. Volume 107, Issue 2, 397-403

Liker, J. (2004). The Toyota Way: 14 Management principles from the world's greatest manufacturer. New York, New York: McGraw Hill Publishing.

Low, D. (2006, September 11-12). Process Analytical Technology-from the perspective of a Biologicals Manufacturer. Real World Applications of PAT and QbD in Drug Process Development and Approval Workshop. American Association of Pharmaceutical Scientists. Crystal City, Virginia.

Maier-Speredelozzi, V., and Hu, S.J. (2002). Selecting Manufacturing System Configurations Based on Performance Using AHP. Transactions of North American Manufacturing Research Institute/Society of Manufacturing Engineers, XXX: 637-644.

Matsui, Y. An Empirical analysis of just-in-time production in Japanese manufacturing companies. International Journal of Production Economics. doi:10.1016/j.ijpe.2006.12.035.

Medendorp, J., Wyse, J., Lodder, R., Tillman, L., Sonti, S., and Jay, M. (2006, May/ June). Rapid Near-Infrared Qualifications of Microcrystalline Cellulose and Sodium Caprate Minitablets Through Intact Enteric Coated Caplets. The Journal of Process Analytical Technology. Vol. 3, Issue 3: 11-17. 
Meier, D. (2001). Pp. 45-70 in Lean Manufacturing: A Plant Floor Guide. Lean Measurements and Their Use. J. Allen, C. Robinson, D. Stewart, eds. Dearborn, Michigan: Society of Manufacturing Engineers.

Monden, Y. (1998). Pp. 221-238 in Toyota Production System: An Integrated Approach to Just-In-Time, $3^{\text {rd }}$ ed. "Autonomous Defects Control" Assures Product Quality. Norcross, Georgia: Institute of Industrial Engineers.

Montgomery, D. (2005a). Design and Analysis of Experiments, $6^{\text {th }} \mathrm{ed}$ Hoboken, NJ. John Wiley \& Sons Inc.

Montgomery, D. (2005b). Introduction to Statistical Quality Control, $5^{\text {th }}$ ed. Hoboken, NJ. John Wiley \& Sons Inc.

Narasimhan, R., Swink, M., and Kim, Soo Wook. (2006). Disentangling leanness and agility: An empirical investigation. Journal of Operations Management. Vol. 24:440-457.

National Institute of Standards and Technology/SEMATECH $e$-Handbook of Statistical Methods. (2006, July 18). http://www.itl.ist.gov/div898/handbook/pri/section3/pri3362.htm, 05 February 2007.

Ohno, T. (1988). Toyota Production System: Beyond Large-Scale Production. New York, New York: Productivity Press.

Otto, K., and Wood, K. (2001). Product Design: Techniques in Reverse Engineering and New Product Development. New Jersey: Prentice Hall.

Plossl, G.W., and Wight, O.W. (1967). Pp. 51 in Production and Inventory Control Principles and Techniques. Fundamentals of Inventory Management. Englewood Cliffs, New Jersey: Prentice Hall Inc.

PROMODEL Corporation. (2003). Promodel User's Guide Version 6. Orem, Utah: Promodel Corporation. 
Quality Solutions (QS) Consult. (2006, November 02). Lean Techniques. http://www.qsconsult.be/ELeanGen.htm. 19 January 2007.

Raman, C.V., and Krishnan, K.S. (1928, March 31). A New Type of Secondary Radiation. Nature, Vol. 121 (3048): 501.

Ratti, E., and Trist, D. The continuing evolution of the drug discovery process in the pharmaceutical industry. Il Farmaco, Vol. 56: 13-19.

Recht, R., and Wilderom, C. Kaizen and culture: on the transferability of Japanese suggestion systems. International Business Review, Vol. 7: 7-22.

Sanchez, S., Moeeni, F., and Sanchez, P. (2006). So many factors, so little time... simulation experiments in the frequency domain. International Journal of Production Economics, Vol. 103: 149-165.

Schonberger, R. (1986). World Class Manufacturing: The Lessons of Simplicity Applied. New York, New York: The Free Press.

Shingo, S. (1985). Zero quality control: source inspection and the poka-yoke system. Translated by A.P. Dillion. Portland, Oregon: Productivity Press.

Smith, A. (1776). An Inquiry into the Nature and Causes of the Wealth of Nations. Reprinted 1937. New York: The Modern Library Publishing.

Stevens-Riley, M. (2005, December 5). It's a Bird, It's a Plane, No Wait, It is Finally Multi-Center Current Thinking on Parametric Release of Drug Products Terminally Sterilized by Moist Heat. PDA Capital Area Chapter Meeting. Gaithersburg, M.D.

Swarbick, B. (2007). Process analytical technology: A strategy for keeping manufacturing viable in Australia. Vibrational Spectroscopy. Vol. 44: 171-178. 
Tirulamai, R., and Porter, D. (2005, July/August). Terminal Sterilization and Potential for Parametric Release. American Pharmaceutical Review. Vol. 8, Issue 4: 26-31.

The Henry Ford Museum. (2003). The Life of Henry Ford. Dearborn, Michigan. http://www.hfmgv.org/exhibits/hf/. 11 January 2007.

Toyota Motor Company. Just In Time. Toyota Production System. http://www.toyota.co.jp/en/vision/production_system/just.html. 19 January 2007.

Tyler, Steven. (2006, September 11-12). Use of mass spectrometry, TGA, and DSC analysis for design of an API drying process and on-line monitoring for residual solvents removal. Real World Applications of PAT and QbD in Drug Process Development and Approval Workshop. American Association of Pharmaceutical Scientists. Crystal City, Virginia.

United States Environmental Protection Agency. (2006a, March 02). Value Stream Mapping. Lean Manufacturing and the Environment Tool Kit. http://www.epa.gov/lean/toolkit/ch3.htm. 09 January 2007.

United States Environmental Protection Agency. (2006a, March 02). Appendix A: Lean Methods. Lean Manufacturing and the Environment Tool Kit. http://www.epa.gov/lean/toolkit/app-a.htm. 09 January 2007.

The United States Pharmacopeial Convention, Inc. (2007). The United States Pharmacopeial Convention $28^{\text {th }}$ Revision. United States Pharmacopeial Convention Inc. Rockville, Maryland.

Vervaet, C., and Remon, JP. (2005). Continuous granulation in the pharmaceutical industry. Chemical Engineering Science 60. Pp. 3949-3957.

Wiggenhorn, M., Presser, I., and Winter, G. (2005, January/February). The Current 
State of PAT in Freeze-Drying. American Pharmaceutical Review. Vol. 8, Issue 1: 38-44.

Wolff, HM. (2000, May). Optimal process design for the manufacture of transdermal drug delivery systems. Pharmaceutical Science and Technology Today. Vol. 3, No. 5 .

Womack, J., Jones, D., and Roos, D. (1990). The Machine That Changed The World. New York, New York: Harper Perennial Publishing.

Zhong, W., Maier-Speredelozzi, V., Bratzel, A., Yang, S., and Hu, S.J. (2000).

"Performance Analysis of Machining Systems with Different Configurations". Proceedings of the Japan USA Automation Conference. Ann Arbor, Michigan.

Zidan, A.S., Sammour, O., Hammad, M., Megrab, N., Habib, M., and Khan, M. (2007). Quality by design: Understanding the formulation variables of a cyclosporine-A self-nanoemulsified drug delivery systems by Box-Behnken design and desirability function. International Journal of Pharmaceutics.

Vol. 332: 55-63. 